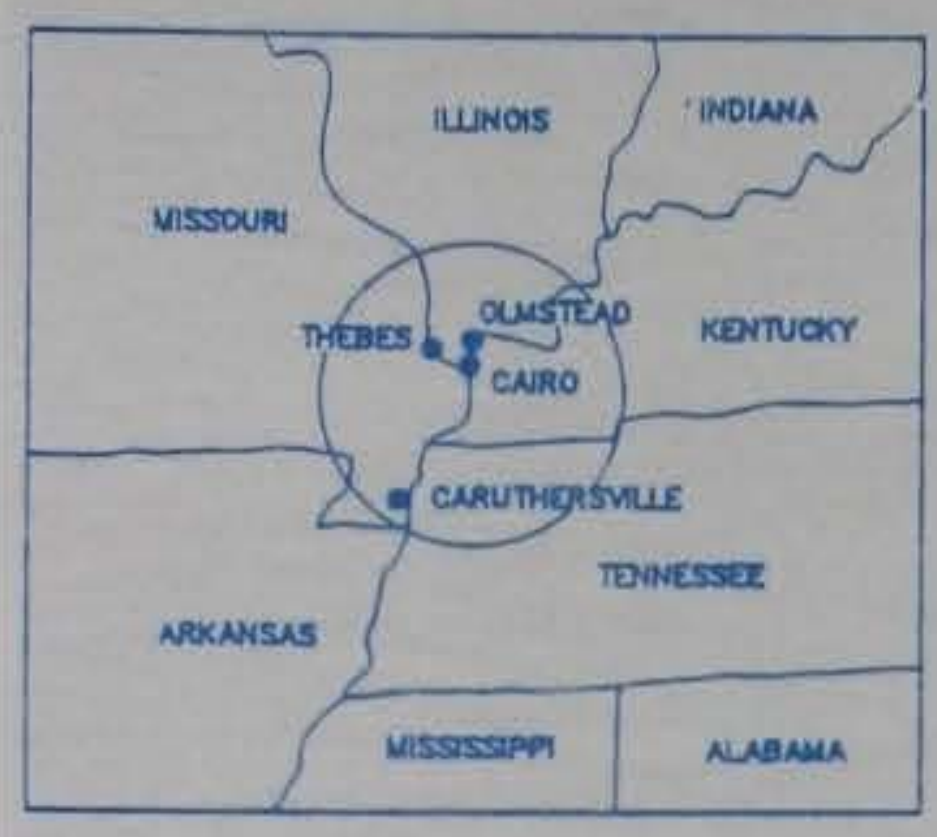

VCINITY MAP

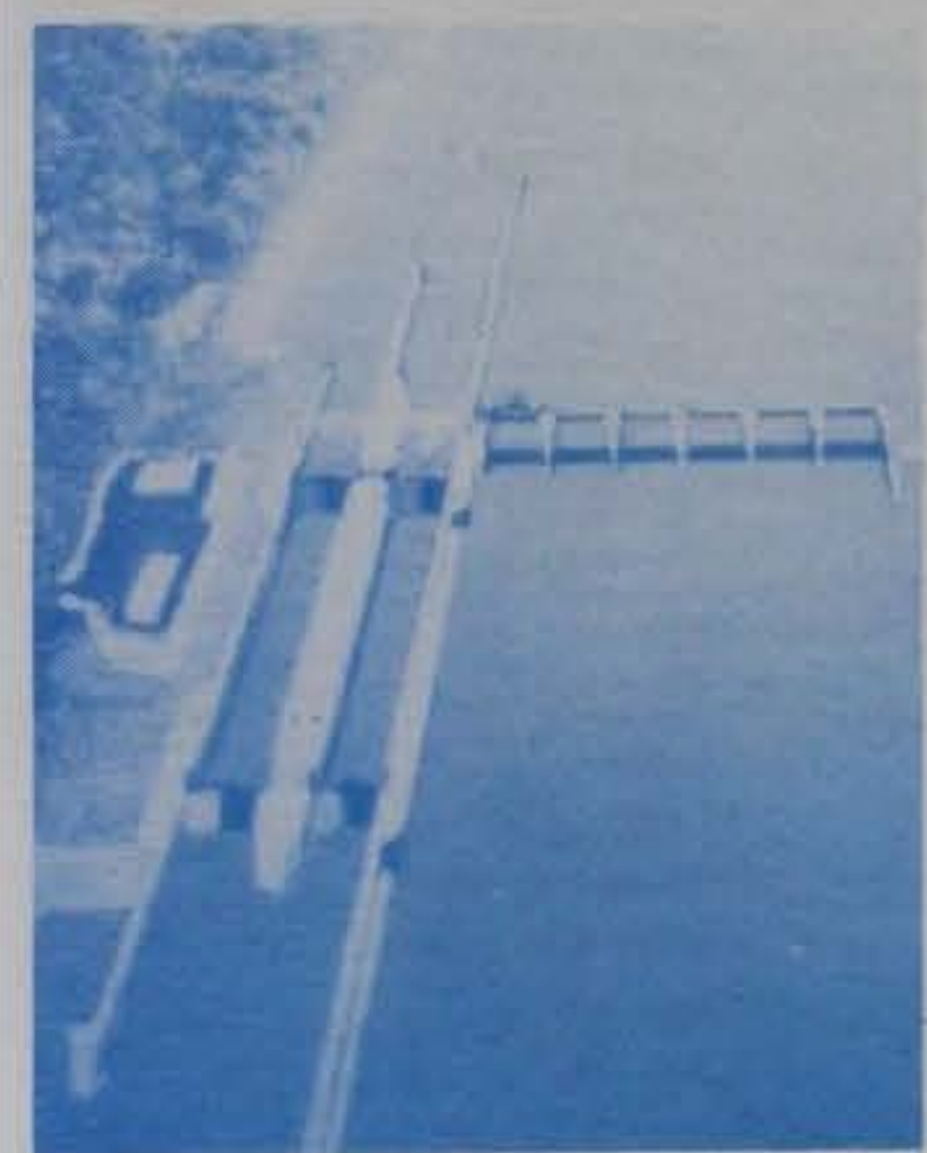

$\frac{30}{3 x}+\frac{2 \Delta}{3 x}=9$,

$\frac{\partial Q}{\partial t}+v \frac{\partial}{\partial x}(\beta Q)+\beta V \frac{\partial Q}{\partial x}-\beta V^{2} B \frac{\partial x}{\partial x}$

$\cdot B A \frac{\partial x}{\partial x}-B A\left(s_{x}-s_{f}-s_{e}\right)+B V^{2} A_{x}$

\section{NUMERICAL MODELING OF UNSTEADY FLOWS THROUGH THE PROPOSED OLMSTED HINGED POOL}

\author{
by \\ Billy H. Johnson, Lisa L. Weisinger \\ Hydraulics Laboratory \\ DEPARTMENT OF THE ARMY \\ Waterways Experiment Station, Corps of Engineers \\ 3909 Halls Ferry Road, Vicksburg, Mississippi 39180-6199 \\ $U S-C E-C$ Property of the \\ United States Government
}

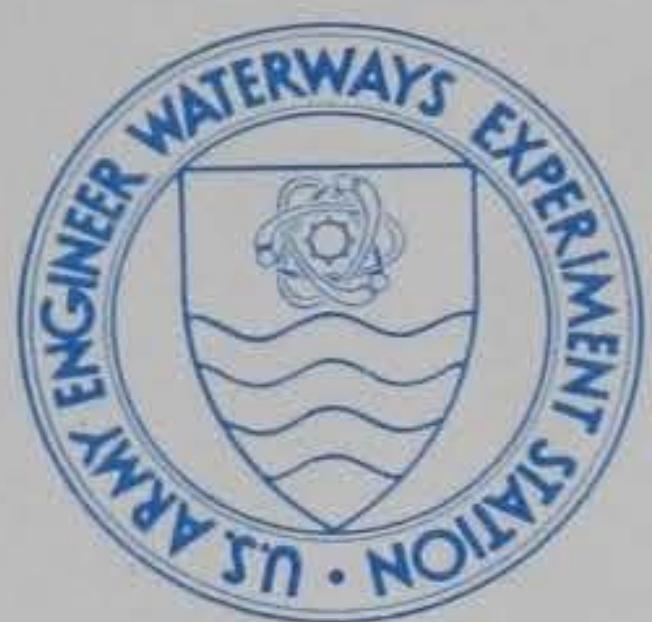

August 1990

Final Report

Approved For Public Release; Distribution Unlimited

F.EこANICH LIZTARY

US ARWY ENAINEAR WATERWAYS

EXPER:...:ENT STATION

VICKSBURG, MISSISSIPPI

Prepared for US Army Engineer District, Louisville Louisville, Kentucky 40201-0059 
Unclassified

\section{REPORT DOCUMENTATION PAGE}

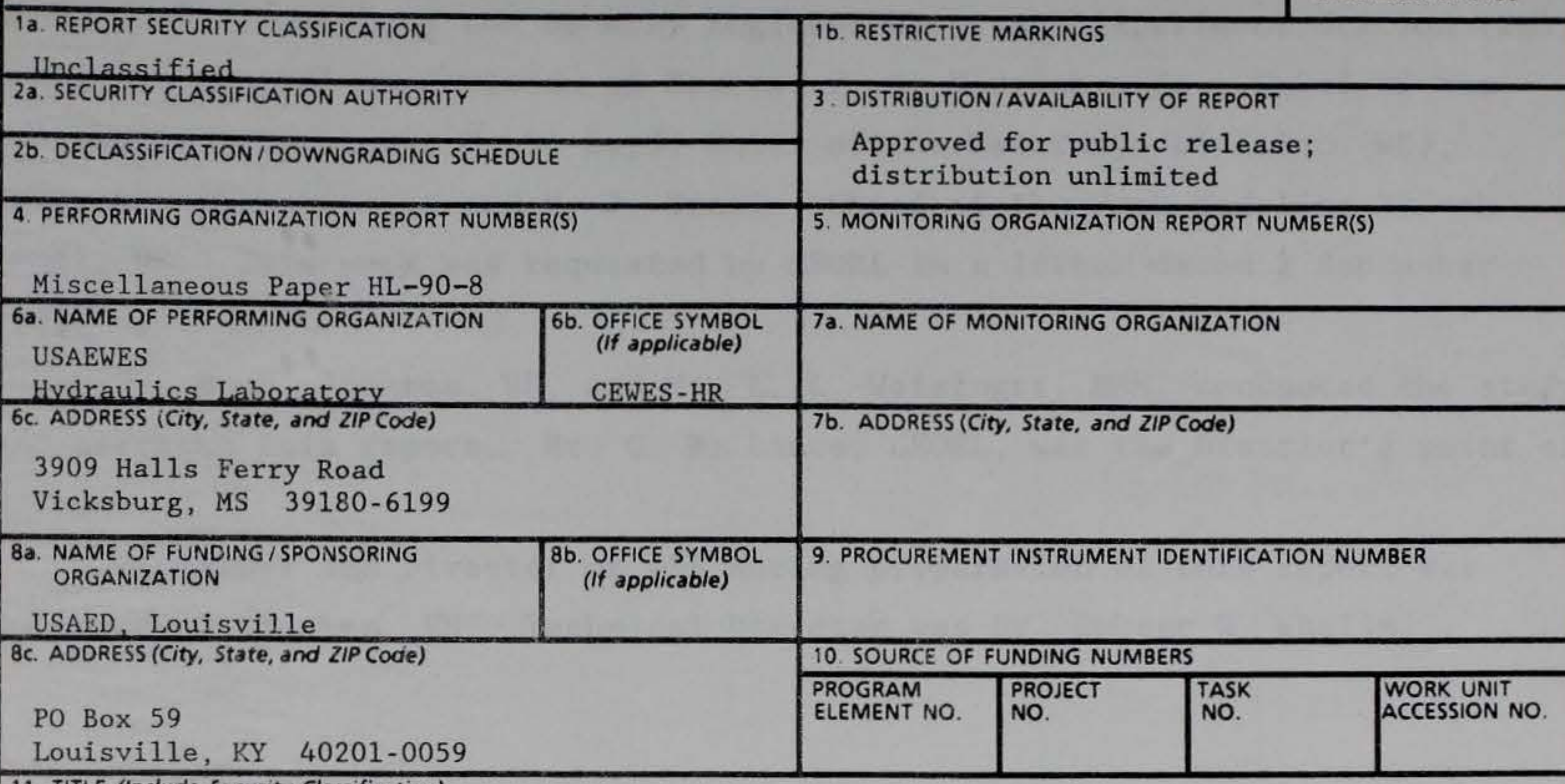

11. TITLE (include Security Classification)

Numerical Modeling of Unsteady Flows Through the Proposed Olmsted Hinged Pool

12. PERSONAL AUTHOR(S)

Johnson, Billy H. ; Weisinger, Lisa L.

\begin{tabular}{l|l}
\hline 13a. TYPE OF REPORT & 13b. TIME COVERED
\end{tabular}

Final report FROM TO 14. DATE OF REPORT (Year, Month, Day) 15. PAGE COUNT 16. SUPPLEMENTARY NOTATION

Available from National Technical Information Service, 5285 Port Royal Road, Springfield, VA 22161

\begin{tabular}{|c|c|c|c|}
\hline \multicolumn{3}{|c|}{ COSATI CODES } & 18. SUBJECT TERMS (Continue on reverse if necessary and identify by block number) \\
\hline FIELD & GROUP & SUB-GROUP & Hinged pool \\
\hline & & & Lock and dam \\
\hline & & & Numerical model \\
\hline
\end{tabular}

19. ABSTRACT (Continue on reverse if necessary and identify by block number)

This report describes a numerical model for computing unsteady flows on the Ohio River with the proposed 0lmsted Locks and Dam project in place. It is anticipated that this project will operate as a hinged pool, with the hinge point being Paducah, KY. In addition to a description of the model, its input requirements, and its capabilities and limitations, results from several applications are presented. Applications, with and without the olmsted Dam in place, for a low flow event in May-June 1988 are discussed along with several hypothetical flow events. These hypothetical events represent different types of outflows from Smithland Dam on the Ohio River, Barkley Dam on the Cumberland River, and Kentucky Dam on the Tennessee River. Results in the form of elevation plots at several locations serve to demonstrate that the hinged pool algorithm performs properly and to illustrate the behavior of the system with the olmsted project in place.

Descriptions of the input data required are presented in Appendixes A-D.

20. OISTRIBUTION/AVAILABILITY OF ABSTRACT \UNCLASSIFIEDNUNLIMITED $\square$ SAME AS RPT 22a. NAME OF RESPONSIBLE INDIVIDUAL

\author{
$\square$ DTIC USERS
}

21. ABSTRACT SECURITY CLASSIFICATION Unclassified 22b. TELEPHONE (Include Ared COde) $22 \mathrm{C}$. OFFICE SYMBOL 


\section{PREFACE}

The work described herein and the preparation of this report were conducted during November 1988-December 1989 for the US Army Engineer District, Louisville (CEORL), by the US Army Engineer Waterways Experiment Station (WES) under the general supervision of Messrs. F. A. Herrmann, Jr., Chief of the Hydraulics Laboratory; M. B. Boyd, Chief of the Waterways Division (WD), Hydraulics Laboratory; and M. J. Trawle, Chief of the Math Modeling Branch (MMB), WD. This work was requested by CEORL in a letter dated 2 September 1988.

Dr. B. H. Johnson, WD, and Ms. L. L. Weisinger, MMB, conducted the study and prepared this report. Mr. G. R. Lance, CEORL, was the District's point of contact.

Commander and Director of WES during preparation of this report was COL Larry B. Fulton, EN. Technical Director was Dr. Robert W. Whalin.

The report should be cited as follows:

Johnson, B. H., and Weisinger, L. L. 1990 (Aug). "Numerical Modeling of Unsteady Flows Through the Proposed Olmsted Hinged Pool," Miscellaneous Paper HL-90-8, US Army Engineer Waterways Experiment Station, Vicksburg, MS. 


\section{CONTENTS}

PREFACE

CONVERSION FACTORS, NON-SI TO SI METRIC

UNITS OF MEASUREMENT.

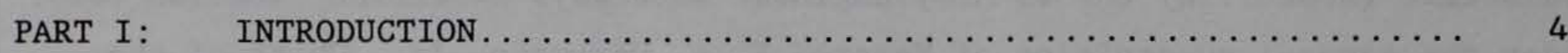

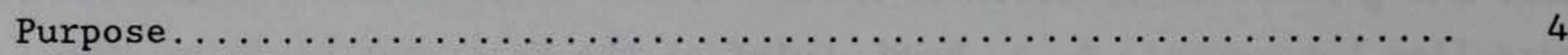

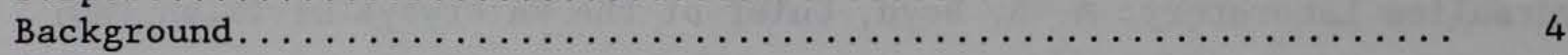

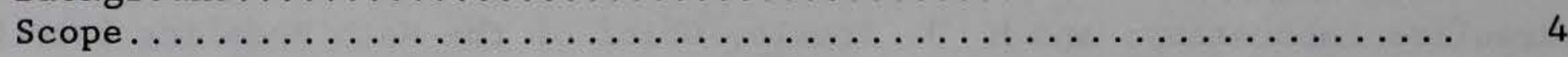

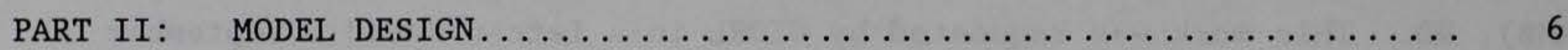

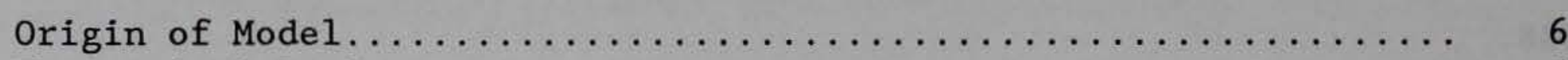

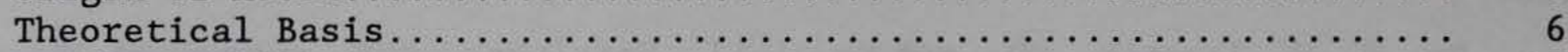

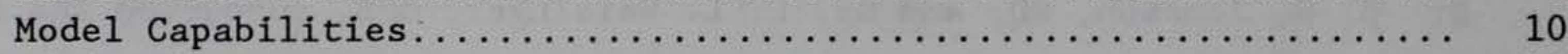

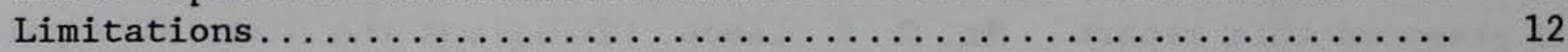

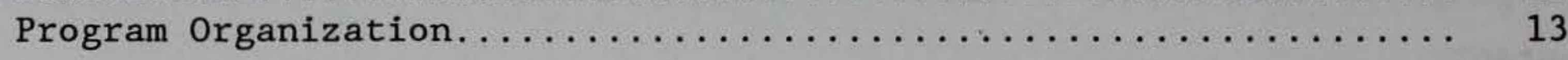

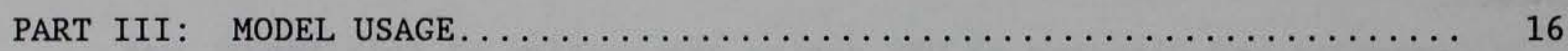

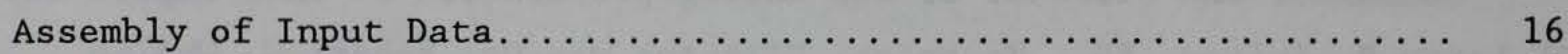

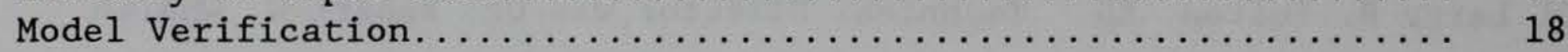

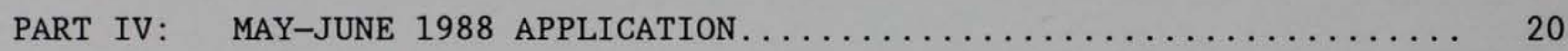

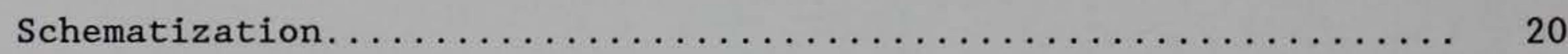

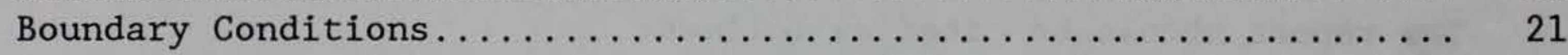

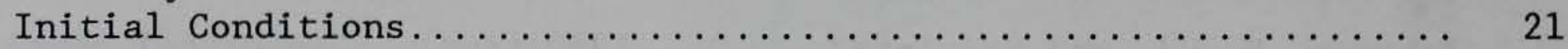

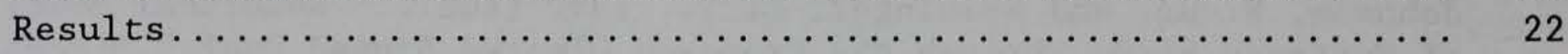

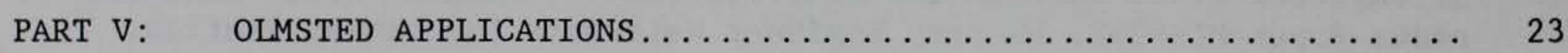

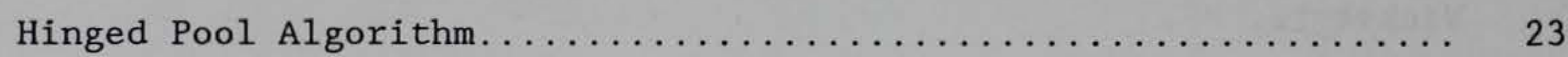

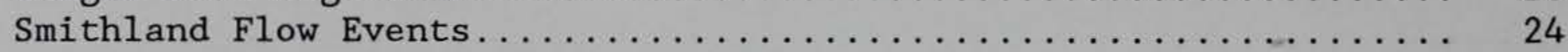

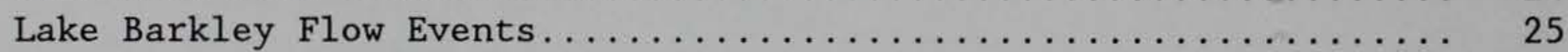

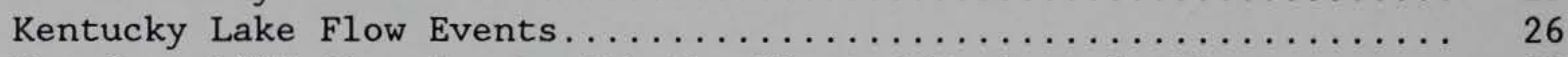

May-June 1988 Flow Event with the Olmsted Project In Place...... 26

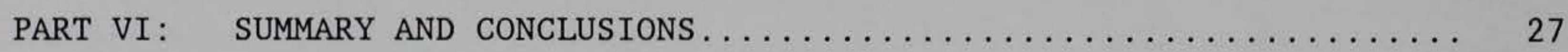

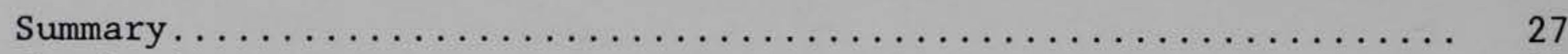

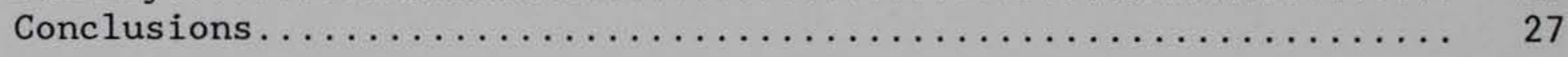

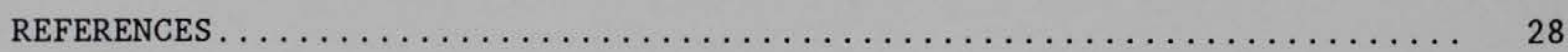

FIGURES $1-73$

APPENDIX A: LIST OF INPUT DATA IN FILE $50 \ldots \ldots \ldots \ldots \ldots \ldots \ldots \ldots \ldots \ldots \ldots \ldots \ldots \ldots \ldots$

APPENDIX B: LIST OF INPUT DATA IN FILE $40 \ldots \ldots \ldots \ldots \ldots \ldots \ldots \ldots \ldots \ldots \ldots \ldots \ldots \ldots$

APPENDIX $C: \quad$ LIST OF INPUT DATA IN FILE $55 \ldots \ldots \ldots \ldots \ldots \ldots \ldots \ldots \ldots \ldots \ldots \ldots$

APPENDIX $D: \quad$ LIST OF INPUT DATA IN FILE ILUG $\ldots \ldots \ldots \ldots \ldots \ldots \ldots \ldots \ldots \ldots$ 


\section{CONVERSION FACTORS, NON-SI TO SI (METRIC) UNITS OF MEASUREMENT}

Non-SI units of measurement used in this report can be converted to SI (metric) units as follows:

Multiply

cubic feet

feet

miles (US statute)

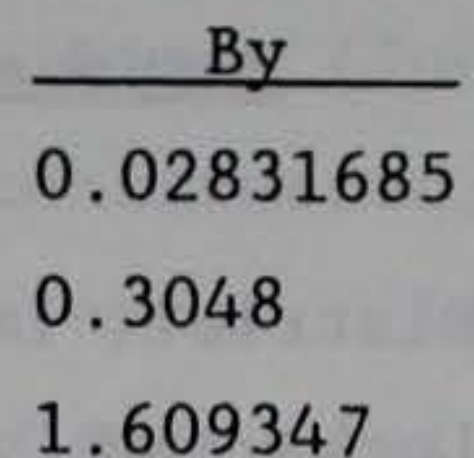

1. 609347
To Obtain cubic metres metres kilometres 


\section{NUMERICAL MODELING OF UNSTEADY FLOWS THROUGH THE \\ PROPOSED OLMSTED HINGED POOL}

PART I: INTRODUCTION

\section{Purpose}

1. The US Army Engineer District, Louisville (CEORL) is studying the impact of building the Olmsted Locks and Dam just downstream of the existing Dam 53 on the Ohio River (see Figure 1). As part of the advanced engineering studies, an evaluation of the proposed hinged pool operations at the project for critical low flow events and for certain operations of the hydroelectric generating stations at Barkley Dam on the Cumberland River and Kentucky Dam on the Tennessee River is required. The development of a numerical modeling capability to compute flow conditions on the Ohio River with the proposed hinged pool operations at the 0lmsted Dam in place was the objective of this study.

\section{Background}

2. For several years, WES has worked with the US Army Engineer Division, Ohio River (CEORD) on the development of a one-dimensional unsteady flow model of the Ohio River and its major tributaries. Results from much of that work and a discussion of the development of a model called FLOWSED is given by Johnson (1982).

3. In a letter from CEORL dated 2 September 1988, wES was requested to modify FLOWSED to account for the removal of Dams 52 and 53 and to incorporate the proposed hinged pool operation at Olmsted Dam. The modified model was to then be applied to demonstrate project behavior for several hypothetical flow events as well as for a critical low flow event during May-June 1988.

\section{Scope}

4. The 1D unsteady flow model FLOWSED has been modified to handle the proposed 0lmsted hinged pool operation and applied to the system shown in Figure 1. Geometric data describing the system were obtained as follows. The 
Louisville District supplied cross section data for the Ohio and Cumberland Rivers. These were then used by the geometric elements program called GEDA (Thomas 1981) to construct tables of flow area and top width versus depth at approximately 1-mile increments. Geometric tables for the Upper and Lower Mississippi Rivers were taken from previous work for ORD (McCarley 1988), as were those specified on the Tennessee River (Johnson 1982).

5. With the geometric tables constructed, the numerical model was first applied to the May-June 1988 low flow event. In this application, Dams 52 and 53 were retained with their influence accounted for by forcing the observed elevations upstream of the dams. The modified FLOWSED model was then applied assuming hypothetical flow events at Smithland, Barkley, and Kentucky Dams. In these applications, Dams 52 and 53 were removed from the system and the proposed Olmsted Dam was assumed to be in operation with the pool hinge point being Paducah, KY. The modified model, with Olmsted Dam in place, was then applied to the May-June 1988 low flow event.

6. This report is intended to serve as a user's guide to aid the District in their use of the model as well as a means of presenting results from the various applications noted above. Therefore, some discussion of the theoretical basis of the model and its limitations and capabilities is given before application results are presented. Finally, detailed lists of the input data required to run the model are presented in the appendices. 
PART II: MODEL DESIGN

\section{Origin of Model}

7. A basic computer program for computing flow and sediment movement in open channels was obtained in 1977 from Dr. Y. H. Chen of Colorado State University. Many modifications which centered around generalizing the code's basic computational structure as well as developing input/output routines were accomplished under funding by CEORD. The resulting computer program could be applied in a very efficient manner to an extremely general river system containing tributaries as well as dams. The resulting model was called FLOWSED to reflect its ability to route flow as well as sediment in open channels. FLOWSED has been further modified by CEORD to remove the sediment computations but the FLOWSED name has been retained. Under funding by the US Army Engineer Division, Lower Mississippi Valley (LMVD) to develop a forecasting model for the Lower Mississippi River, the solution scheme in FLOWSED was restructured and sediment computations also removed. That model is called BIRM (Johnson 1983). The CEORD FLOWSED model has been used in this study.

\section{Theoretical Basis}

\section{Basic equations}

8. For the case of one-dimensional open-channel flows within rigid boundaries, the flow behavior can be adequately described by the de SaintVenant partial differential equations of unsteady flow. These equations, which are presented below, are derived by considering the conservation principle for mass and for the momentum of the flow.

Flow Continuity: $\frac{\partial Q}{\partial x}+\frac{\partial A}{\partial t}=q_{\ell}$

Momentum: $\frac{\partial \mathrm{Q}}{\partial \mathrm{t}}+\mathrm{V} \frac{\partial}{\partial \mathrm{x}}(\beta \mathrm{Q})+\beta \mathrm{V} \frac{\partial \mathrm{Q}}{\partial \mathrm{x}}-\beta \mathrm{V}^{2} \mathrm{~B} \frac{\partial \mathrm{y}}{\partial \mathrm{x}}$

$$
+g A \frac{\partial y}{\partial x}=g A\left(S_{x}-S_{f}-S_{e}\right)+\beta V^{2} A_{x}^{y}
$$


9. Equations 1 and 2 are the set of equations governing the motion of water in open channels in a one-dimensional sense and involve four unknowns; namely, the flow discharge $Q$, the flow depth $y$, the frictional slope $S_{f}$, and an eddy loss term $s_{e}$. Other variables such as the lateral inflows and geometry data are expected to be known. To achieve closure of the system, two additional relations are required. These are provided by Manning's equation which relates the friction slope to the flow and channel characteristics,

$$
S_{f}=\frac{n^{2} Q|Q|}{2.25 A^{2} R^{4 / 3}}
$$

and an equation to account for losses due to large-scale eddies formed in the flow at rather abrupt changes in the cross sections along the channel

$$
S_{e}=\frac{K_{e}}{2 g} \frac{\partial v^{2}}{\partial x}
$$

With these additional relations, one can then solve for the basic unknowns Q and $y$. Variables in the equations are defined as:

A Total cross-sectional area of channel

$\mathrm{A}_{\mathrm{x}}^{\mathrm{y}} \quad$ Derivative of $\mathrm{A}$ with respect to channel distance at a constant flow depth

B Top width of water surface

g Acceleration due to gravity

$\mathrm{K}_{\mathrm{e}} \quad$ Coefficient in eddy head loss term

n Coefficient in Manning's Equation

Q Flow discharge in cfs

$\mathrm{q}_{\ell} \quad$ Lateral discharge of water

$\mathrm{R} \quad$ Hydraulic radius

$\mathrm{S}_{\mathrm{X}} \quad$ Slope of channel bed

$\mathrm{S}_{\mathrm{f}} \quad$ Friction slope

$\mathrm{S}_{\mathrm{e}} \quad$ Eddy head loss term

$t \quad$ Time

V Average flow velocity 
$\mathrm{x} \quad$ Distance along the channel

$y$ Depth of water in the channel

z Elevation of channel bed

$\beta \quad$ Momentum correction factor

$\partial / \partial t \quad$ Derivative with respect to time

$\partial / \partial \mathrm{x} \quad$ Derivative with respect to channel distance

10. The governing equations do not in general possess analytic solutions. One must therefore rely upon numerical techniques such as finite differences to obtain a solution. The finite difference approximations used in FLOWSED to express the partial derivatives of a function $\phi$, where $\phi$ represents the dependent variables $\mathrm{Q}$ and $\mathrm{y}$ are given as

$$
\begin{aligned}
& \frac{\partial \phi}{\partial \mathrm{x}} \simeq\left(\frac{\phi_{i+1}^{\mathrm{n}+1}-\phi_{i}^{\mathrm{n}+1}}{\Delta \mathrm{x}}\right) \\
& \frac{\partial \phi}{\partial t} \cong \frac{1}{2 \Delta t}\left[\left(\phi_{i}^{\mathrm{n}+1}-\phi_{i}^{\mathrm{n}}\right)+\left(\phi_{i+1}^{\mathrm{n}+1}-\phi_{i+1}^{\mathrm{n}}\right)\right]
\end{aligned}
$$

where

$$
\begin{aligned}
& \Delta x=\text { spatial computation step } \\
& \Delta t=\text { time computation step }
\end{aligned}
$$

11. Constructing difference equations from the governing differential equations through use of the finite difference approximations presented above results in a linear-implicit finite difference scheme. The difference form of the governing equations written over a computational cell formed by sections $i$ and $i+1$ take the form

$$
\begin{aligned}
& \mathrm{K}_{\mathrm{k} 1}^{\mathrm{n}} \mathrm{Q}_{i}^{\mathrm{n}+1}+\mathrm{k}_{\mathrm{k} 2}^{\mathrm{n}} \mathrm{Y}_{i}^{\mathrm{n}+1}+\mathrm{K}_{\mathrm{k} 3}^{\mathrm{n} Q_{i+1}^{\mathrm{n}+1}}+\mathrm{k}_{\mathrm{k} 4}^{\mathrm{n}} \mathrm{Y}_{i+1}^{\mathrm{n}+1}=\mathrm{E}_{k}^{\mathrm{n}} \\
& \mathrm{K}_{\ell 1}^{\mathrm{n}} \mathrm{Q}_{i}^{\mathrm{n}+1}+\mathrm{K}_{\ell 2}^{\mathrm{n}} \mathrm{Y}_{i}^{\mathrm{n}+1}+\mathrm{K}_{\ell 3}^{\mathrm{n}} \mathrm{Q}_{i+1}+\mathrm{K}_{\ell 4}^{\mathrm{n}} \mathrm{Y}_{i+1}^{\mathrm{n}+1}=\mathrm{E}_{\ell}^{\mathrm{n}}
\end{aligned}
$$

where $k=2 i, \quad \ell=2 i+1$ and the coefficients $k$ and $E$ are functions of known variables from the previous time line. These equations are then solved using what is commonly called the double sweep algorithm. The interaction between the main river and a tributary being handled in a dynamic fashion as 
opposed to being treated as lateral inflow is simulated by the following continuity and energy equations:

$$
\begin{aligned}
& Q_{3}=Q_{2}+Q_{1} \\
& Z_{2}+Y_{2}+\frac{v_{2}^{2}}{2 g}=Z_{3}+Y_{3}+\alpha_{2} \frac{v_{3}^{2}}{2 g}+\left(S_{f} \Delta x\right)_{2} \\
& Z_{1}+Y_{1}+\frac{v_{1}^{2}}{2 g}=Z_{3}+Y_{3}+\alpha_{1} \frac{v_{3}^{2}}{2 g}+\left(S_{f} \Delta x\right)_{1}
\end{aligned}
$$

in which $\alpha$ is the energy correction factor, $s_{f} \Delta x$ is the energy head loss and subscripts $1,2,3$, as illustrated below, refer to sections above the confluence on the tributary and main river and below the confluence on the main river.

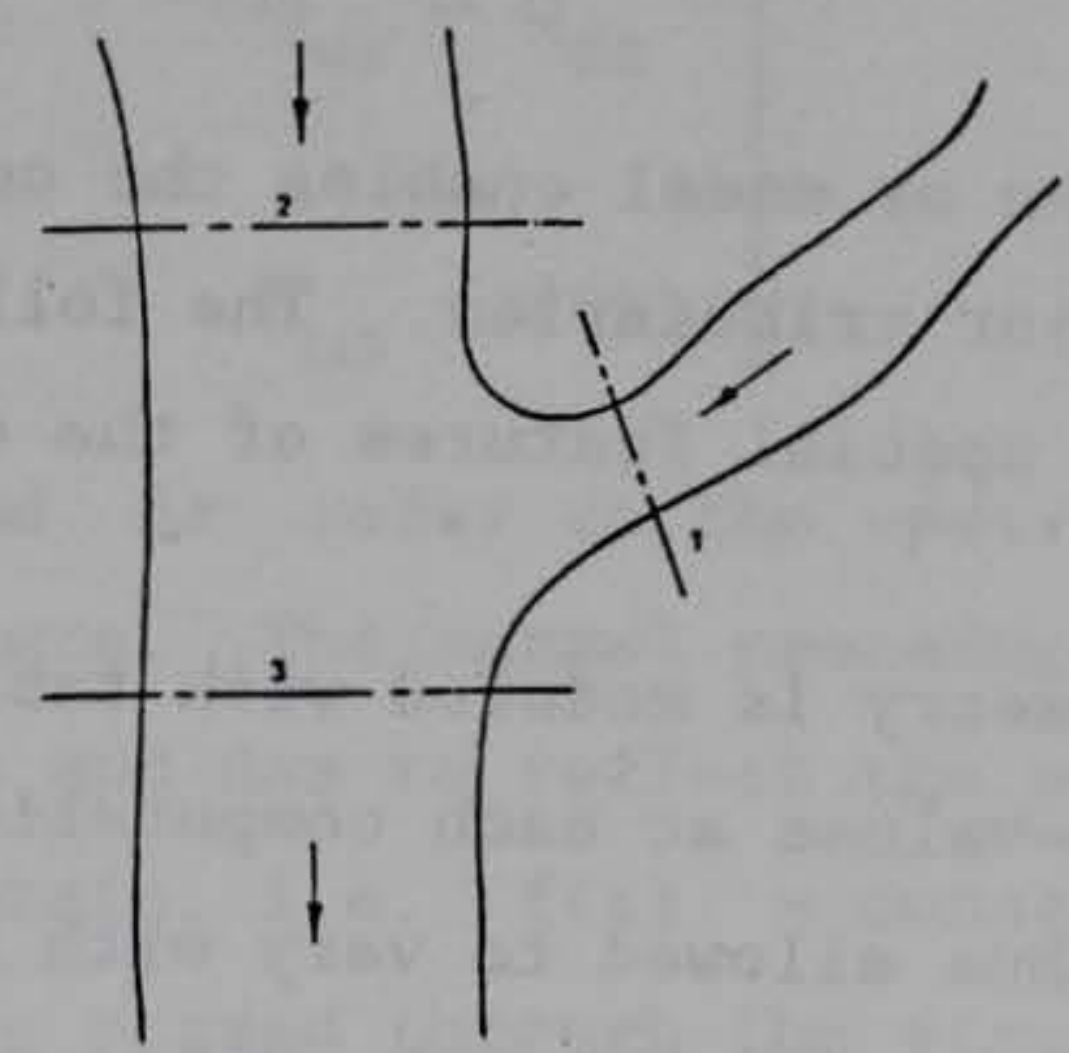

For brevity, details concerning how the junction equations are incorporated into the overall solution scheme using the double sweep algorithm are not presented. Similar computations are discussed by Chen (1973) and Johnson (1982).

\section{Time step restrictions}

12. The solution scheme employed is an implicit finite difference scheme. Unlike explicit schemes, implicit schemes are unconditionally stable. Therefore, the computational time step is not restricted as far as numerical stability is concerned. However, it should be remembered that the time step 
employed does influence the accuracy of the computations. Numerical experimentation can reveal insight into the effect of the time step.

\section{Boundary computations}

13. Boundary conditions are incorporated directly into the overall solution scheme. This is made possible by writing the boundary conditions in the form of Equation 6. Details are provided by Chen (1973) with additional discussion by Johnson (1982).

\section{Initial conditions}

14. The equations to be solved constitute a hyperbolic system and initial values of the dependent variable, i.e. water surface elevation and discharge must be prescribed to begin the time marching of the solution. A steady-flow profile or perhaps a transient profile from previous computations can be used. The specification of initial conditions is flexible due to the characteristic of hyperbolic equations that the solution becomes independent of initial conditions after a sufficient length of time.

\section{Model Capabilities}

15. The basic program or model enables the computation of unsteady flow in a main river and its major tributaries. The following discussion describes particular capabilities or special features of the computer code.

\section{Geometric data}

16. The channel geometry is modeled with tables of elevation versus flow area, top width and n-values at each computation point along the study reach. The n-values are thus allowed to vary with elevation at a particular node as well as with distance along the channel. Overbank storage is handled by specifying the cross-sectional area versus elevation. The overbank crosssectional areas are then internally converted to plan form areas. Figure 2 illustrates the delineation between flow area and overbank storage, which is obviously very subjective. More details concerning the geometry data are presented later.

\section{Boundary conditions}

17. An upstream boundary condition is prescribed by a flow discharge hydrograph. A point on the hydrograph is coded as a discharge value and the number of time steps before a new value will be read. Only those points required to approximate the hydrograph with a sequence of straight lines need to 
be entered because linear interpolation is used to develop required values during the computations.

18. At the downstream boundary, a rating curve, a discharge or an elevation hydrograph may be input. An elevation hydrograph is input in exactly the same way as a discharge hydrograph at an upstream boundary. Rating curves are input by representing the rating curve as a sequence of linear segments. Each linear segment is then defined by specifying the discharge and corresponding elevation at the end of the segment.

Local inflow

19. Local inflow may be specified in any computation reach of the study area. Inflows for each specified reach are input in the same manner as the upstream discharge hydrographs.

Locks and dams

20. To account for the effect of navigation locks and dams, the following equations are utilized:

$$
\left.\begin{array}{l}
\mathrm{Q}_{\mathrm{us}}=\mathrm{Q}_{\mathrm{ds}} \\
\mathrm{Y}_{\mathrm{us}}=f(t)
\end{array}\right\}
$$

where the subscripts us and ds refer to the upstream and downstream sections surrounding the structure. The normal procedure is to input a constant elevation upstream of a lock and dam to reflect the pool elevation the lock operator is expected to maintain, i.e. $f(t)=$ constant. With such a procedure, the flow required to be passed through the structure in order to maintain the upstream elevation is computed. Theoretically, the operator could then use gate rating curves to make the gate adjustments required to pass the computed flow. In hydropower feasibility studies, one may wish to specify some time variation of a particular pool rather than prescribing a constant value. Hinged pool operations such as those at the proposed Olmsted Dam require special treatment and are discussed later.

Levees

21. To handle the effect of levee overtopping, the equation for the discharge over a weir

$$
q=C \Delta \mathrm{H}^{3 / 2}
$$


where $H$ is the height of water over the levee and $C$ is the discharge coefficient, is invoked to compute lateral outflow from the channel whenever the water surface elevation exceeds the height of the levee. Basic assumptions in the current handling of levees is that the levees do not fail and flow which leaves the channel as a result of levee overtopping is lost from the system. The location and average height of the levee must be specified as input. Overbanks

22. The lateral inflow $\mathrm{q}_{\ell}$ consists of two components, $\mathrm{q}_{\ell_{1}}$ and $\mathrm{q}_{\ell_{2}}$, induced by the handling of flood plains and tributaries, respectively. For overbank storage, ${ }^{\mathrm{q}} \ell_{1}$ is computed from

$$
q_{\ell_{1}}=-\frac{A_{f}}{\Delta x \Delta t} \Delta h
$$

where $A_{f}$ is the surface area of the flood plain and $\Delta h$ is the change over a time period $\Delta t$ of the water surface elevation (see Figure 2).

\section{Print and time step options}

23. Results may be printed at any net point and at any multiple of the computational time step desired. In addition, through input data one can change the print interval and/or time step during a run. Two forms of printed output can be requested. One consists of basically only the computed discharge and water surface elevation; whereas, the other also contains various geometric information.

\section{Limitations}

24. The model provides a solution of the one-dimensional equations describing the motion of water in open channels with irregular cross sections. Therefore, the river reach to be modeled should be reasonably straight with the free surface assumed to be a horizontal line across the section. In addition, the pressure field is assumed to vary in the vertical direction in a hydrostatic manner. Thus, vertical accelerations are negligible, i.e., the flow is gradually varied. Also, the density of the water is homogeneous.

25. The computer model is not a network model since multiple connected systems, i.e., closed loops, cannot be handled. However, it is a junction 
model since any number of tributaries into the main river are handled in a fully dynamic fashion. In addition, lateral inflows from minor tributaries or ungaged local flows can be accommodated.

26. A current limitation on the physical region is that there can only be one downstream boundary at which a rating curve is employed. In its present form, there is another limitation on the specification of boundary conditions. At an upstream boundary only discharges can be prescribed; whereas, at a downstream boundary either a rating curve, discharges, or water surface elevations may be specified.

\section{Program Organization}

$\underline{\text { Size }}$

27. Depending upon the specification of DIMENSION statements, FLOWSED can be applied to a system composed of any number of branches, locks and dams, etc. The application of FLOWSED in this study was conducted on a VAX 3300 computer.

\section{Subroutines}

28. FLOWSED is composed of a main program and 14 subroutines. A brief discussion of each is presented below.

LOCKDAM - This subroutine sets the coefficients in the equations applied over a computational reach containing a navigation lock and dam. For example, to force the discharge to be the same upstream and downstream of a dam the coefficients in the equation

$$
\begin{gathered}
\mathrm{C}_{\ell, 1} \mathrm{Q}_{\mathrm{i}}+\mathrm{C}_{\ell, 2} \mathrm{Y}_{\mathrm{i}}+\mathrm{C}_{\ell, 3} \mathrm{Q}_{\mathrm{i}+1}+\mathrm{C}_{\ell, 4} \mathrm{Y}_{\mathrm{i}+1}=\mathrm{E}_{\ell} \\
\text { are set to } \\
\mathrm{C}_{\ell, 1}=1, \mathrm{C}_{\ell, 3}=-1, \mathrm{C}_{\ell, 2}=\mathrm{C}_{\ell, 4}=\mathrm{E}_{\ell}=0 .
\end{gathered}
$$

LINEAR - This subroutine linearly interpolates for the flow area, top width, and Manning's n from the geometric tables for a particular water surface elevation.

FLOOD - The surface area of the floodplain used in computing $\mathrm{q}_{\ell_{1}}$ is determined in FLOOD. 
INITIAL - This subroutine is only called once, i.e. when the computations are initialized. Various minor computations are performed, e.g. the flood plain area which is input as a cross-sectional area is changed to surface area and the spatial computational steps are computed.

JOINTER - This subroutine joins results from the forward sweep on the main river and a tributary with the confluence equations so that the forward sweep on the main river can then continue.

COEFFIT - As noted in the discussion of the solution scheme, the coefficients in the system of linear algebraic equations are dependent upon information known from the previous time line. These coefficients are computed in COEFFIT.

FORWARD - This subroutine computes the coefficients in the forward sweep of the double sweep solution algorithm.

BACKWARD - In this subroutine the double sweep algorithm is completed by computing the unknown variables.

NEWFLOW - This subroutine is called at the end of each time step to update new flow conditions which are then used to initiate computations on the next time line.

DAMRC - Coefficients required when applying a rating curve as an internal boundary are computed in DAMRC. Such a boundary condition might be employed at a dam where control is retained even though all gates are out of the water.

DOWNCOD - The rating curve at the downstream end of the main river must be cast into the form of the difference Equation 6 . This is accomplished by breaking the rating curve up into linear segments and computing the appropriate coefficients. These coefficients are computed in DOWNCOD. 
BRYCAL - This subroutine either reads new boundary values or interpolates to provide boundary values at intermediate times. The order on reading boundary conditions is upstream first, then the downstream boundary and finally any dams that have time varying elevations or discharges prescribed.

LATERAL - This subroutine is very similar to BRYCAL. Its function is to either read or interpolate for updated values of lateral inflows.

HINGE - Computations governing the 0lmsted hinged pool operations are performed here. An attempt is made to keep the water surface elevation below Smithland Dam above 302 feet ORD while maintaining the elevation at Paducah, KY, at 300 feet ORD. Gages on the Ohio River are referenced to the Ohio River Datum (ORD) while those on the other rivers are referenced to the National Geodetic Vertical Datum (NGVD). 
29. There are three basic steps that one must perform in using FLOWSED. First, the study area is discretized and necessary input data are assembled. Second, the model is verified using sets of historical data. Finally, the model is applied using the boundary conditions representing the problem of interest and results are analyzed.

\section{Assembly of Input Data}

\section{Discretization of study area}

30. The particular finite difference solution scheme in FLOWSED allows for irregular spacing of the computation points. Therefore, discretizing the study area should be relatively simple. Basically, computational points are located at a gaging station or locations where results are desired and to establish enough points so that the calculations will produce a smooth water surface profile. For problems involving hydropower surges over relatively short distances one may wish to have a grid spacing of $1000 \mathrm{ft}$ or less; whereas, for routing flows in rivers covering distances of hundreds of miles a grid spacing of 1 to 5 miles is normally sufficient. Finally, one should attempt to place computational points at locations such that the physical geometry is adequately described.

\section{Input data}

31. With its present structure, input is read from four files. The input data can be broken into several groups; e.g. general control parameters, plotting, branch information, junction information, locks and dams, coefficients in the eddy head loss term, initial conditions, information on levees, geometric tables, and boundary conditions. Each is briefly discussed below. A detailed list of required and optional input data and the proper format for coding are presented in the appendices.

32. Several parameters that describe the system being modeled and determine the various forms of output must be input. These include the number of computational points or nodes, branches, junctions and locks and dams as well as the numbers of the nodes at which printed output is desired. As previously noted, the print interval as well as the time step can be changed during a run. 
33. If requested, computed results for plotting are written to a file. Plot identifiers and node numbers must be input.

34. Depending upon DIMENSION statements, FLOWSED can be applied to a system composed of any number of branches containing any number of nodes. For each branch, one must input the first and last node numbers on that branch as well as information related to the type of boundary condition to be applied if the branch contains either an upstream or downstream boundary. It is important to remember that all branches and corresponding nodes on the main river are numbered, beginning at the upstream boundary, before numbering the first tributary. An example of the proper numbering sequence is given below for a system composed of five branches and 29 nodes or computational points.

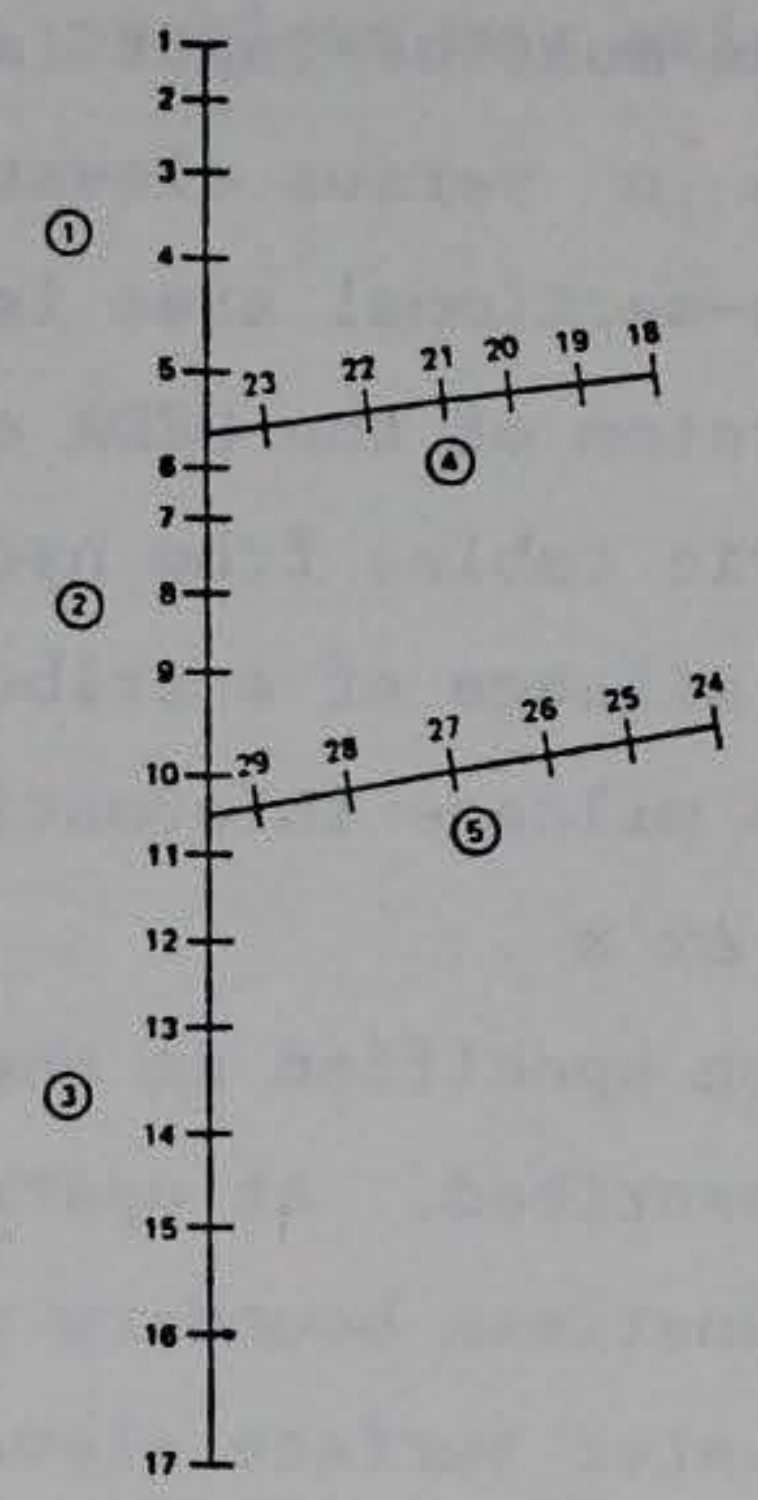

At each junction one must input the number of the three branches composing that junction.

35. The effect of locks and dams on the flow field can be handled by FLOWSED. A descriptive title plus the elevation to be maintained and the node immediately upstream must be input. In addition, through an input parameter one specifies whether the dam maintains a fixed elevation until control is lost or either time-varying elevations (discharge) or a rating curve will be prescribed. The hinged pool operations at 0lmsted Dam is a special case.

36. Coefficients required in the eddy head loss term can be prescribed as spatially varying data or can be set equal to constant values if desired. The role of these coefficients can be seen from the expression presented for $\mathrm{S}_{\mathrm{e}}$ in Equation 4. 
37. Initial values of the water surface elevation and flow discharge must be prescribed at each node. Initial values are not extremely crucial since their effect dies out fairly quickly. If lateral inflows are specified, they must also be initially prescribed.

38. One can specify that certain reaches contain levees that will be overtopped. The average elevation of the levee within the reach and the upstream node of the reach must be input. Lateral outflow is then computed from Equation 10 .

39. The geometric tables constitute the majority of the input data required by FLOWSED. At each node in the system a geometric table consisting of three parts must be input. First, a descriptive title, the river mileage and the bank and bed elevations must be input (see Figure 2). Next, the flow area, top width, and Manning's $n$ versus elevation are input for the channel. Finally, the flood plain cross-sectional area is input for elevations above the top of the channel. A version of the GEDA code by Thomas (1981) is normally used to generate geometric tables from hydrographic survey data. It might be noted that the river mileage of a tributary must be zero at its junction with the main river since mileage information is used to compute the computational spatial steps, $\Delta x^{\prime} s$.

40. If a branch has been specified as one having an open boundary, a boundary condition must be prescribed. At upstream boundaries, the discharge must be specified. At the downstream boundary of the main river, either a rating curve, discharges, or water surface elevations must be input. Similar data are lateral inflows and time-varying pool elevations (discharges).

\section{Model Verification}

41. With the necessary input data assembled and coded as shown in the appendices, the model is then verified by adjusting the values for Manning's $\mathrm{n}$ and/or geometry data to better represent the physical system. These adjustments continue until the comparison between computed and recorded results at several locations along the study area is considered adequate for data sets representing a range of conditions. If large differences occur, reasons for those differences should be determined, e.g. if a sufficient time lag occurred between the sets of historical data used, the physical system may have 
significantly changed, resulting in the need for more recent geometry data and/or new values of Manning's $n$.

42. Strict adjustment guidelines are difficult to state. The best procedure is probably to begin with a reasonable n-value that is constant over the study area. These values are then gradually adjusted with elevation as well as along the channel. A useful point to remember is that changes in $n$ at a particular point affect results at upstream points more than at downstream computational points. In addition, increases in $n$ throughout the modeled system raise the water surface while reducing the discharge. If it appears that unreasonable n-values are required to verify the model, the geometry data should be reanalyzed. As a final note, when attempting to model floods in large river systems, problems may arise from uncertainties in the ungaged runoff. 


\section{PART IV: MAY-JUNE 1988 APPLICATION}

\section{$\underline{\text { Schematization }}$}

43. A schematization of the study area which is composed of the Ohio River from Smithland Dam to its junction with the Mississippi River, the Mississippi River from Thebes, IL to Caruthersville, MO, the Cumberland River from Barkley Dam to its junction with the Ohio River and the Tennessee River from Kentucky Dam to its junction with the Ohio River is presented in Figure 3. The system is discretized with 155 computational points and 7 branches. Key nodes are numbered on Figure 3. The spatial step, i.e. $\Delta x$, is variable but is generally one mile or less on the Ohio, Cumberland and Upper Mississippi Rivers and about 5 miles on the Tennessee and Lower Mississippi Rivers.

44. As previously noted, a major step in assembling the model is the generation of the geometry tables to be input at each of the computational points. Geometry tables on the Ohio and Cumberland Rivers were constructed from cross sectional data provided by the District. New tables were constructed rather than using existing tables from earlier modeling studies to increase the spatial resolution in the channel (as well as along the channel) to better handle low flows. The previous studies were primarily concerned with modeling flood flows. Existing geometry tables on the Mississippi and Tennessee Rivers from the earlier studies make up the remainder of the geometric model. After this study was completed, it was determined that all of the geometry data on the Ohio River as well as the Ohio River gages are referenced to the Ohio River Datum (ORD). However, geometry data and gages on the other rivers of the modeled system are referenced to the NGVD. As an example of the difference between the two datums, the conversion at mile 38 above the Ohio-Mississippi junction is

$$
\mathrm{ORD} \cong \mathrm{NGVD}+0.45
$$

Results presented herein are based upon assuming ORD $=$ NGVD. Implications of this assumption are discussed later. 


\section{Boundary Conditions}

45. Outflows from Smithland Dam, Barkley Dam, and Kentucky Dam plus the Upper Mississippi River flow at Thebes, MO, were provided by the District. Except for the Smithland flows, which were adjusted, these were prescribed as boundary conditions. The rating curve presented in Figure 4 was prescribed as the downstream boundary condition at Caruthersville, MO. As noted, the Smithland outflow hydrograph was adjusted. This is illustrated in Figure 5. The unadjusted outflow was determined from the Smithland tailwater rating which the District considers suspect. An inspection of the original Smithland discharge versus elevation presented in Figure 6 reveals a data discontinuity that is difficult to explain with backwater effects constant over the period 20 May-10 June 1988. Therefore, an adjustment of the Smithland outflow seemed justified and was required to force the computed elevation to match the recorded elevation. It should be noted that the District considers an upgrade of the Smithland tailwater rating to be warrented. A plot of all inflows prescribed is given in Figure 7.

46. In addition to the outer boundary conditions, internal boundaries at L\&D 52 and L\&D 53 were prescribed. Normally, L\&D 52 is operated to maintain a minimum elevation of 302 feet ORD just upstream of the dam with L\&D 53 operated to maintain a minimum elevation of 290 feet ORD. However, from an inspection of Figure 9 it can be seen that L\&D 53 did not maintain a minimum elevation of 290 feet in this way during much of the 20 May-10 June 1988 low flow event. Therefore, the actual elevations shown in Figures 8 and 9 were prescribed as internal boundary conditions at L\&D 52 and L\&D 53, respectively.

\section{Initial Conditions}

47. Initial conditions were created by holding the outflow from the Smithland, Barkley, and Kentucky Dams and the Thebes discharge constant for 10 days. Model results were then saved and employed as the initial state for the 20 May-10 June 1988 application as well as the 0lmsted applications discussed in PART V. The Smithland outflow was set to be $40,000 \mathrm{cfs}$ with the Barkley, Kentucky, and Thebes flows set to be $6,000,12,000$ and $120,000 \mathrm{cfs}$, respectively. 


\section{Results}

48. Comparisons of computed and recorded elevations at several locations are presented in Figures 10-17. As shown in Figure 10, the adjusted Smithland Dam discharge presented in Figure 5 results in a relatively good match of the elevations. If the original Smithland outflows are prescribed, the comparison presented in Figure 18 results. Thus, it is believed the adjusted flows are closer to reality. Generally, the computed elevations match the observed elevations to within 0.5 to 1.0 foot. Given the uncertainty of the inflow into the system, the comparisons seem reasonable. There were no discharge data available at interior points for comparison with computed results.

49. In analyzing these comparisons, it should be remembered that the Ohio River geometric tables as well as the Ohio River gages are referenced to the Ohio River Datum; whereas, the remainder of the modeled area is referenced to the NGVD. However, at mile 38 this difference is less than 0.50 feet. Strictly speaking, the Ohio River geometric tables and the recorded elevations should be shifted so that the complete model is referenced to the NGVD. It is not believed shifting the geometric tables will have a significant impact on computed results. Thus, computed results could probably be viewed as relative to the NGVD except that the observed elevations at L\&D 52 and L\&D 53 that are imposed as boundary conditions were not adjusted to the NGVD. Thus the comparison of computed and observed elevations presented is not exact. In additional work planned for the District this discrepancy will be coriected. 


\section{PART V: OLMSTED APPLICATIONS}

\section{Hinged Pool Algorithm}

50. FLOWSED handles dams as interior boundaries that are driven through the specification of either an elevation or discharge, or perhaps a rating curve. Prior to this study, an interior elevation boundary could either be prescribed by time varying data or by a constant value that is maintained until the dam tailwater rises to approximately meet the dam headwater. When this occurs, the dam is removed from the system until the headwater elevation falls below the specified constant value at which it is to be maintained. The hinged pool algorithm for the operation of olmsted Dam is based upon prescribing the water surface elevation at the dam, but the prescribed elevation is determined in a different manner.

51. It is anticipated that the 0lmsted gates will be operated to maintain an elevation of 300 feet ORD at the Paducah, KY, gage. Thus, Paducah is the hinge point of the 0lmsted Pool. However, if by maintaining an elevation of 300 feet at Paducah the Smithland Dam tailwater falls below 302 feet ORD, then the gates will be operated to force the Smithland tailwater up to 302 . Since the operation of the olmsted gates can only force elevations just upstream of the dam to lie between 295 and 300 feet, for some extremely low flow conditions it may not be possible to maintain the Smithland tailwater at or above 302 feet.

52. The hinged pool algorithm is based upon utilizing results from several steady state runs in which various combinations of inflows and olmsted elevation settings were prescribed to determine the corresponding water surface elevations downstream of Smithland Dam and at Paducah, KY. Depending upon the Smithland, Barkley, and Kentucky inflows, these results then determine the water surface elevation upstream of olmsted Dam. For example, if the sum of the discharge from Smithland, Barkley and Kentucky Dams is less than $65,000 \mathrm{cfs}$, the 0lmsted elevation is prescribed to be 300 feet to force the Smithland tailwater above 302 feet.

53. The algorithm operates such that an elevation setting to force the Smithland tailwater above 302 feet is first computed. However, if the Smithland tailwater from the previous time step ( $\Delta t=1$ hour) is greater than 302 feet, an elevation setting that will force the elevation at Paducah to 
remain near 300 feet is computed and used.

54. With this procedure, the elevation hydrograph prescribed and the resulting discharge computed through the dam tends to be rather erratic. To alleviate this problem, resulting in a much smoother operation at 0lmsted, the computed elevations at 0lmsted are saved and at the end of the simulation are smoothed using the following three point smoothing equation,

$$
E^{n}=\frac{E^{n-1}+E^{n}+E^{n+1}}{3}
$$

where $\mathrm{n}$ represents a point in time. The complete simulation is then rerun with the smoothed elevations prescribed as the time varying boundary condition upstream of the Olmsted Dam.

55. With L\&D's 52 and 53 removed from the system and the Olmsted Dam in place, several hypothetical inflow events were simulated to demonstrate the behavior of the olmsted algorithm. Finally, the 20 May-10 June 1988 low flow event was simulated with the proposed 0lmsted project in place.

\section{Smithland Flow Events}

56. Two hypothetical Smithland outflow events have been simulated. In both cases the Barkley and Kentucky outflows were constant at 6,000 and $12,000 \mathrm{cfs}$, respectively, while the Upper Mississippi River flow was taken to be a constant $120,000 \mathrm{cfs}$. The generation of the initial conditions has previously been discussed.

57. As illustrated in Figure 19, the first Smithland flow event had the flow dropping from 40,000 cfs to 20,000 cfs over 3 days and then was held constant for 3 days. Over the next 3 days the flow increased to $80,000 \mathrm{cfs}$ and was again held constant for 3 days. The flow was then decreased over three days to $20,000 \mathrm{cfs}$ again and remained constant for the remainder of the 20 day simulation.

58. The computed water surface elevations at several locations are presented in Figures 20-26. Note that for flows of $20,000 \mathrm{cfs}$ and $6,000 \mathrm{cfs}$ from Smithland and Barkley, respectively, the Smithland tailwater falls below 302 feet even though the elevation forced at 0lmsted is 300 feet (see Figure 24). Figure 22 shows that the hinged pool algorithm does maintain the 
water surface elevation at Paducah, KY, very near the target of 300 feet. 59. The inflows for the second Smithland flow event are given in Figure 27. The hydrograph is similar in shape to the first flow event but with a maximum of $200,000 \mathrm{cfs}$. Computed elevations at several locations are presented in Figures 28-34. As illustrated in Figure 32, 01msted looses control from about day 9 to day 13. From Figure 30, it can be seen that the elevation at Paducah, KY, can no longer be controlled and rises to a maximum of about 302 feet during this period. This flow event demonstrates that the hinged pool algorithm functions properly throughout a flow event in which control is lost and then regained.

\section{Lake Barkley Flow Events}

60. Two flow events from Lake Barkley have been simulated with the Olmsted project in place. Inflows for the first event are presented in Figure 35. The Smithland discharge was held at a constant 40,000 cfs along with $12,000 \mathrm{cfs}$ and $120,000 \mathrm{cfs}$ at Kentucky Dam and Thebes, IL, respectively. The Barkley outflow hydrograph was taken to be very similar to the first Smithland flow event with a maximum flow of $80,000 \mathrm{cfs}$. Computed elevations at several locations are presented in Figures 36-42. A comparison of Figures 40 and 24 shows similar control exercised at 0lmsted but with the upper pool elevation between days 9 and 12 decreased about 1 foot more because of the total maximum flow moving down the Ohio River now being $132,000 \mathrm{cfs}$ as opposed to the total maximum flow being 98,000 cfs during the first Smithland flow event.

61. The second Barkley flow event simulated contains three rapidly varying flows in the first 5 days of the total 10 day simulation. Inflows for this event are shown in Figure 43. As can be seen, the maximum flows for the three peaks are $20,000 \mathrm{cfs}, 40,000 \mathrm{cfs}$ and $60,000 \mathrm{cfs}$. Computed elevations at several locations are presented in Figures 44-50. The peak of the maximum surge created at Barkley is about 16 feet. From Figure 46 it can be seen that operation of the 0lmsted pool essentially completely attenuates the surge at Paducah, KY, with the surge showing up again downstream of the Olmsted Dam. Figure 49 shows a corresponding maximum computed surge at Cairo, IL of about 3 feet. 


\section{Kentucky Lake Flow Events}

62. Two flow events similar to the two Barkley flow events have been simulated for Kentucky Lake outflows. Inflows for the first event are presented in Figure 51 and represent a gradually varied Kentucky outflow with a maximum of $80,000 \mathrm{cfs}$. The other inflows are held constant as shown. Computed elevations at several locations are presented in Figures 52-58. Results are quite similar to those from the first Barkley flow event.

63. Inflows for the second Kentucky flow event are given in Figure 59. The discharge hydrograph from Kentucky Lake is similar to that for the second Barkley flow event and represents more rapidly varying flows. Computed elevations at several locations are presented in Figures 60-66. The operation of the 0lmsted Dam to maintain an elevation of 300 feet at Paducah, KY, is essentially the same as that computed for the similar second Barkley flow event.

\section{May-June 1988 Flow Event with the Olmsted Project In Place}

64. Inflows for this period have previously been presented in Figure 7 . This application is identical to the previous application with these inflows except that now the 01msted Dam is in place and L\&D's 52 and 53 have been removed. Computed elevations are presented in Figures 67-73. As can be seem in Figure 69, the Paducah, KY, elevation is maintained throughout the simulation near 300 feet; however, as illustrated in Figure 67, the Smithland and Barkley inflows are not sufficient over the last 7 days to maintain a Smithland tailwater above 302 feet. During this period, Figure 71 shows that 0lmsted is exercising maximum control of the pool, i.e. an elevation of 300 feet is being forced. Figure 10 illustrates that with L\&D 52 in place, the Smithland tailwater does remain above 302 feet during this same period. 


\section{Summary}

65. A numerical model called FLOWSED for computing 1D unsteady flows in river systems has been modified to handle the proposed 0lmsted project. These modifications were required since the 0lmsted pool is to be a hinged pool with the hinge point being Paducah, KY. Thus, the Olmsted gates will be operated to maintain a relatively constant elevation of 300 feet ORD at Paducah.

66. After reconstructing geometry tables on the Ohio River to provide increased resolution for low flow events, the model was applied to a low flow event in May-June 1988 with L\&D 52 and L\&D 53 in place to demonstrate its ability to reproduce observed data. Several flow events were then simulated with the proposed 0lmsted project in place. These events included the observed May-June 1988 event as well as several hypothetical flow events involving Smithland, Barkley, and Kentucky outflows.

\section{Conclusions}

67. The major conclusion to be drawn from the study is that the hinged pool algorithm appears to be operating properly and yields reasonable results. It does appear that due to the uncertainty in specifying low flows from Smithland Dam, an investigation into the Smithland tailwater rating is required. Also, a sensitivity analysis should be conducted to assess the impact of using Ohio River geometric data referenced to the Ohio River Datum rather than the NGVD. In addition, a sensitivity analysis should be conducted on the Tennessee River geometric data to determine if an update of these data is warranted. As a final note, it is acknowledged that adjustments of the olmsted hinged pool algorithm will probably be required to better reflect actual operating conditions once the project has been constructed and data are available. 


\section{REFERENCES}

Chen, Y. H. 1973. "Mathematical Modeling of Water and Sediment Routing in Natural Channels," Ph.D. Dissertation at Colorado State University, Fort Collins, CO.

Johnson, B. H. 1982. "Development of a Numerical Modeling Capability for the Computation of Unsteady Flow on the Ohio River and Its Major Tributaries," Technical Report HL-82-20, US Army Engineer Waterways Experiment Station, Vicksburg, MS.

Johnson, B. H. 1983. "User's Guide for Branched Implicit River Model (BIRM) with Application to the Lower Mississippi river," Unpublished Internal Report in Hydraulics Laboratory, US Army Engineer Waterways Experiment Station, Vicksburg, MS.

Thomas, W. A. 1981. "New Version of Geometric Elements from Cross-Section Coordinates," by Hydrologic Engineering Center. Inhouse report in Hydraulic Analysis Division of US Army Engineer Waterways Experiment Station, Vicksburg, MS.

McCarley, R. W. 1988. "Ohio River Flood Routing Model Development," Unpublished Internal Report in Hydraulics Laboratory, US Army Engineer Waterways Experiment Station, Vicksburg, MS. 


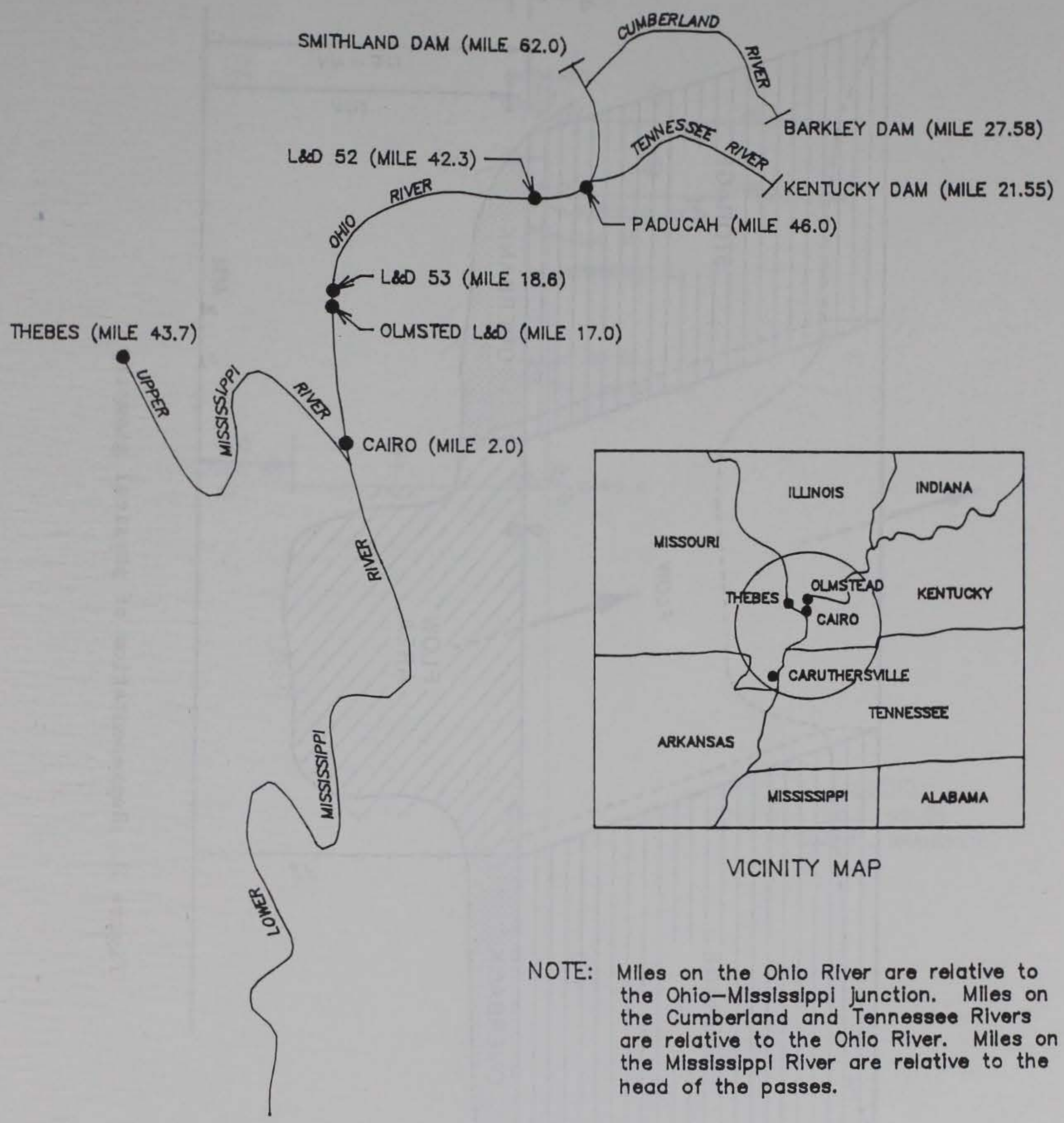

CARUTHERSVLLE, MO (MILE 848.0)

Figure 1. Map of study area 


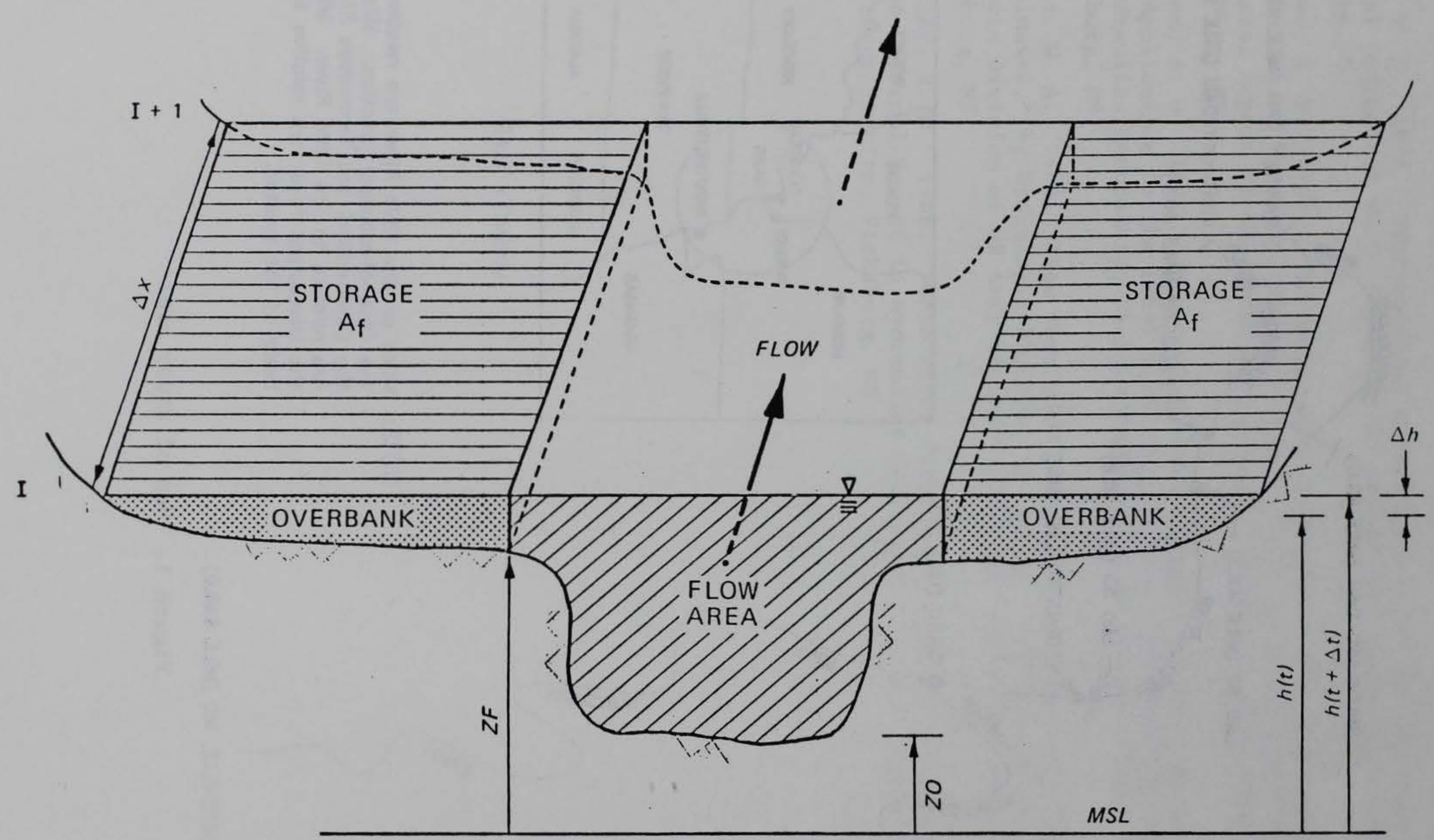

Figure 2. Representation of physical geometry 


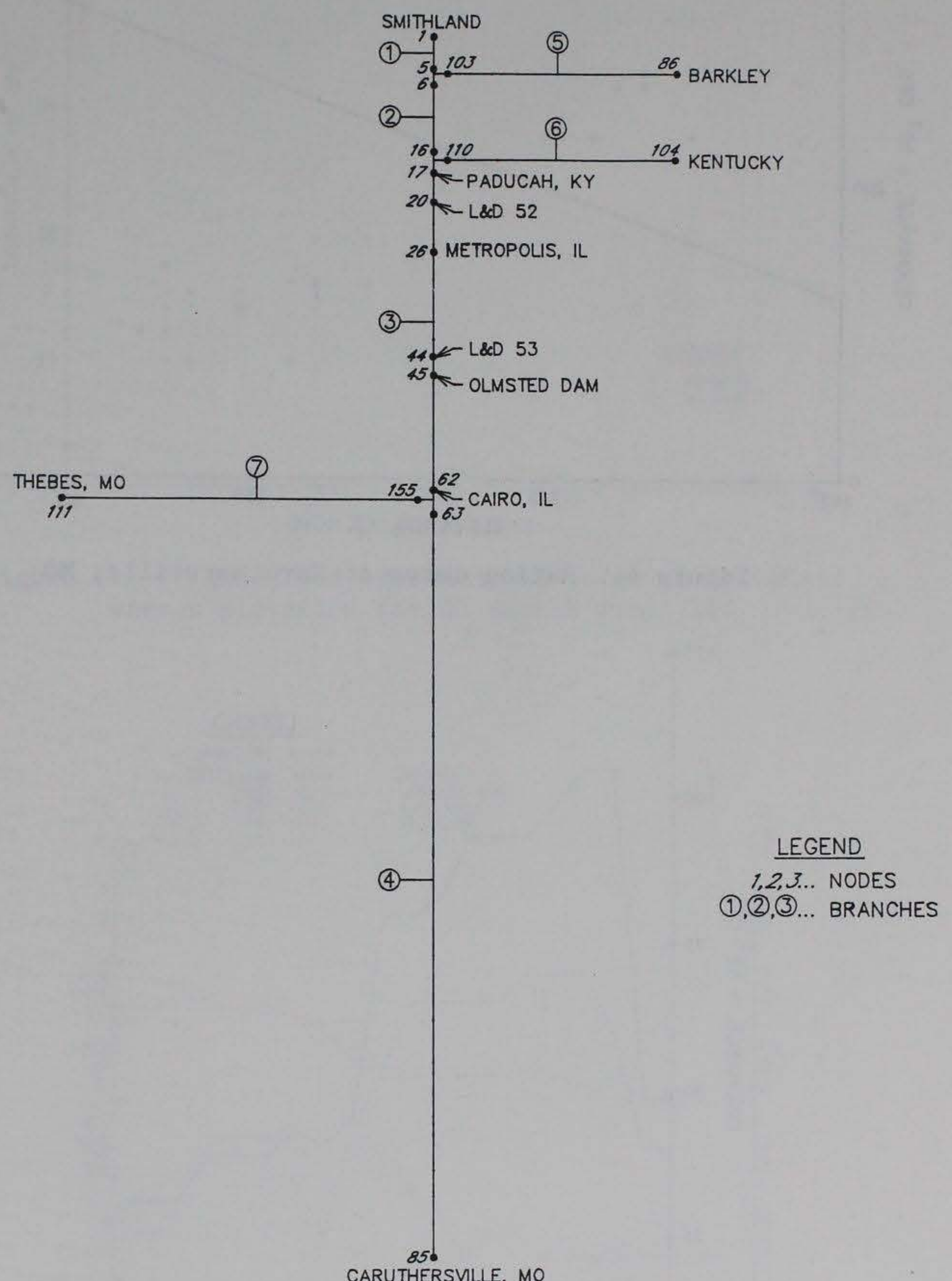

Figure 3. Schematization of study area 


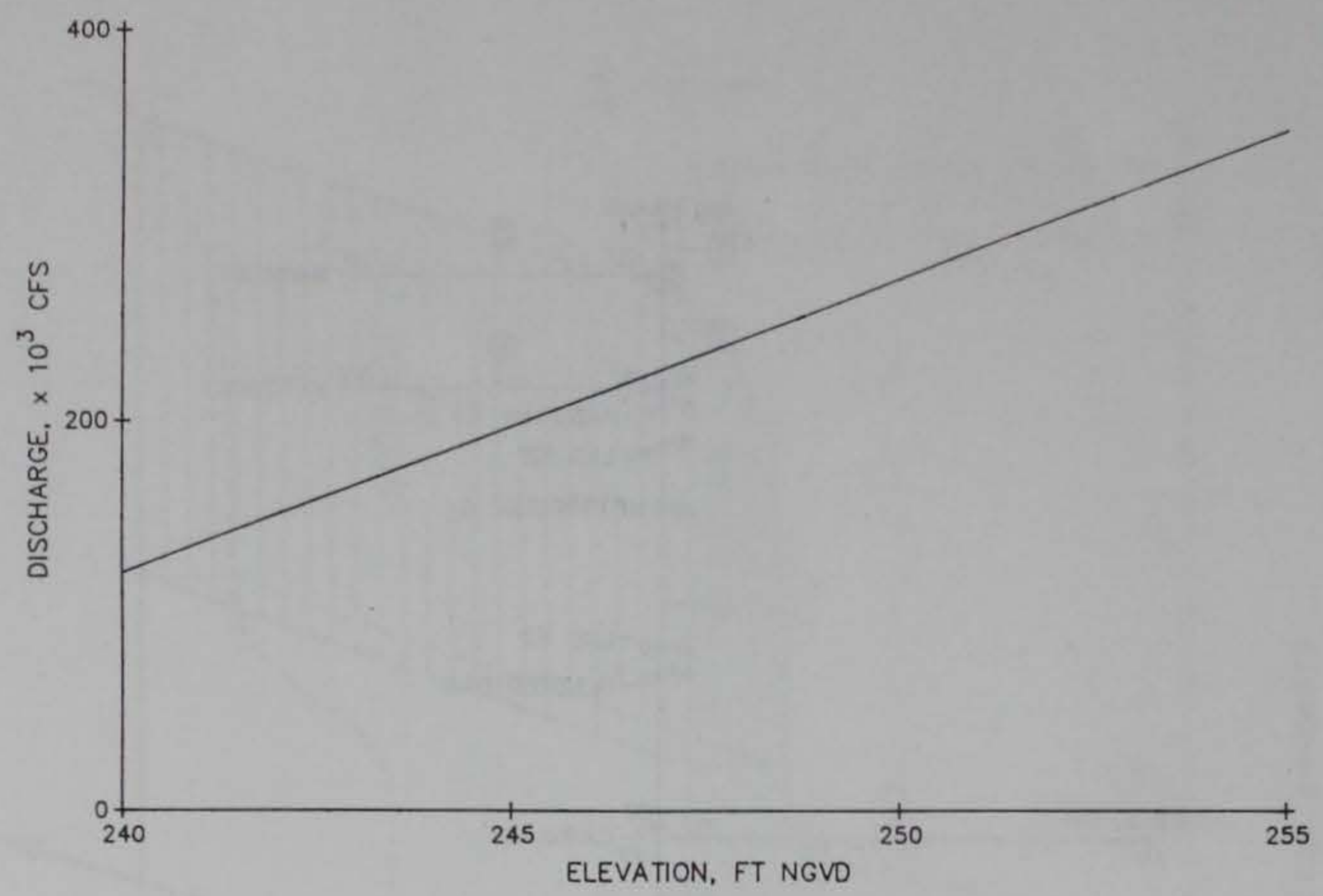

Figure 4. Rating curve at Caruthersville, Mo

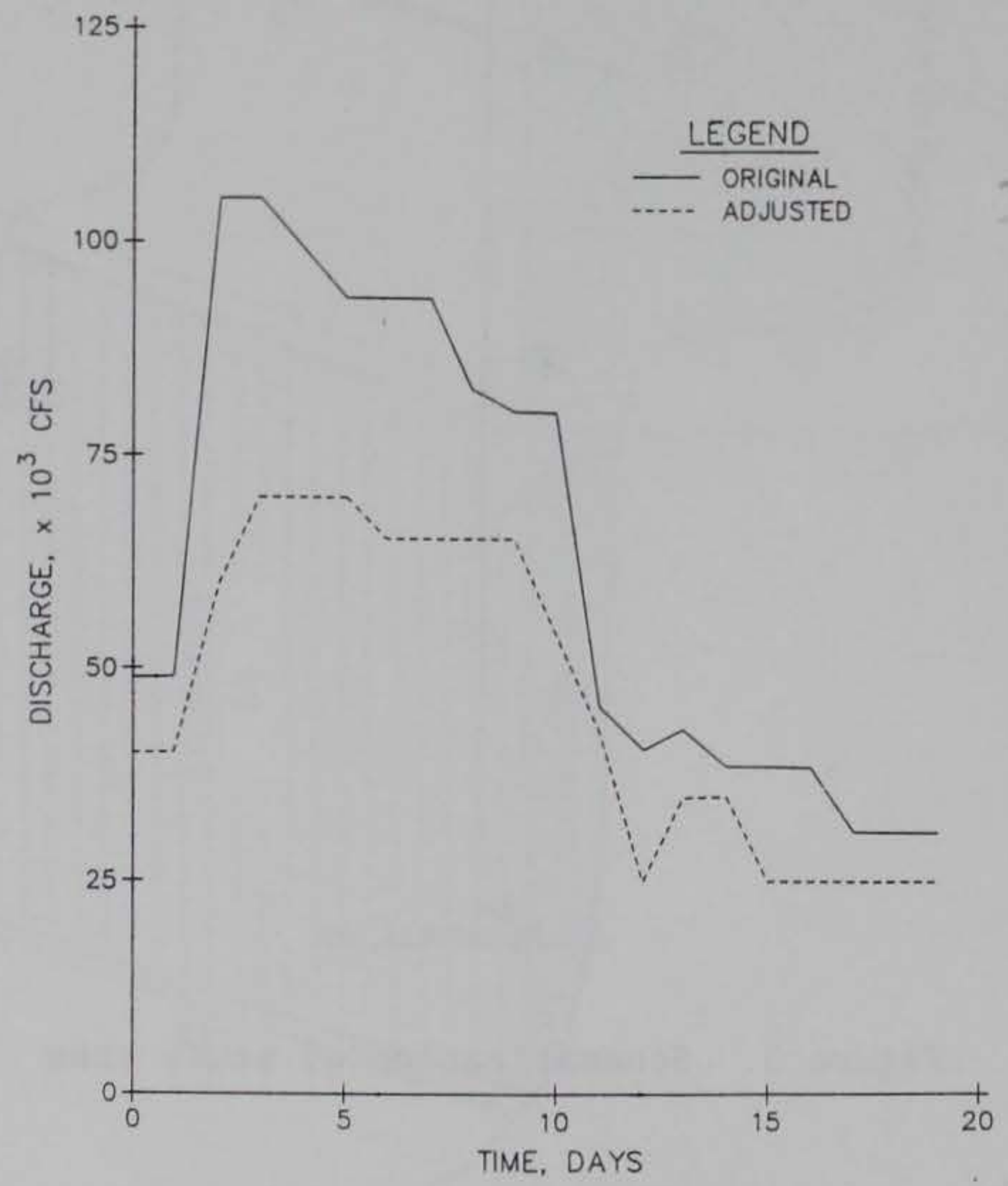

Figure 5. Smithland discharge for 20 May-10 June 1988 


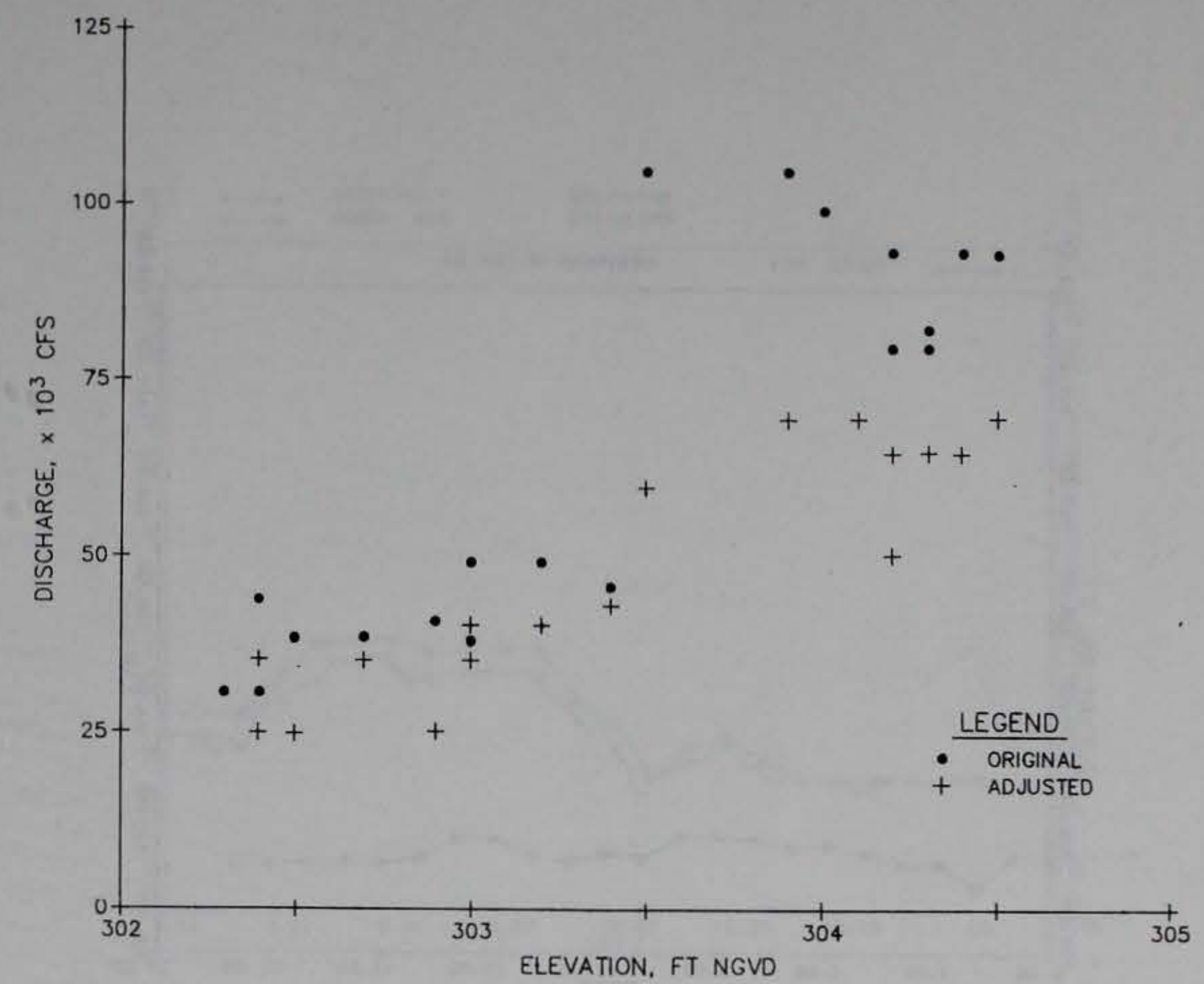

Figure 6. Original and adjusted discharge at Smithland versus elevation for 20 May-10 June 1988

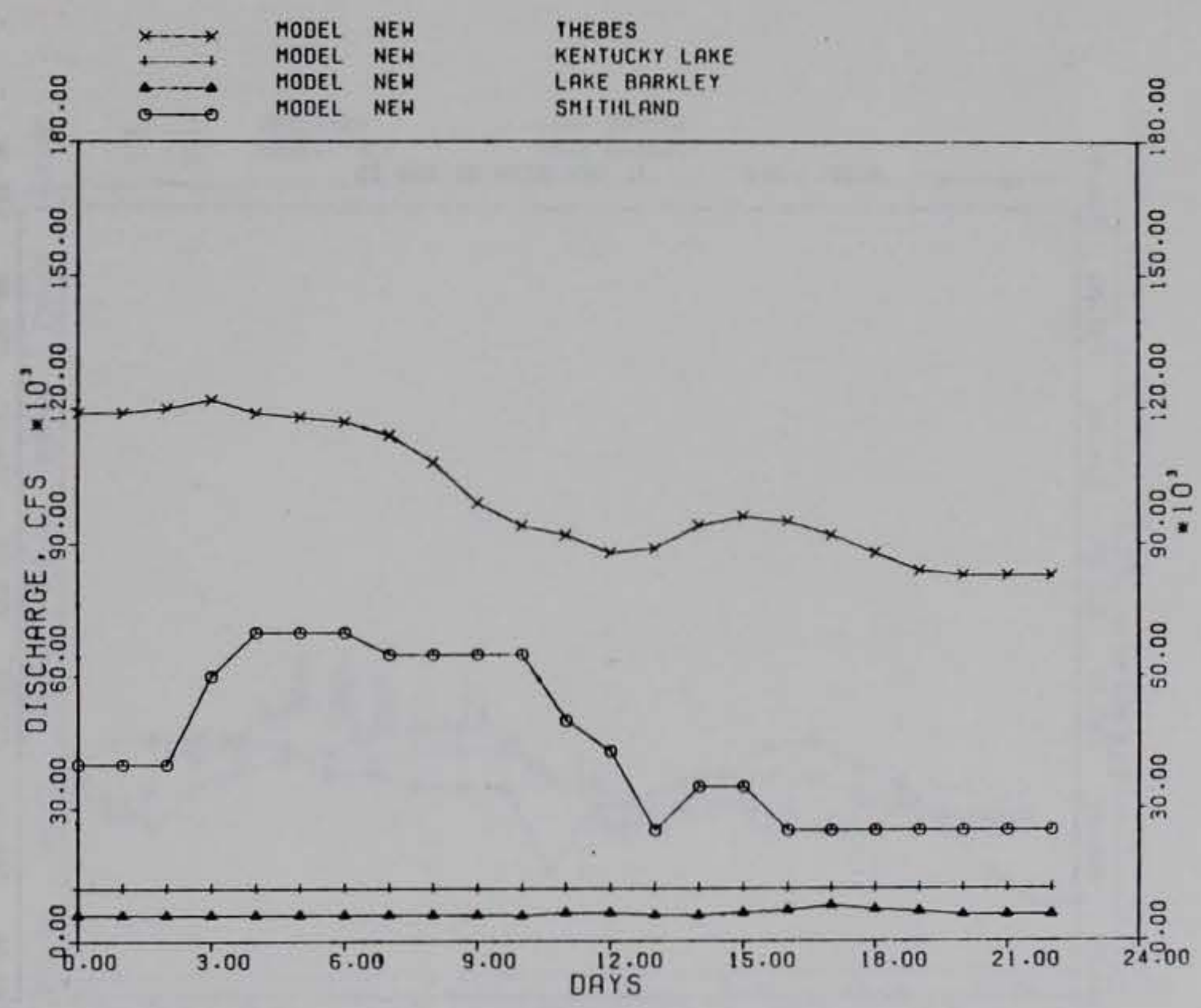

Figure 7. Inflow boundary conditions for 20 May-10 June 1988 application without 0lmsted in place 


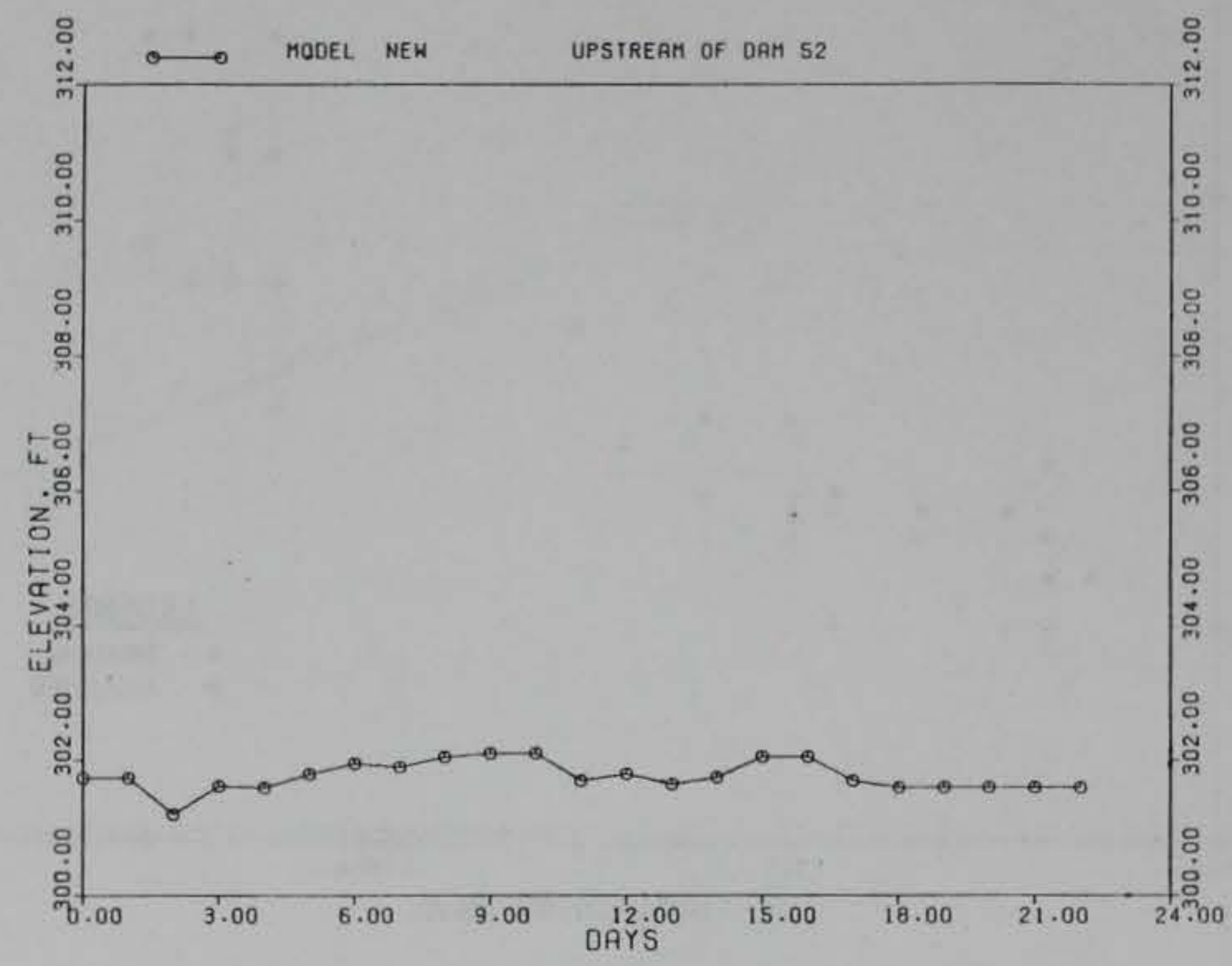

Figure 8. Observed elevations (ORD) upstream of L\&D 52 for May-June 1988 without Olmsted in place

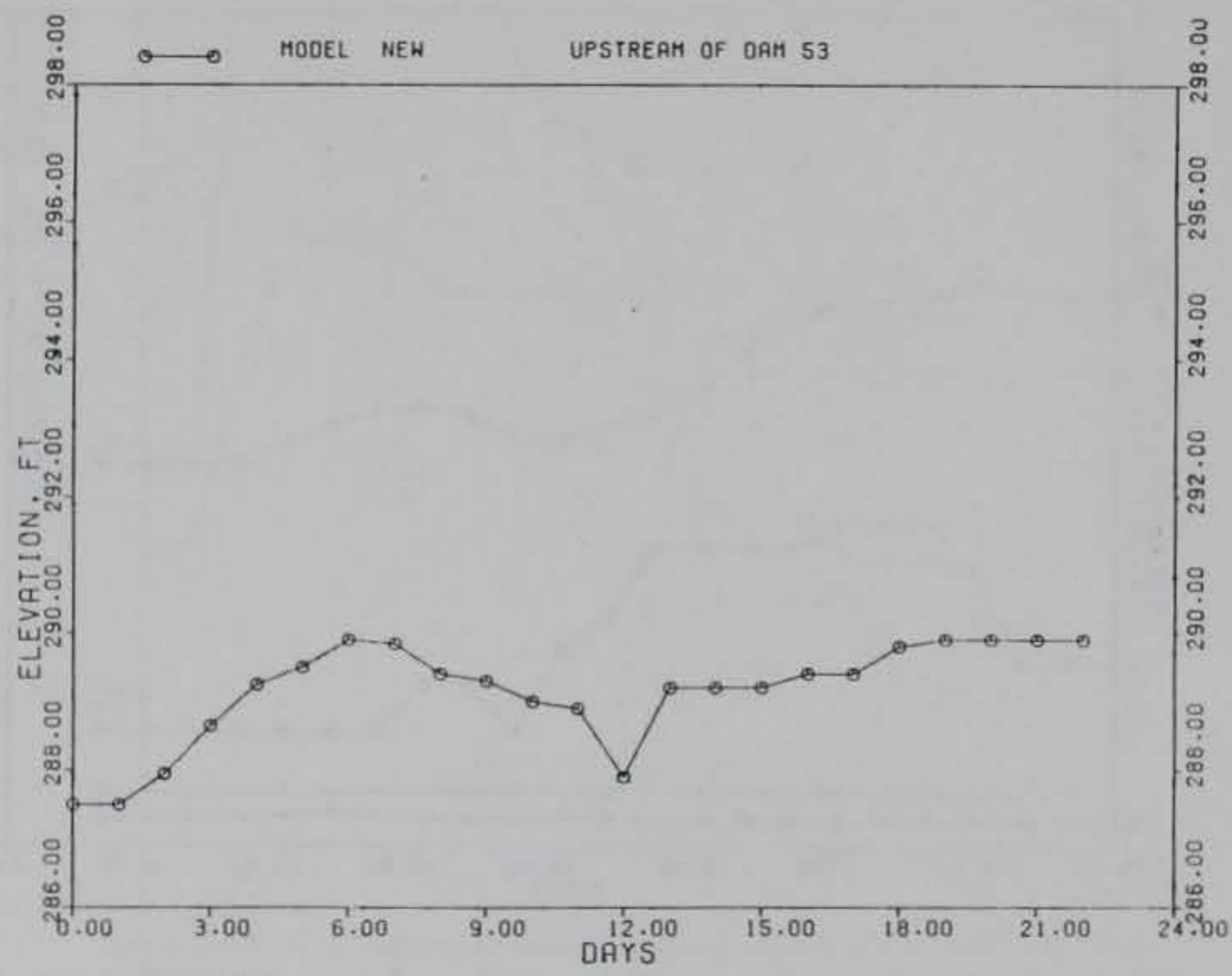

Figure 9. Observed elevations (ORD) upstream of L\&D 53 for May-June 1988 without Olmsted in place 


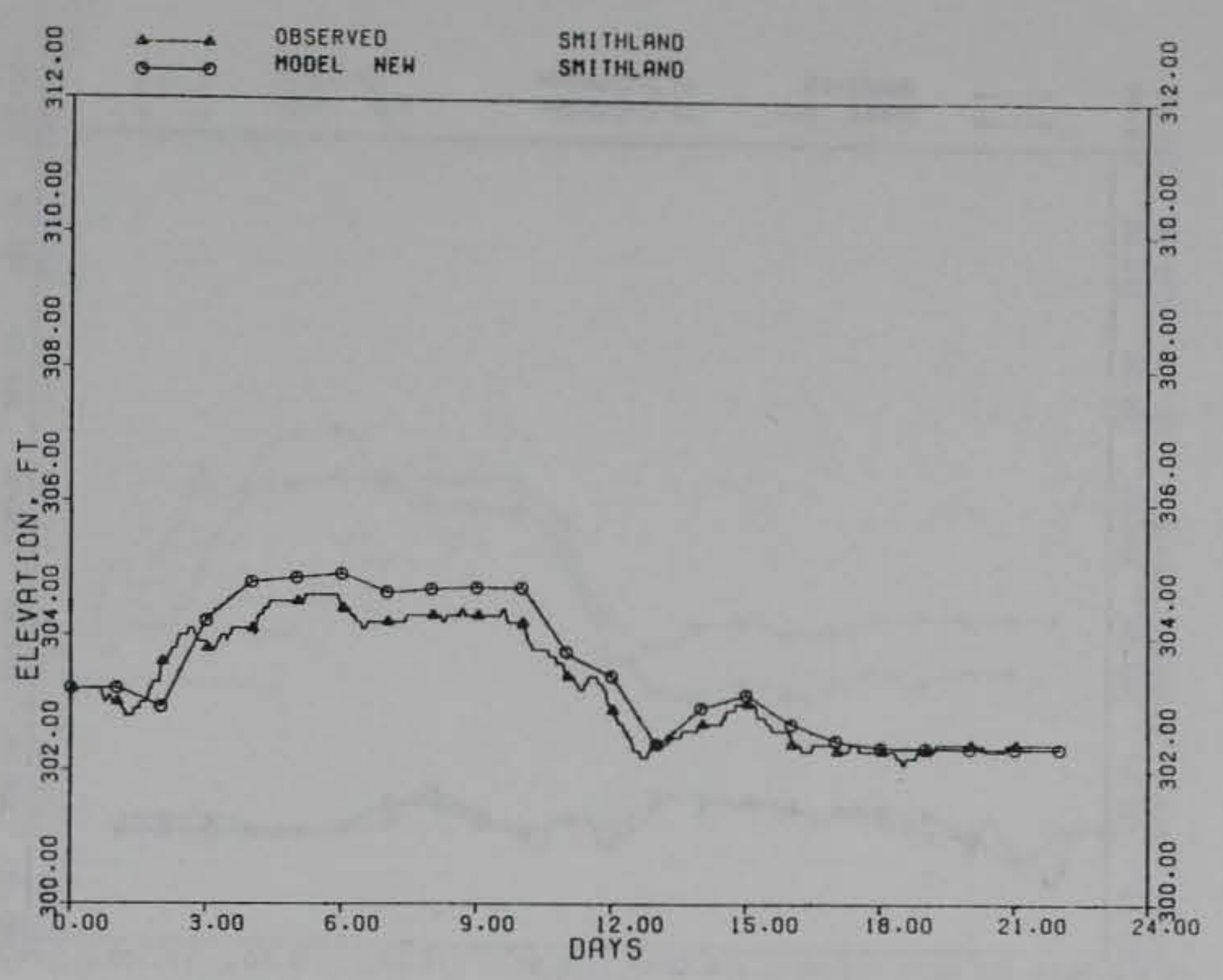

Figure 10. Comparison of observed $(O R D)$ and computed ( $\approx$ NGVD) elevations at Smithland for May-June 1988 without Olmsted in place

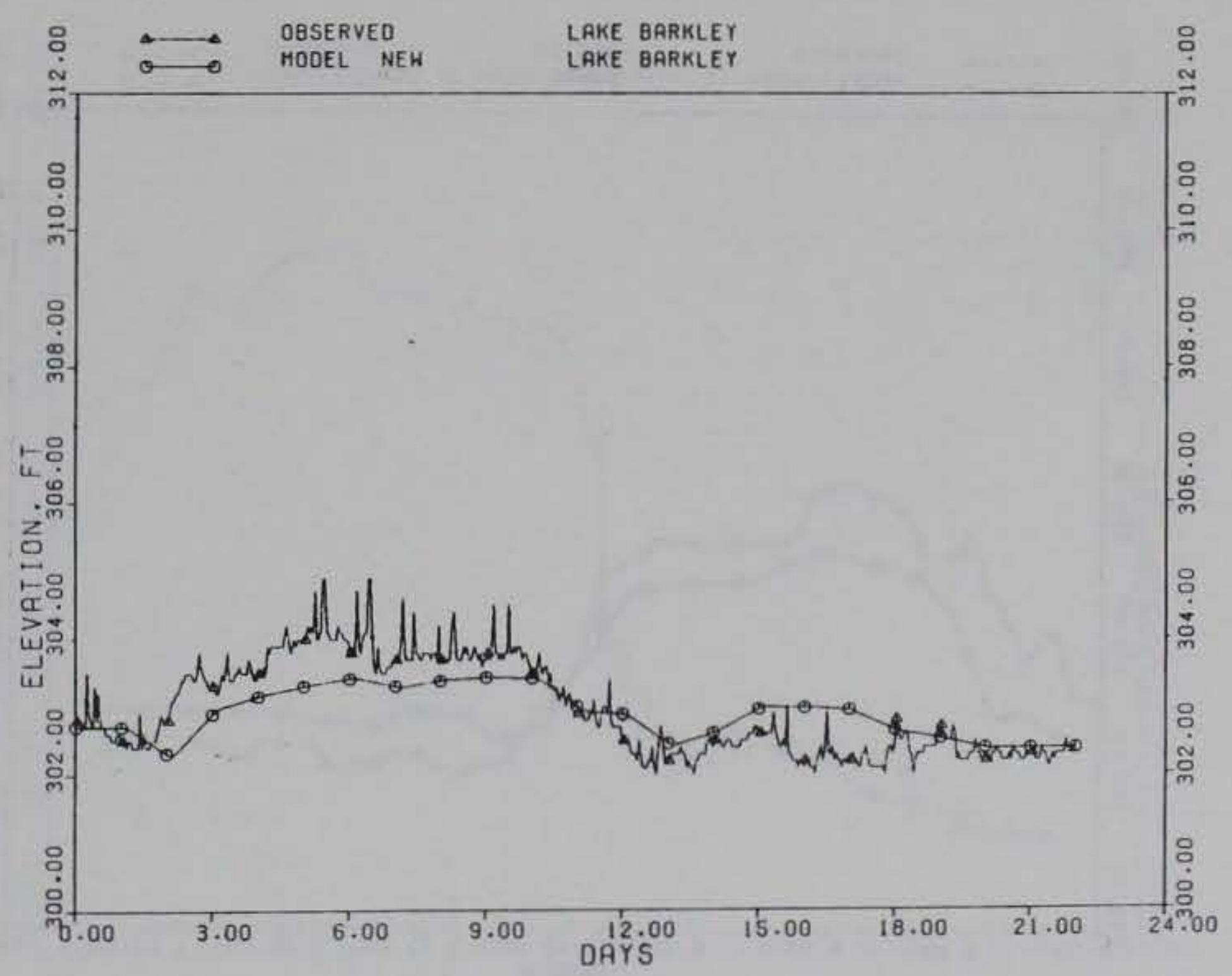

Figure 11. Comparison of observed (NGVD) and computed ( $\approx$ NGVD) Barkley tailwater for May-June 1988 without 0lmsted in place 


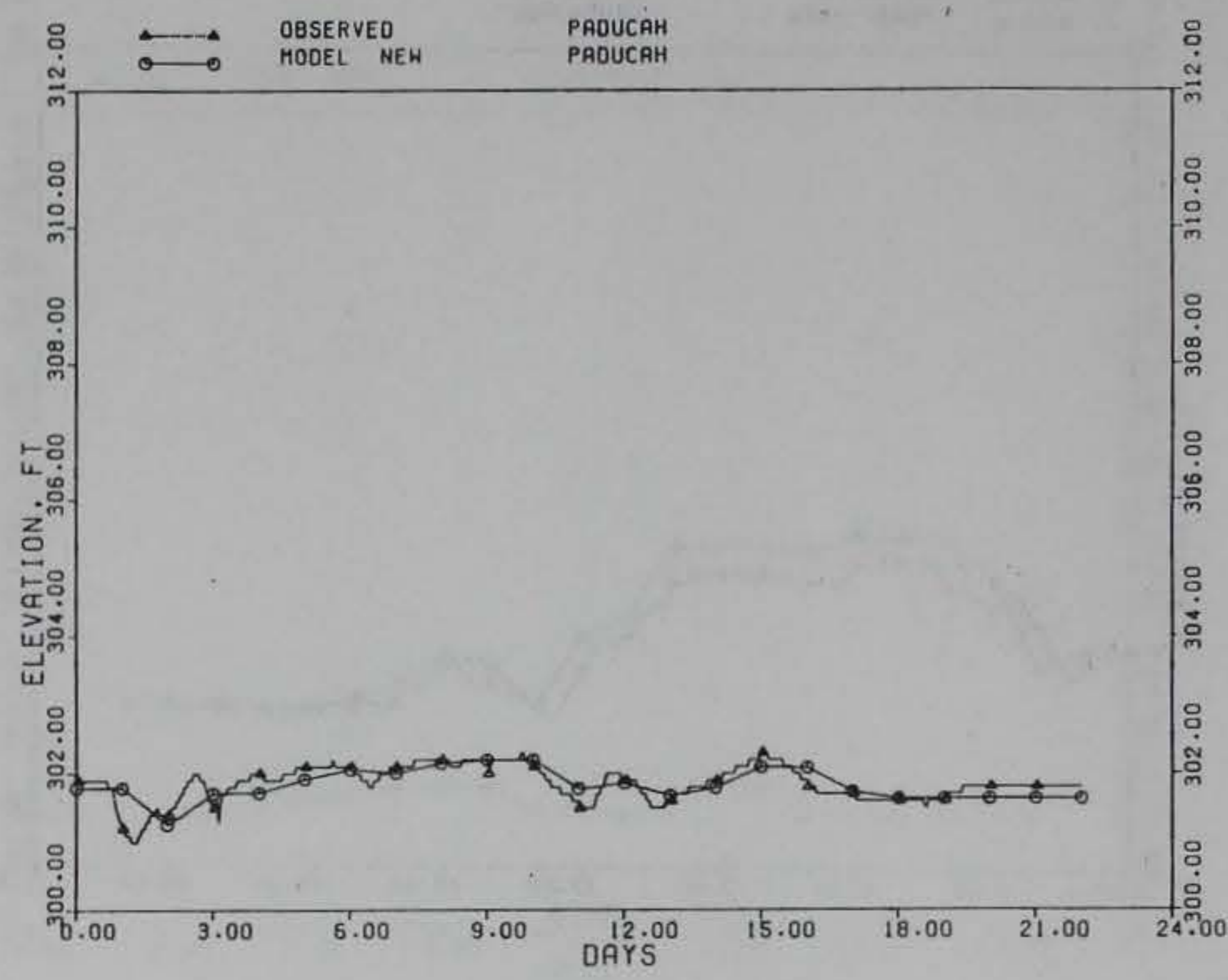

Figure 12. Comparison of observed (ORD) and computed ( $\approx$ NGVD) elevations at Paducah, KY, for May-June 1988 without Olmsted in place

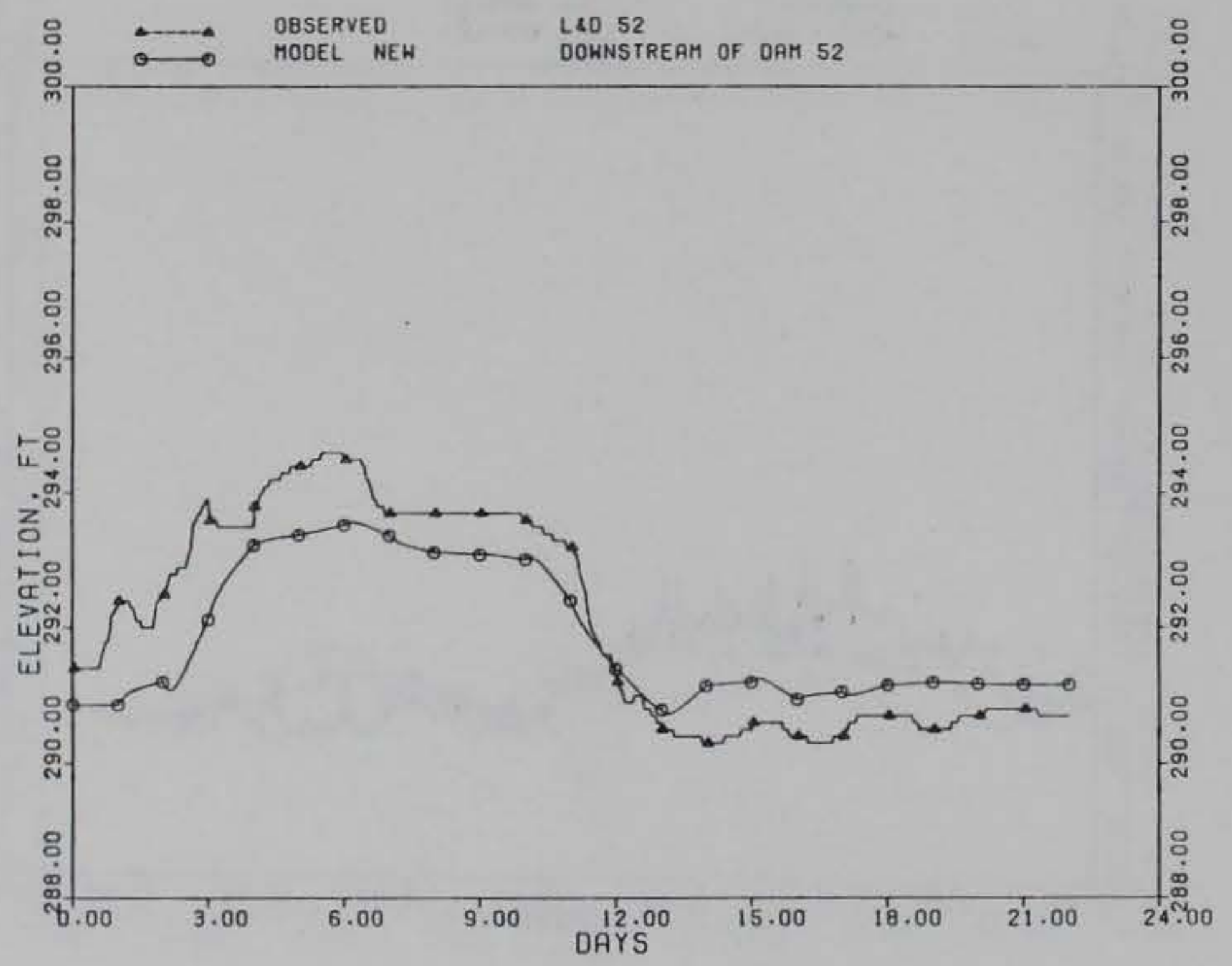

Figure 13. Comparison of observed $(O R D)$ and computed ( $\approx$ NGVD) L\&D 52 tailwater for May-June 1988 without Olmsted in place 


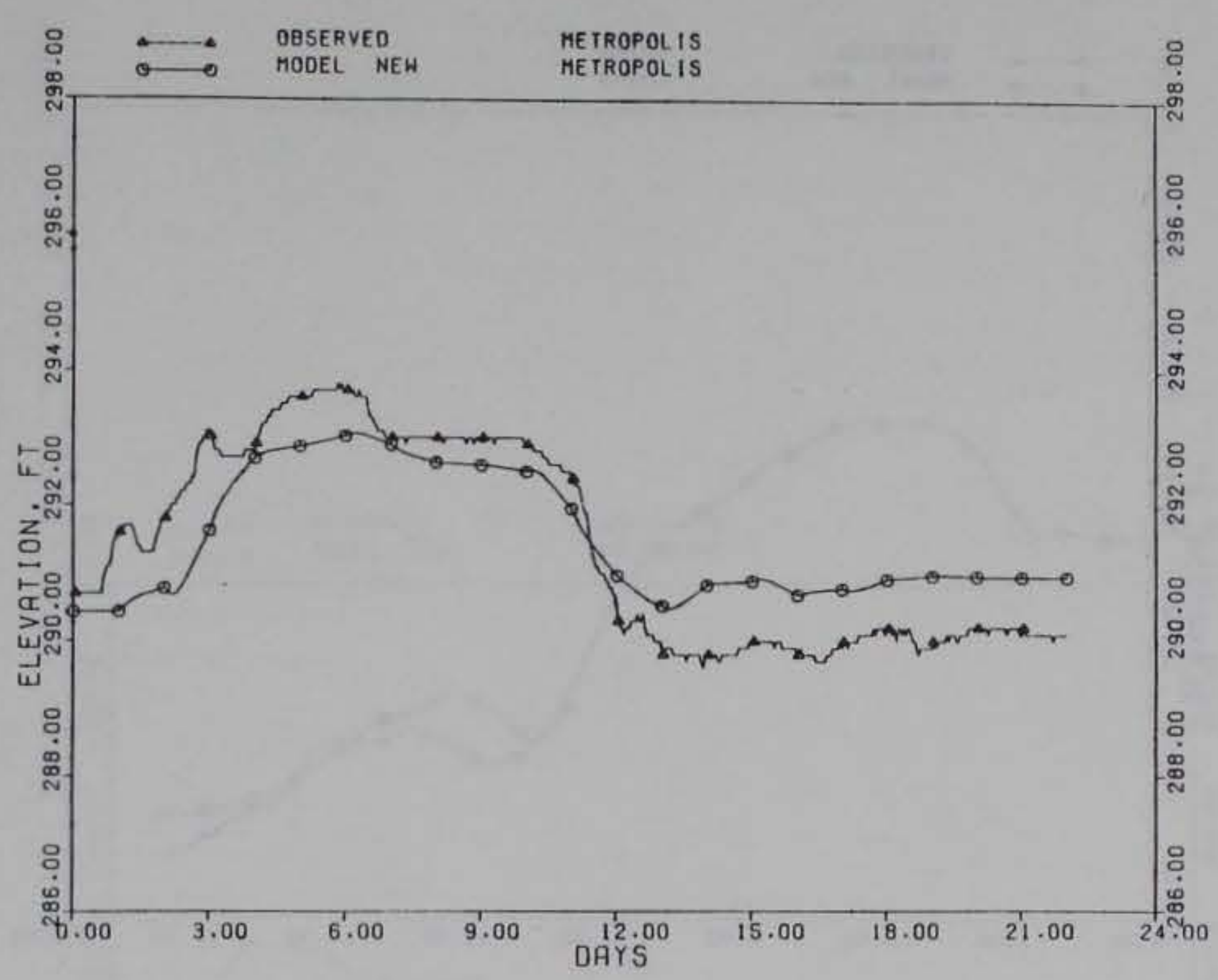

Figure 14. Comparison of observed (ORD) and computed ( $\approx$ NGVD) elevations at Metropolis, IL, for May-June 1988 without Olmsted in place

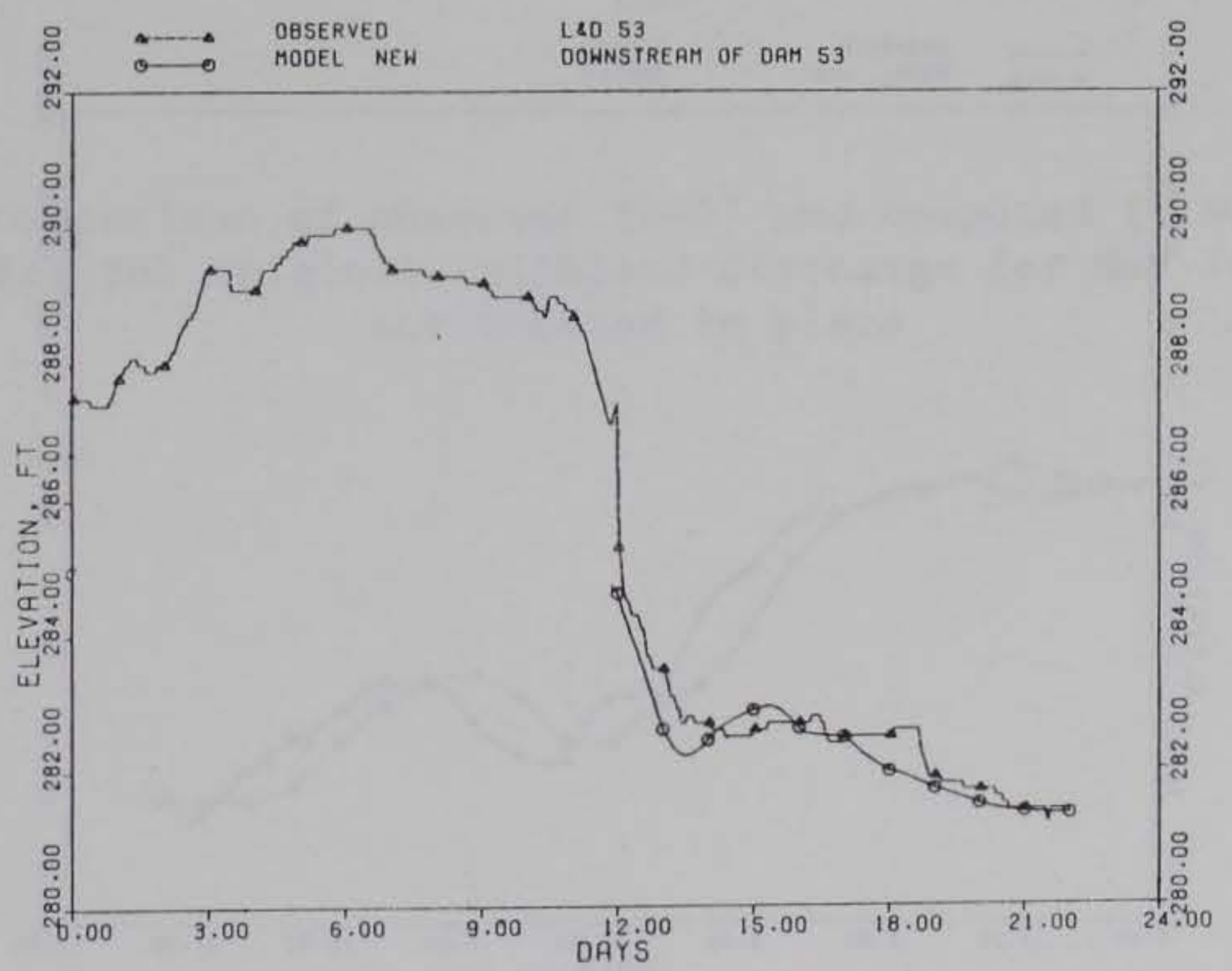

Figure 15. Comparison of observed (ORD) and computed ( $\approx$ NGVD) L\&D 53 tailwater for May-June 1988 without Olmsted in place 


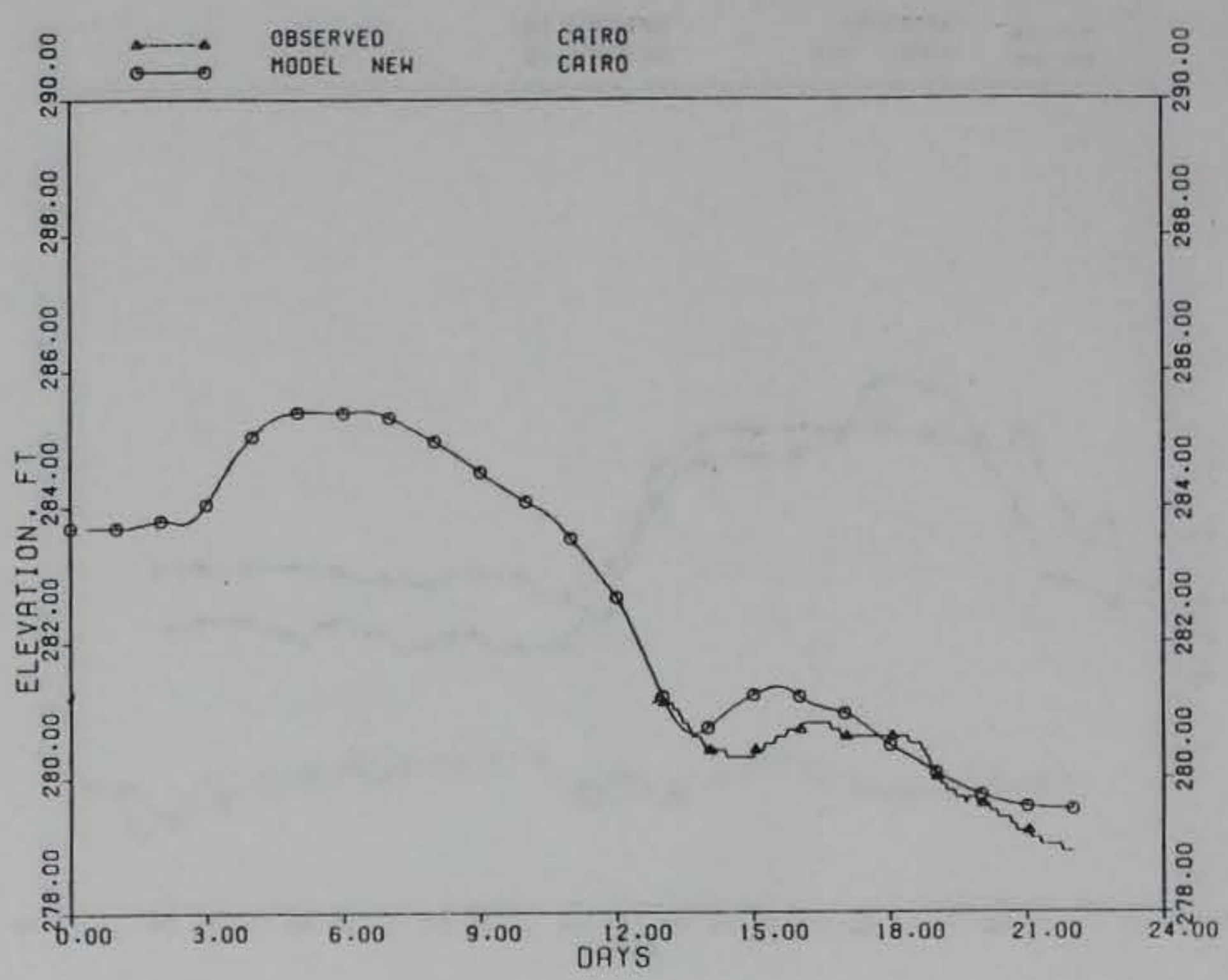

Figure 16. Comparison of observed (ORD) and computed ( $\approx$ NGVD) elevations at Cairo, IL, for May-June 1988 without Olmsted in place

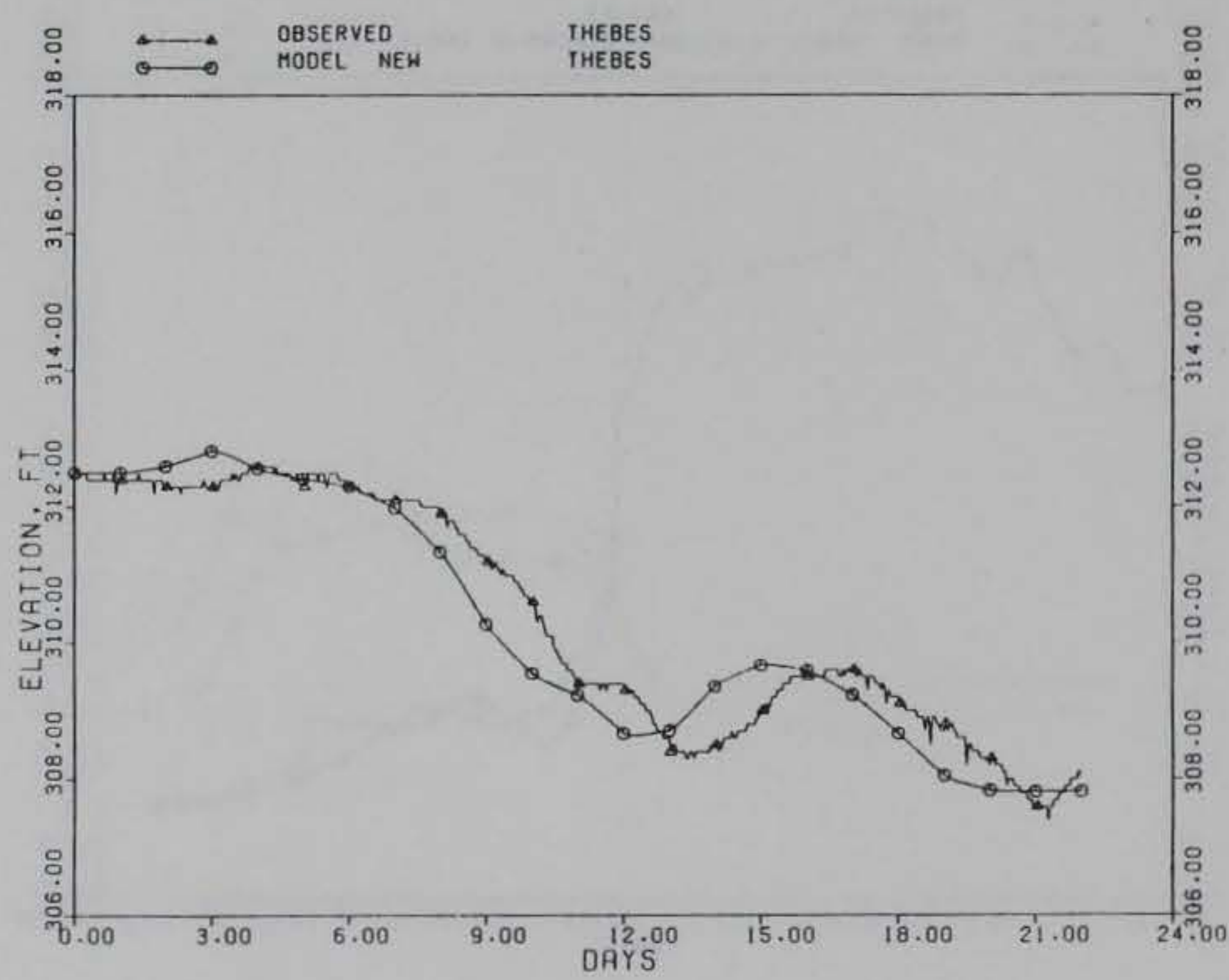

Figure 17. Comparison of observed (NGVD) and computed ( $\approx$ NGVD) elevations at Thebes, MO, for May-June 1988 without Olmsted in place 


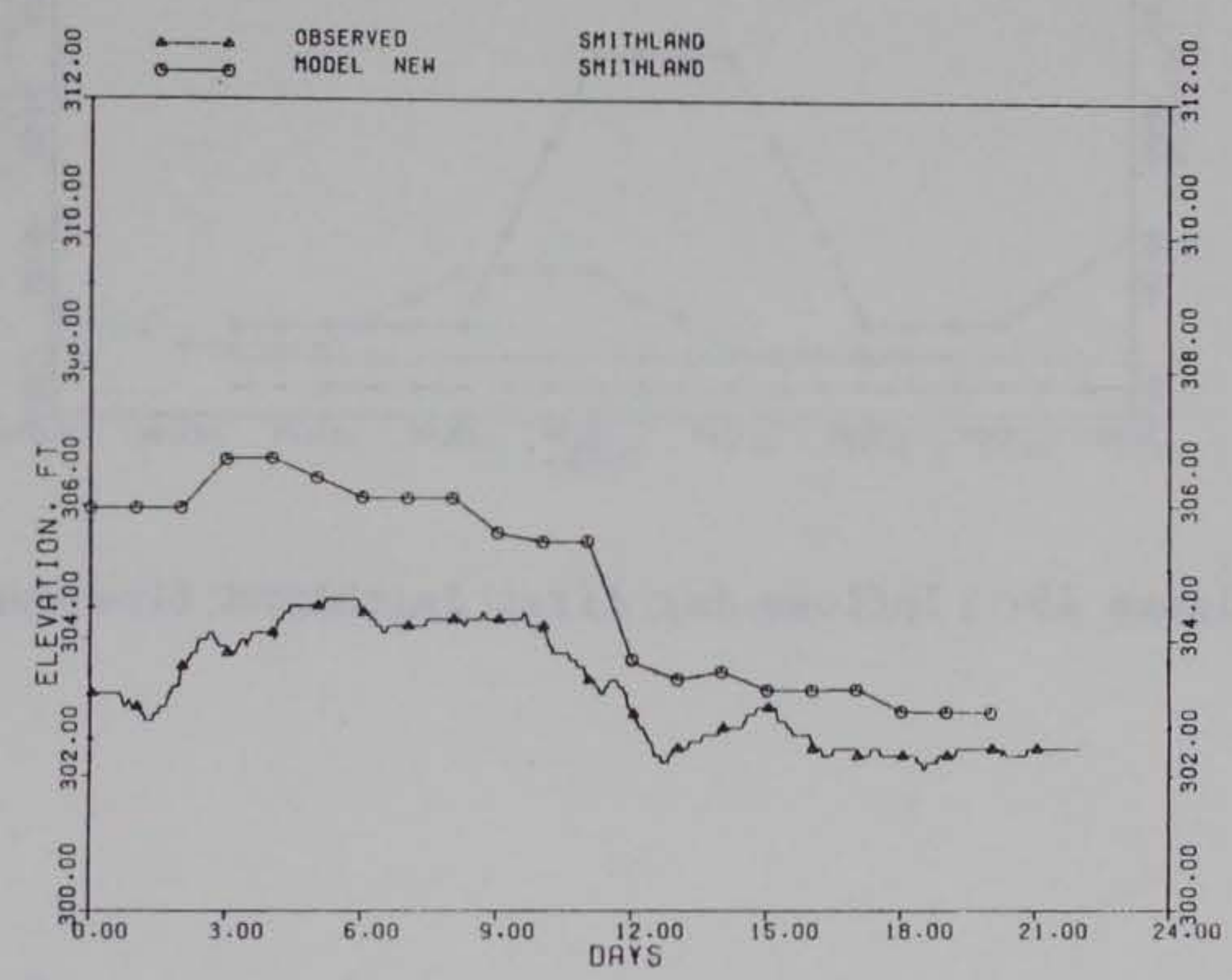

Figure 18. Comparison of observed (ORD) and computed ( $\approx$ NGVD) Smithland tailwater using the original Smithland discharge for May-June 1988 without Olmsted in place 


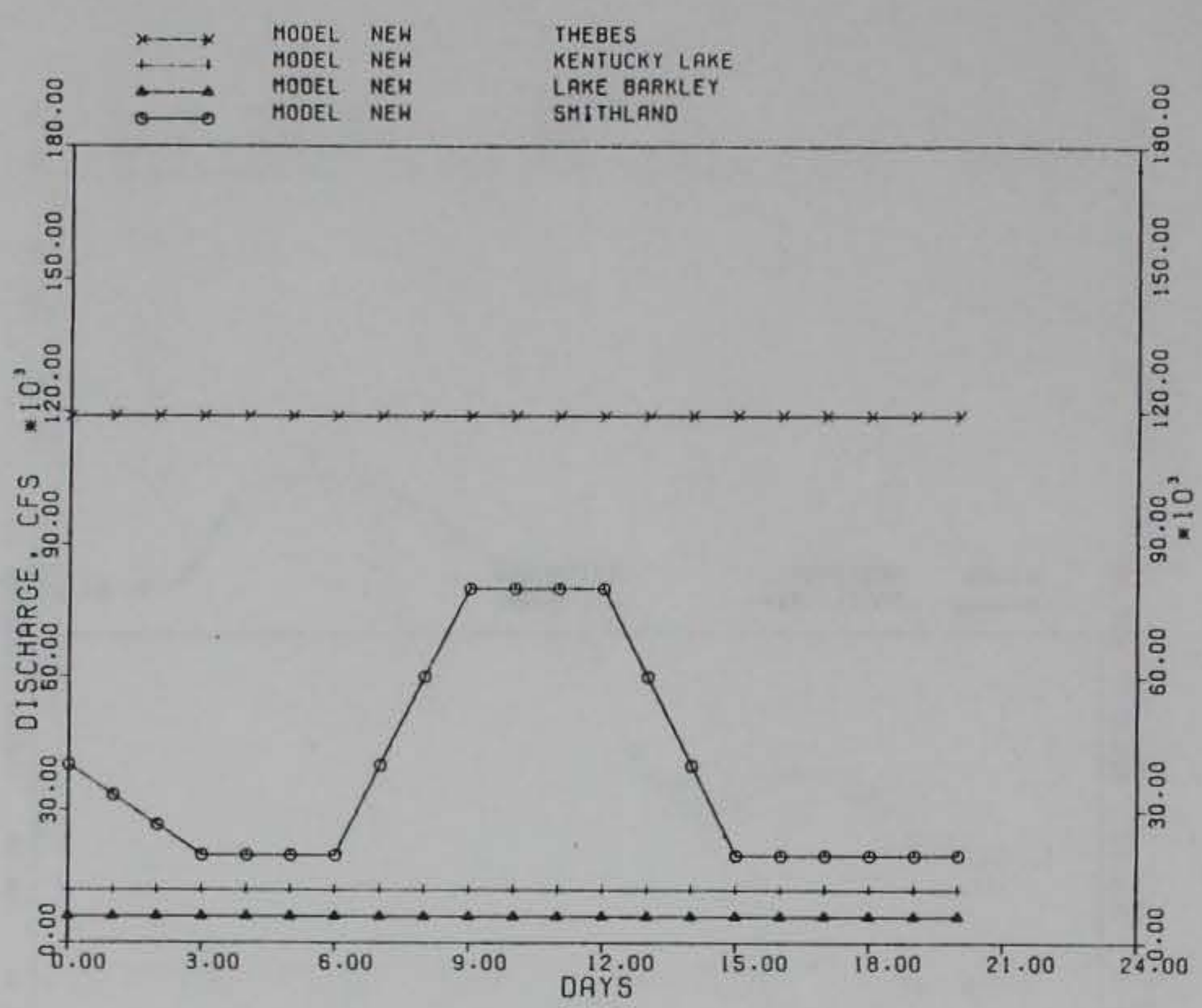

Figure 19. Inflows for first Smithland flow event

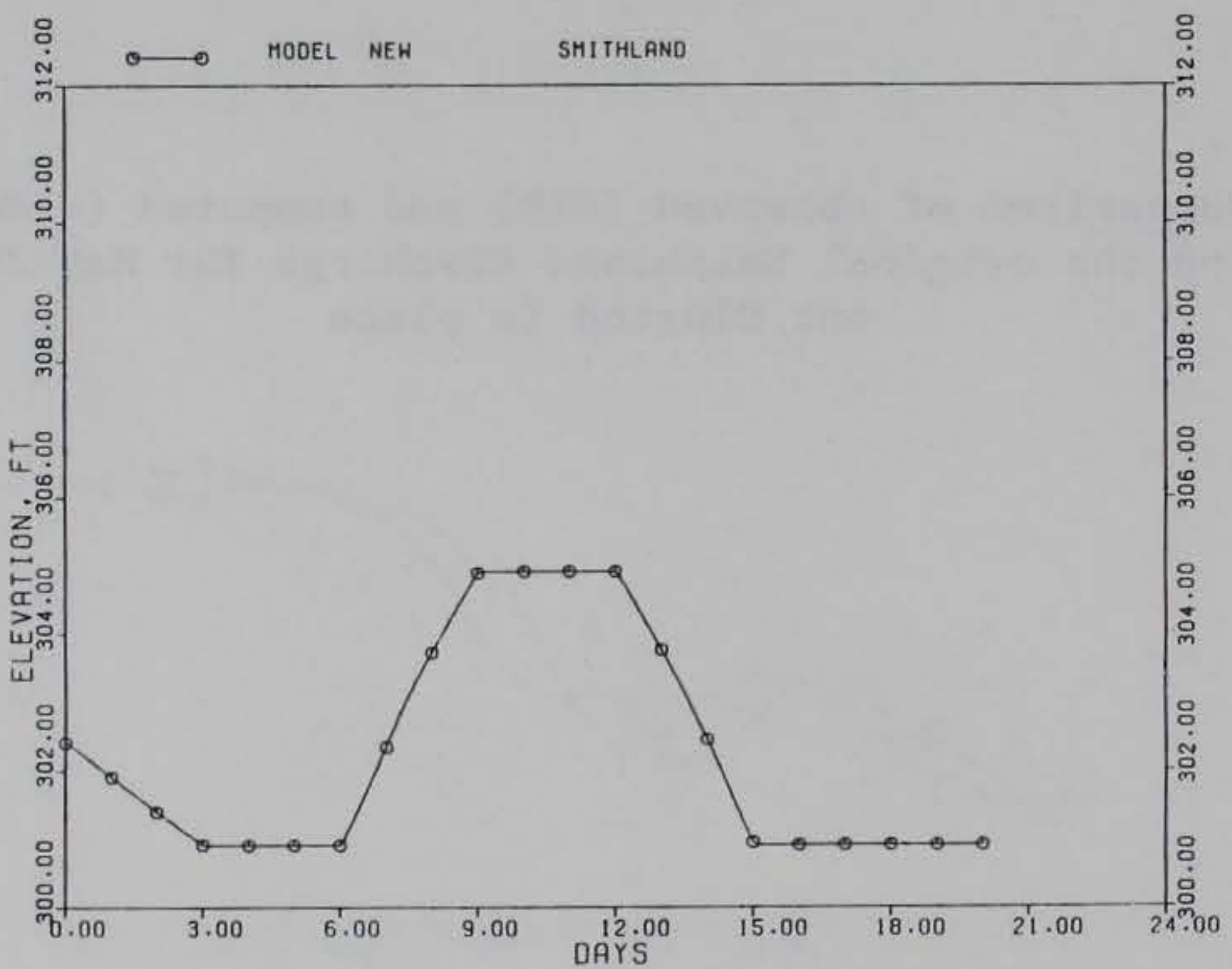

Figure 20. Computed $(\approx$ NGVD) Smithland tailwater for first Smithland flow event 


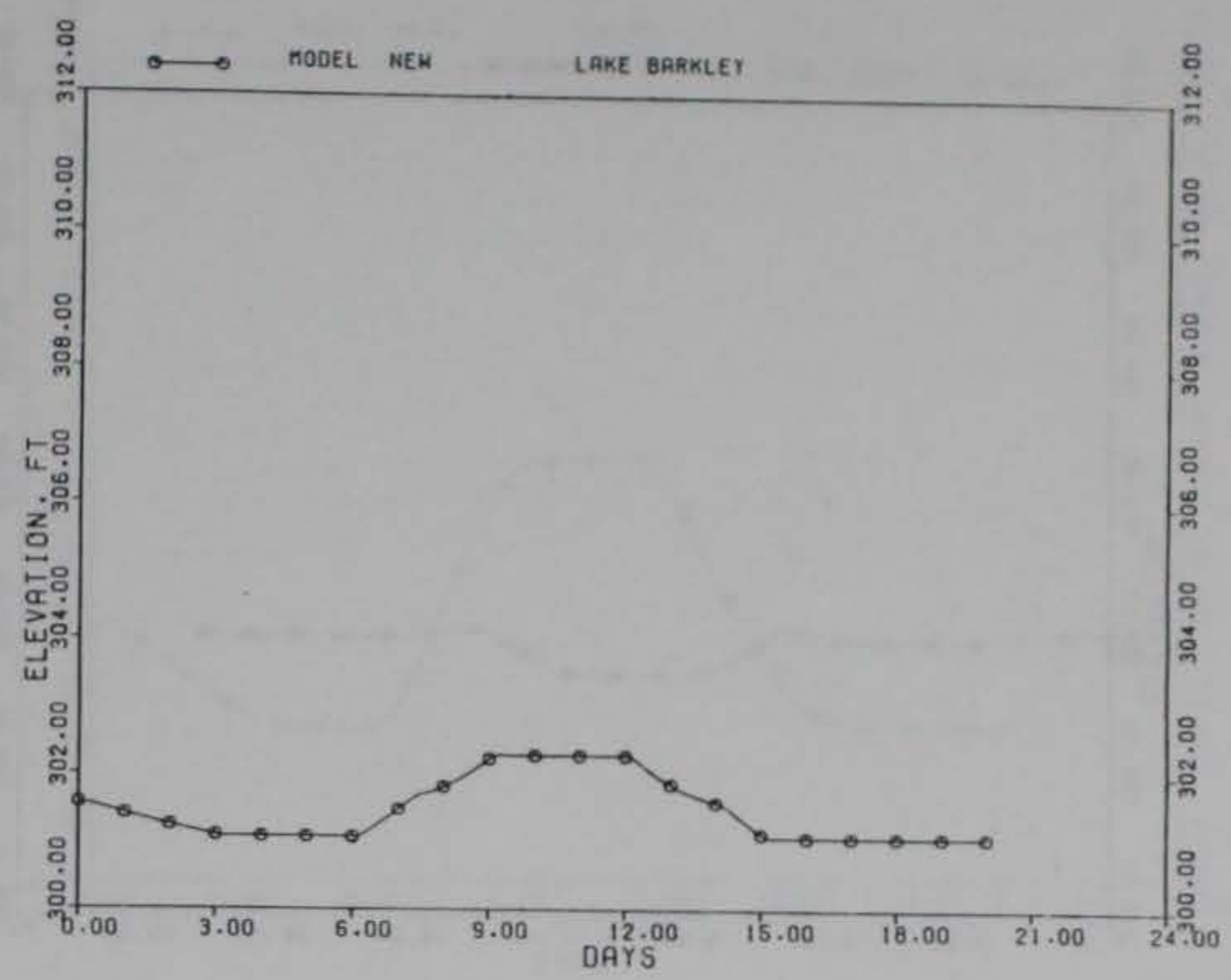

Figure 21. Computed ( $\approx$ NGVD) Barkley tailwater for first Smithland flow event

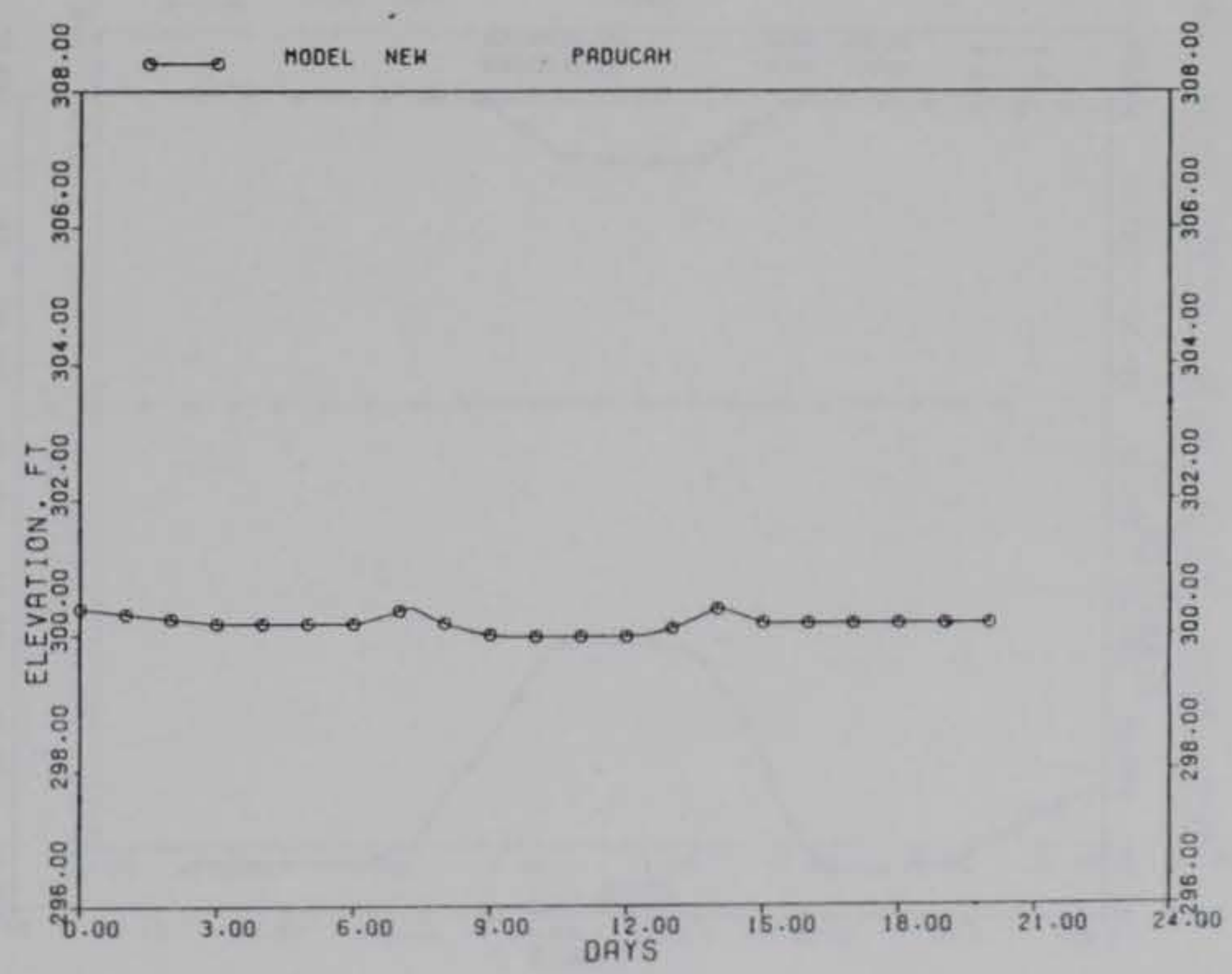

Figure 22. Computed ( $\approx$ NGVD) elevations at Paducah, KY, for first Smithland flow event 


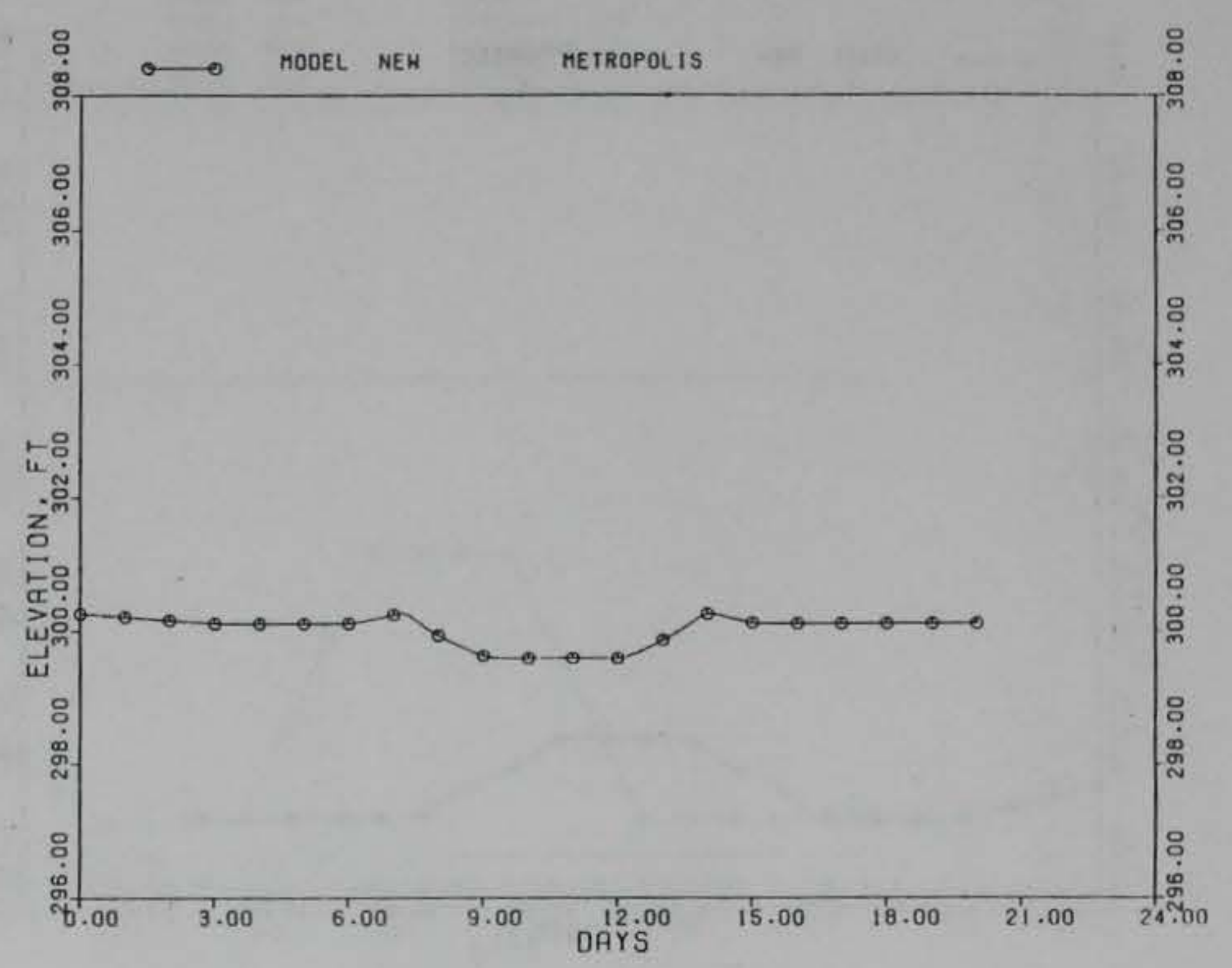

Figure 23. Computed ( $\approx$ NGVD) elevations at Metropolis, IL, for first Smithland flow event

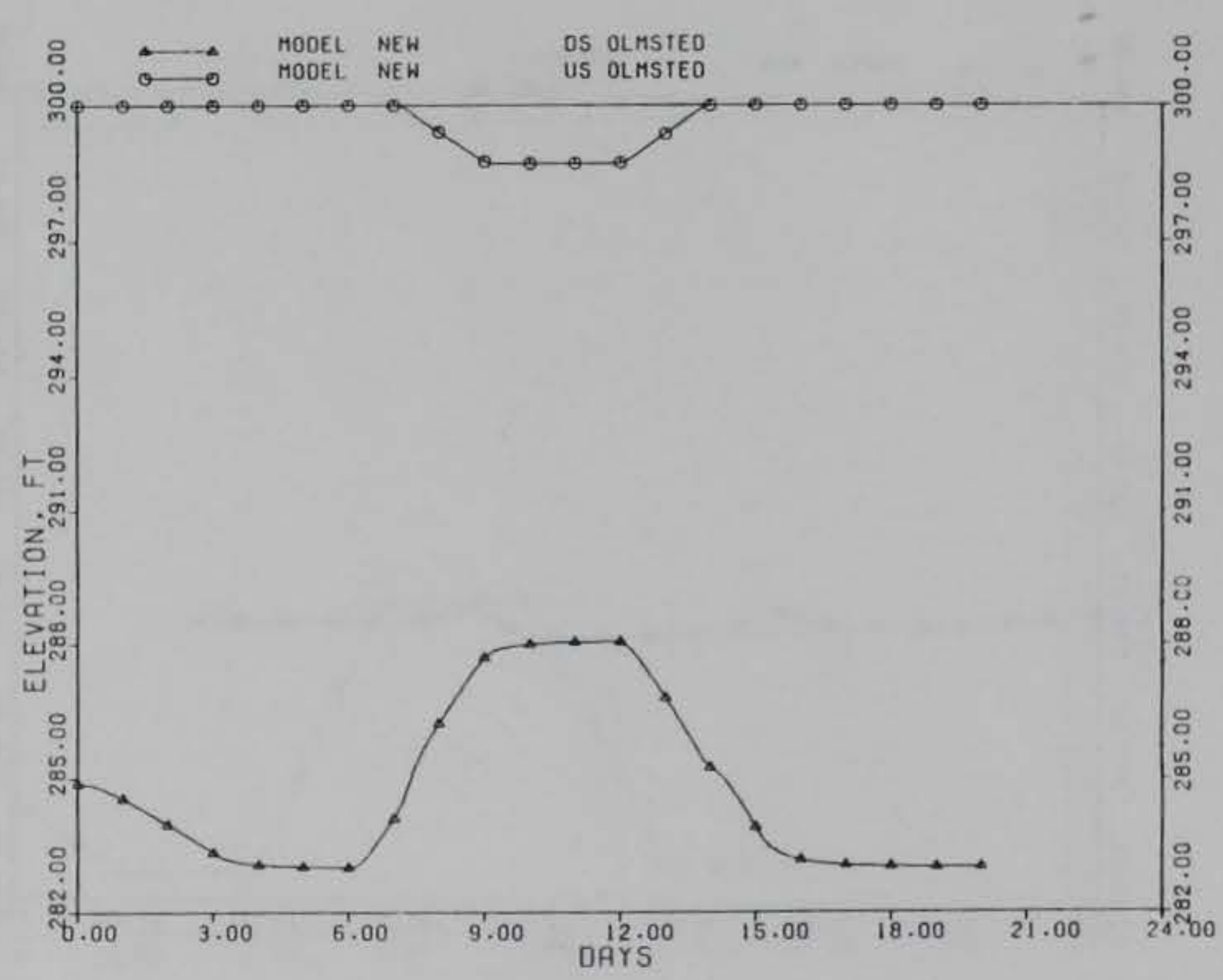

Figure 24. Computed $(\approx$ NGVD) Olmsted headwater and tailwater for first Smithland flow event 


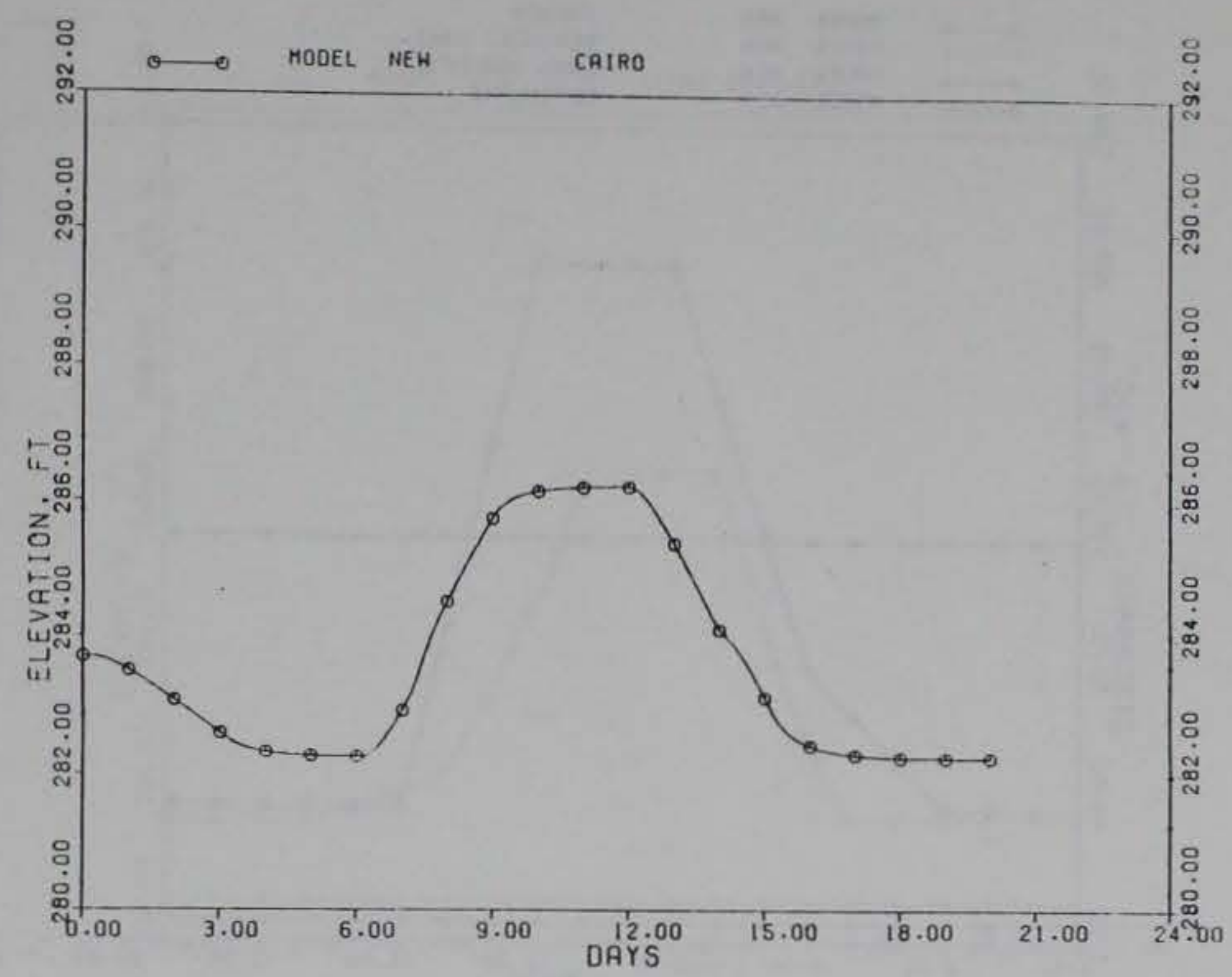

Figure 25. Computed ( $\approx$ NGVD) elevations at Cairo, IL, for first Smithland flow event

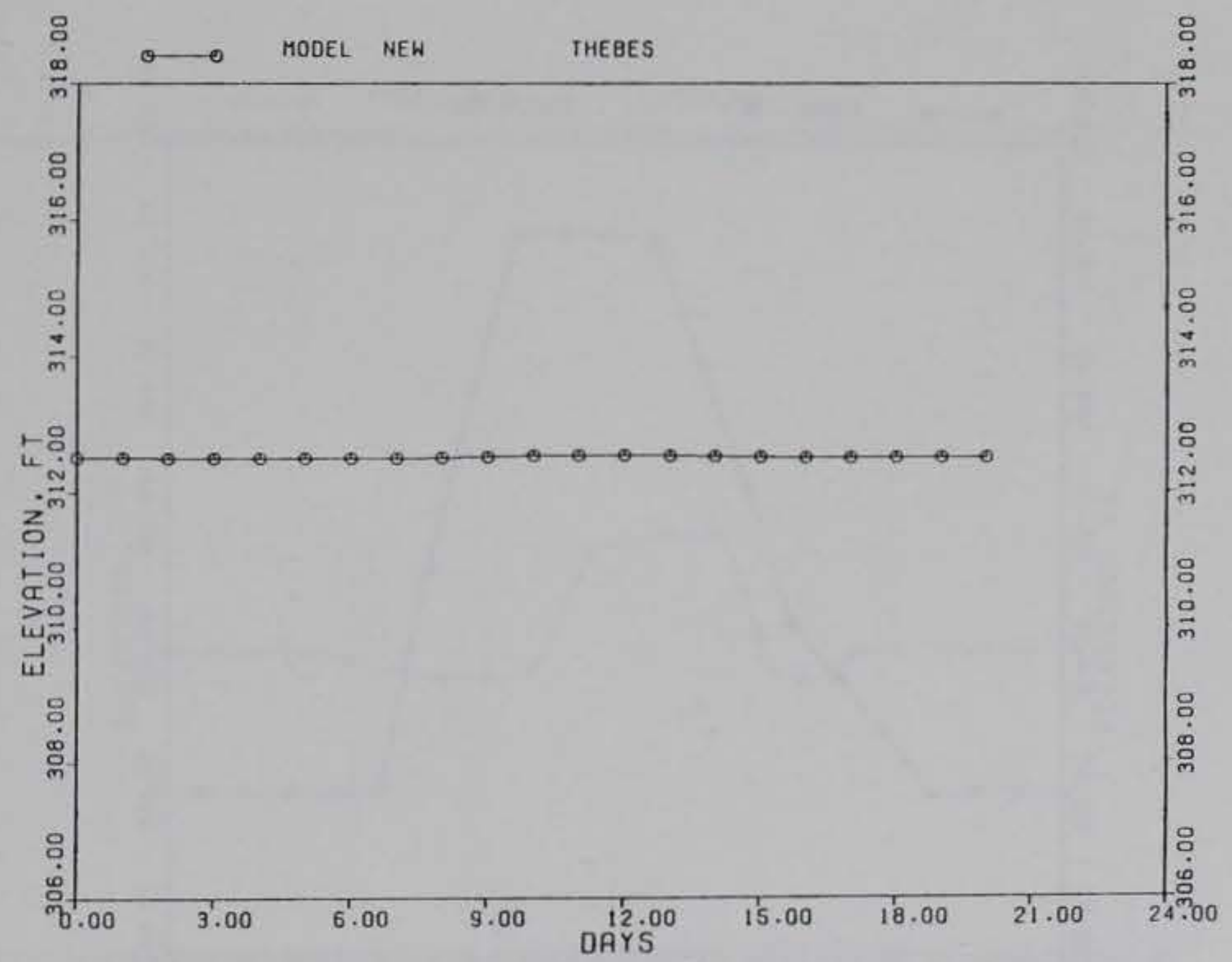

Figure 26. Computed ( $\approx$ NGVD) elevations at Thebes, MO, for first Smithland flow event 


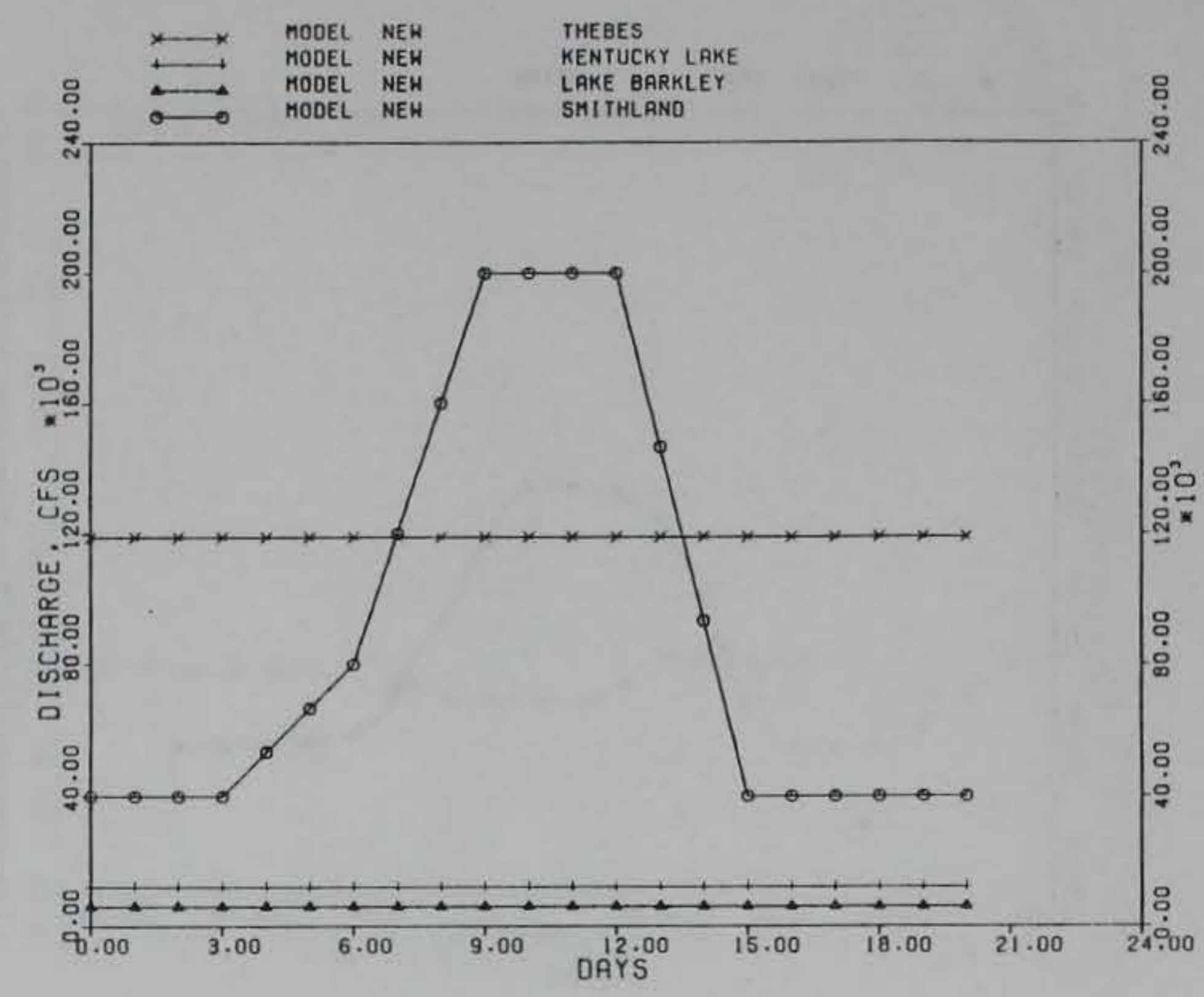

Figure 27. Inflows for second Smithland flow event

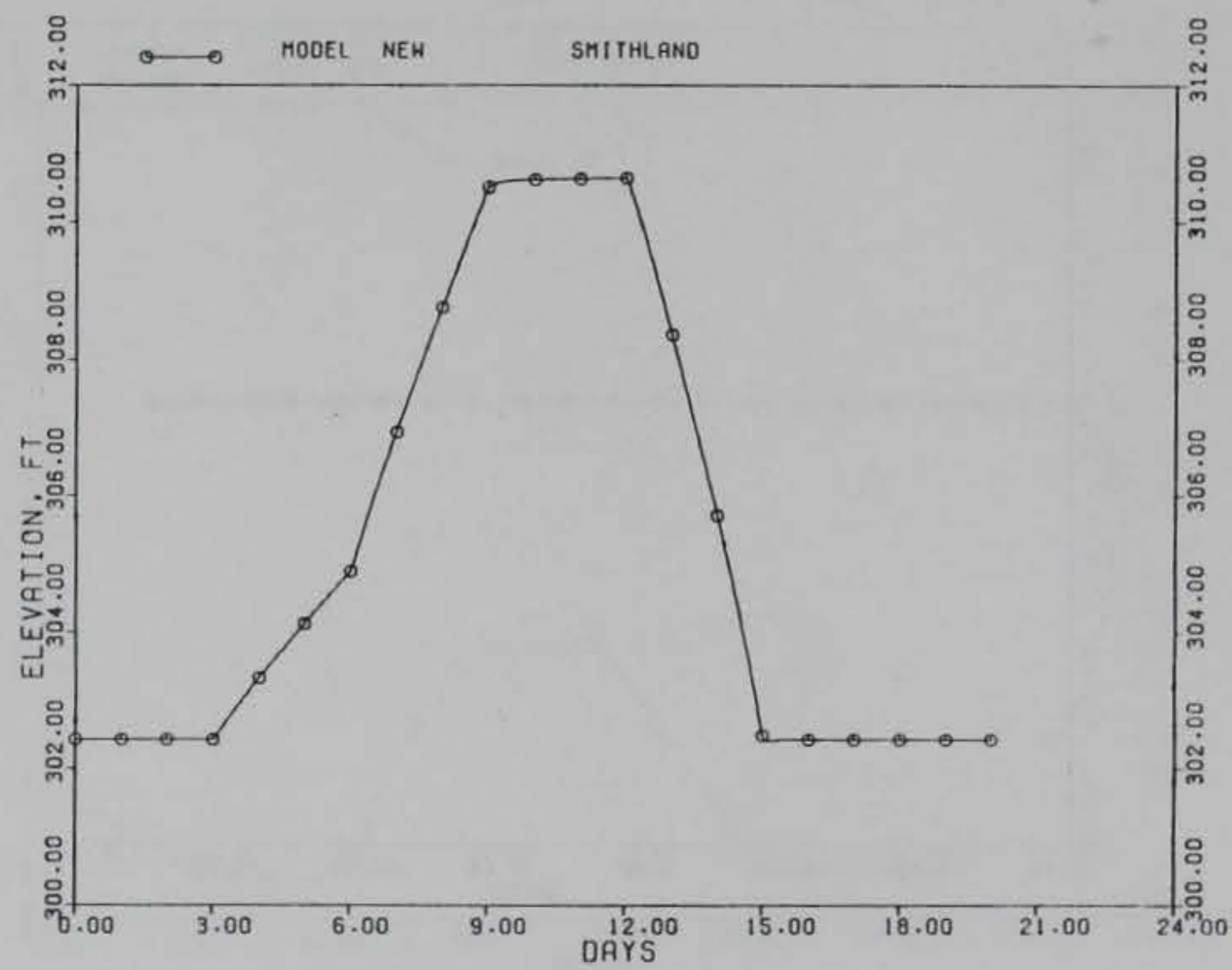

Figure 28. Computed ( $\approx$ NGVD) Smithland tailwater for second Smithland flow event 


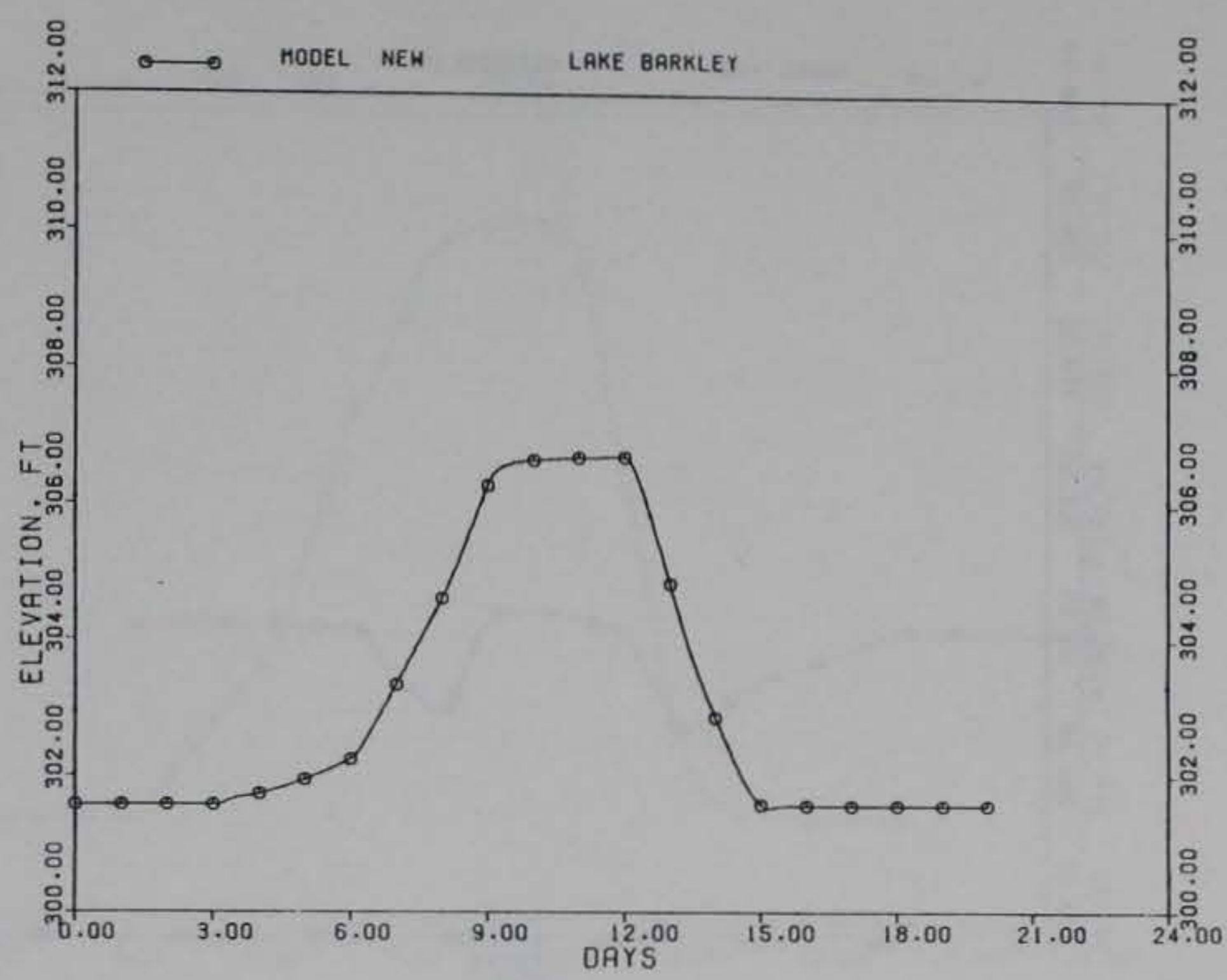

Figure 29. Computed ( $\approx$ NGVD) Barkley tailwater for second Smithland flow event

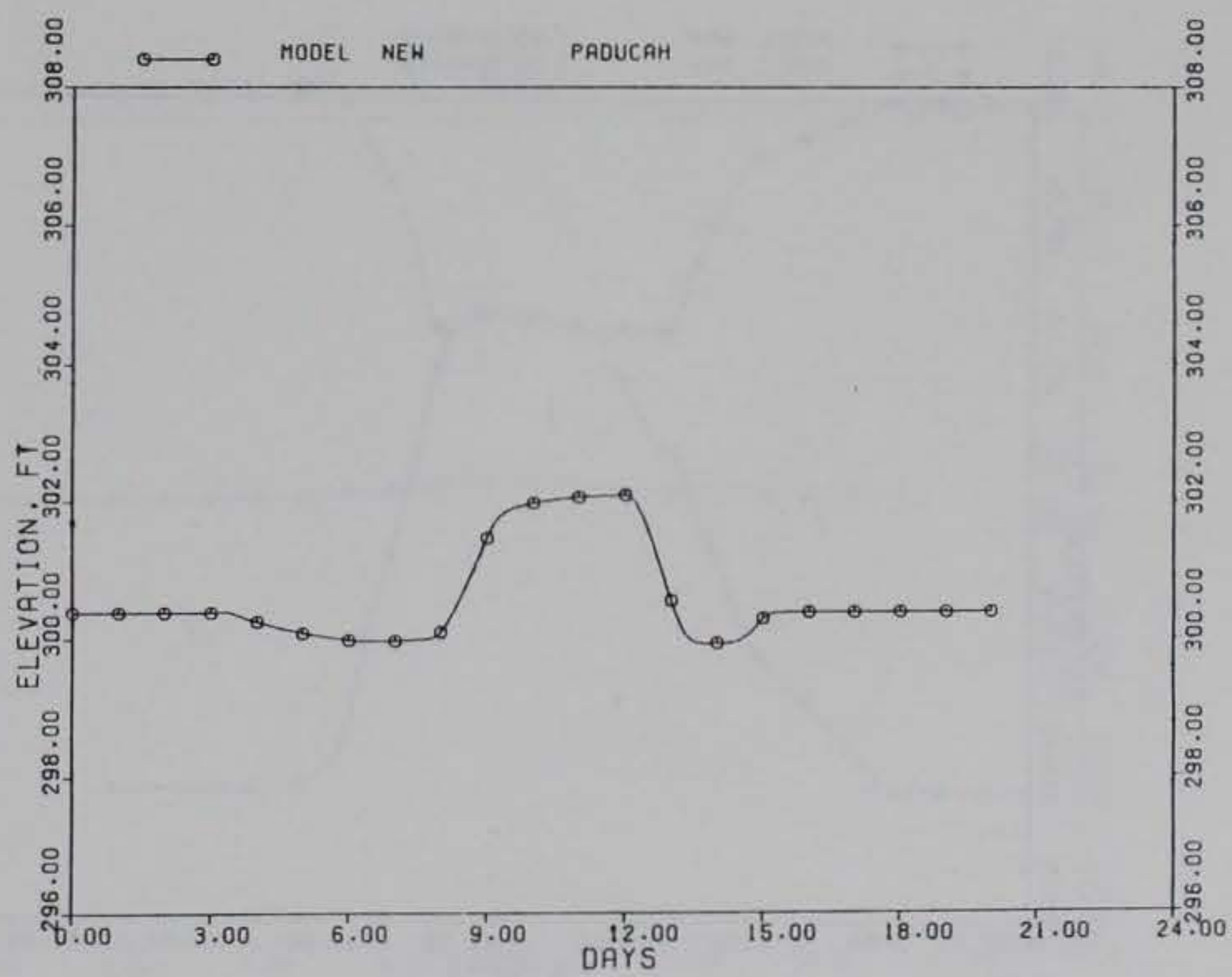

Figure 30. Computed $(\approx$ NGVD) elevations at Paducah, KY, for second Smithland flow event 


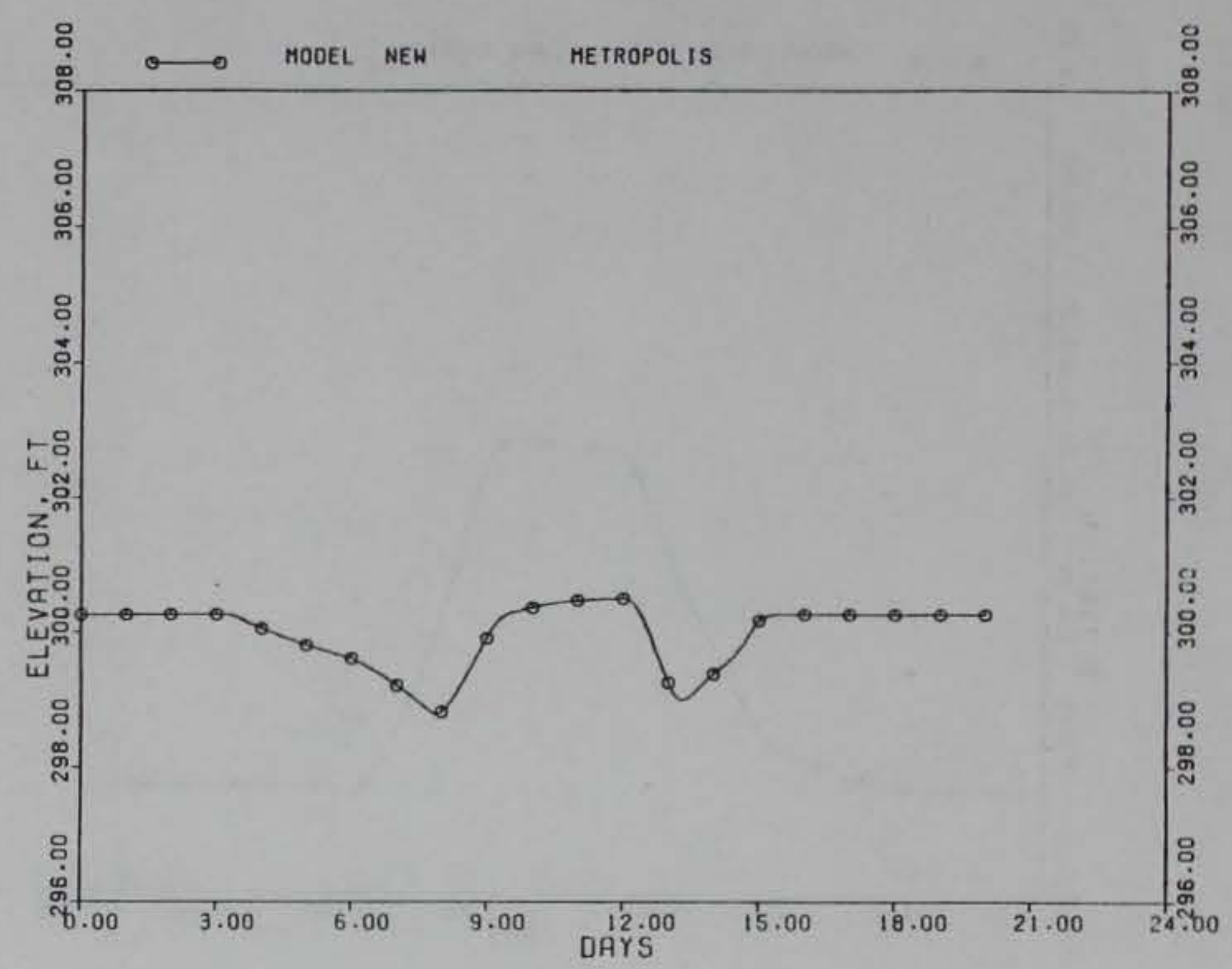

Figure 31. Computed ( $\approx$ NGVD) elevations at Metropolis, IL, for second Smithland flow event

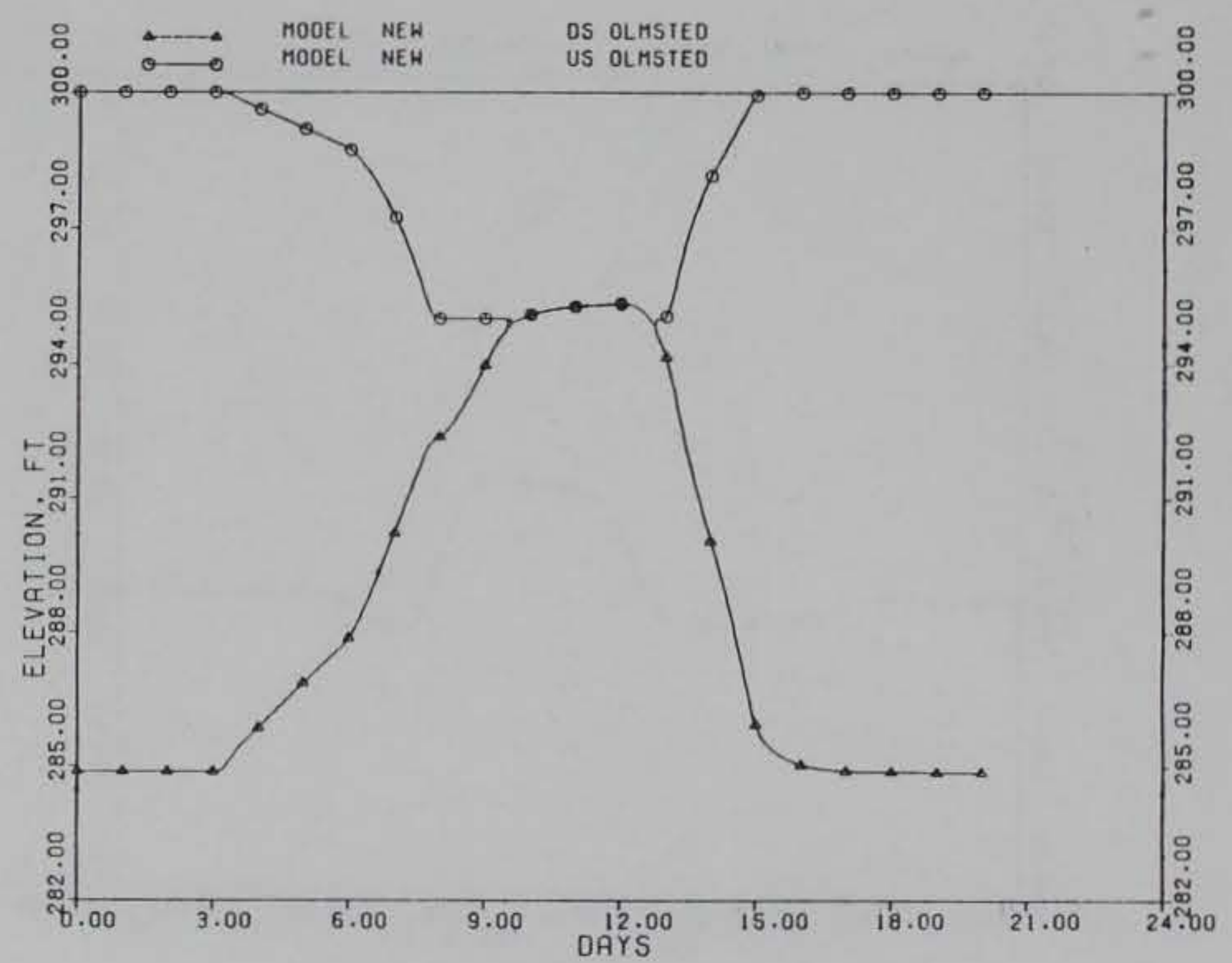

Figure 32. Computed ( $\approx$ NGVD) Olmsted headwater and tailwater for second Smithland flow event 


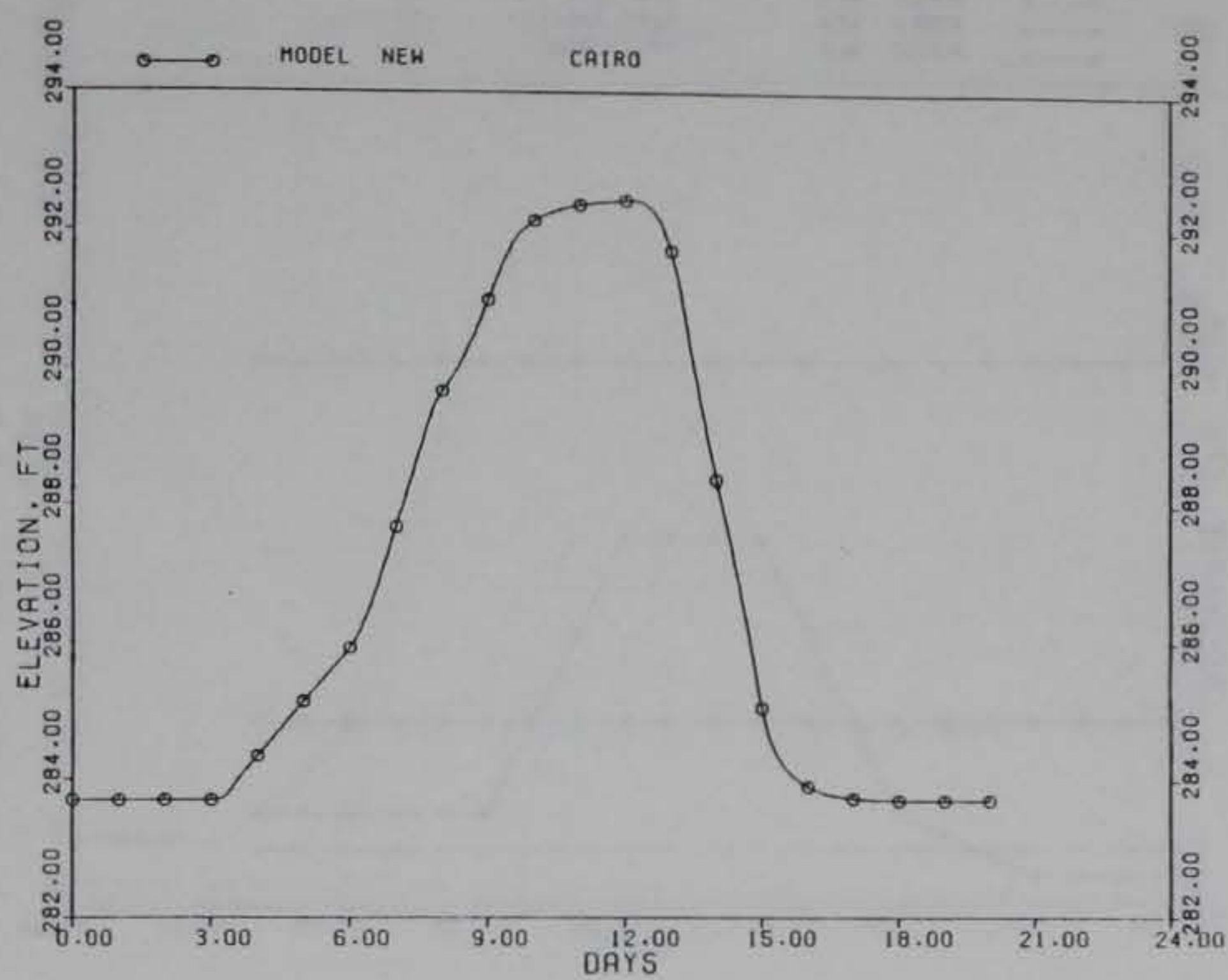

Figure 33. Computed ( $\approx$ NGVD) elevations at Cairo, IL, for second Smithland flow event

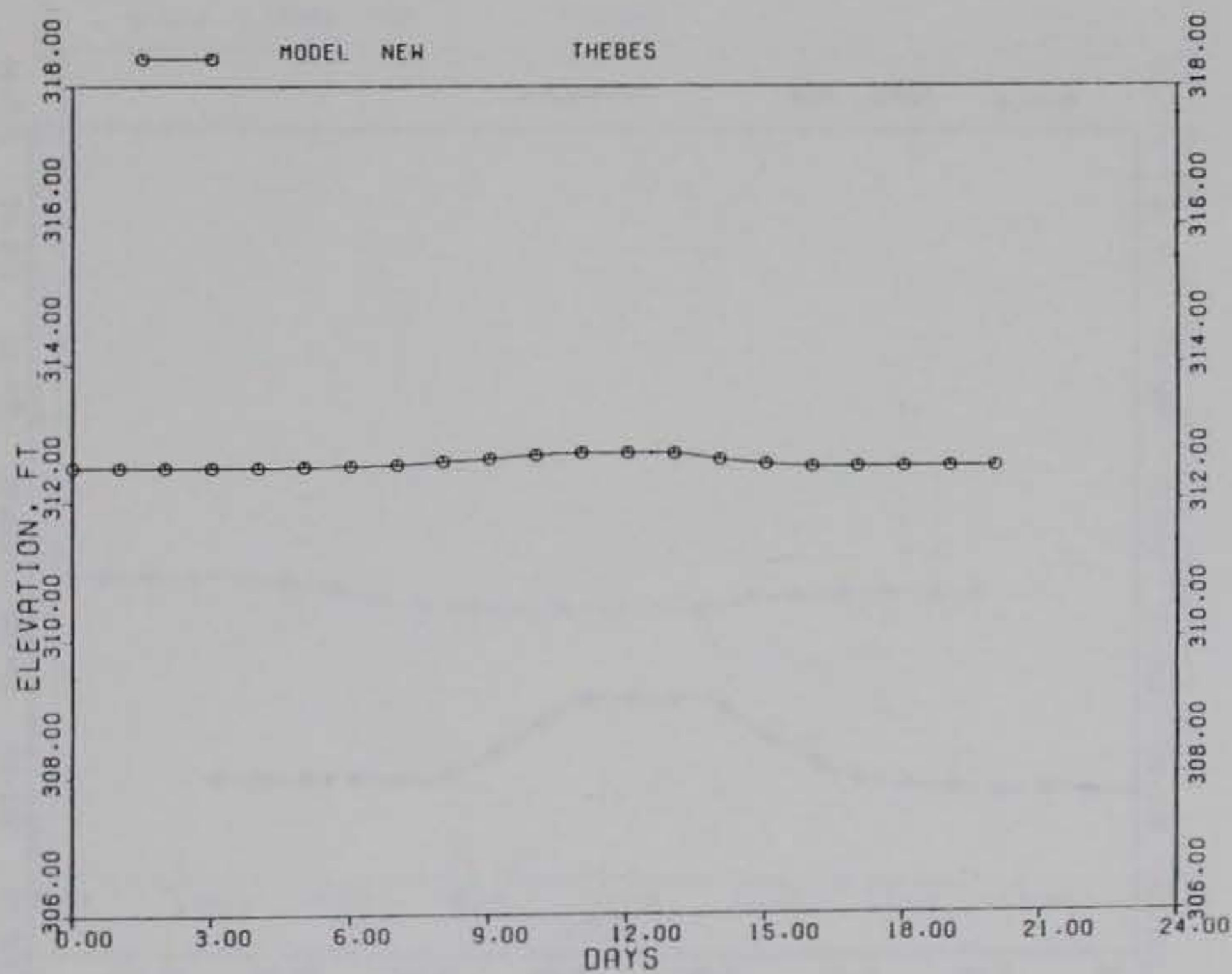

Figure 34. Computed ( $\approx$ NGVD) elevations at Thebes, MO, for second Smithland flow event 


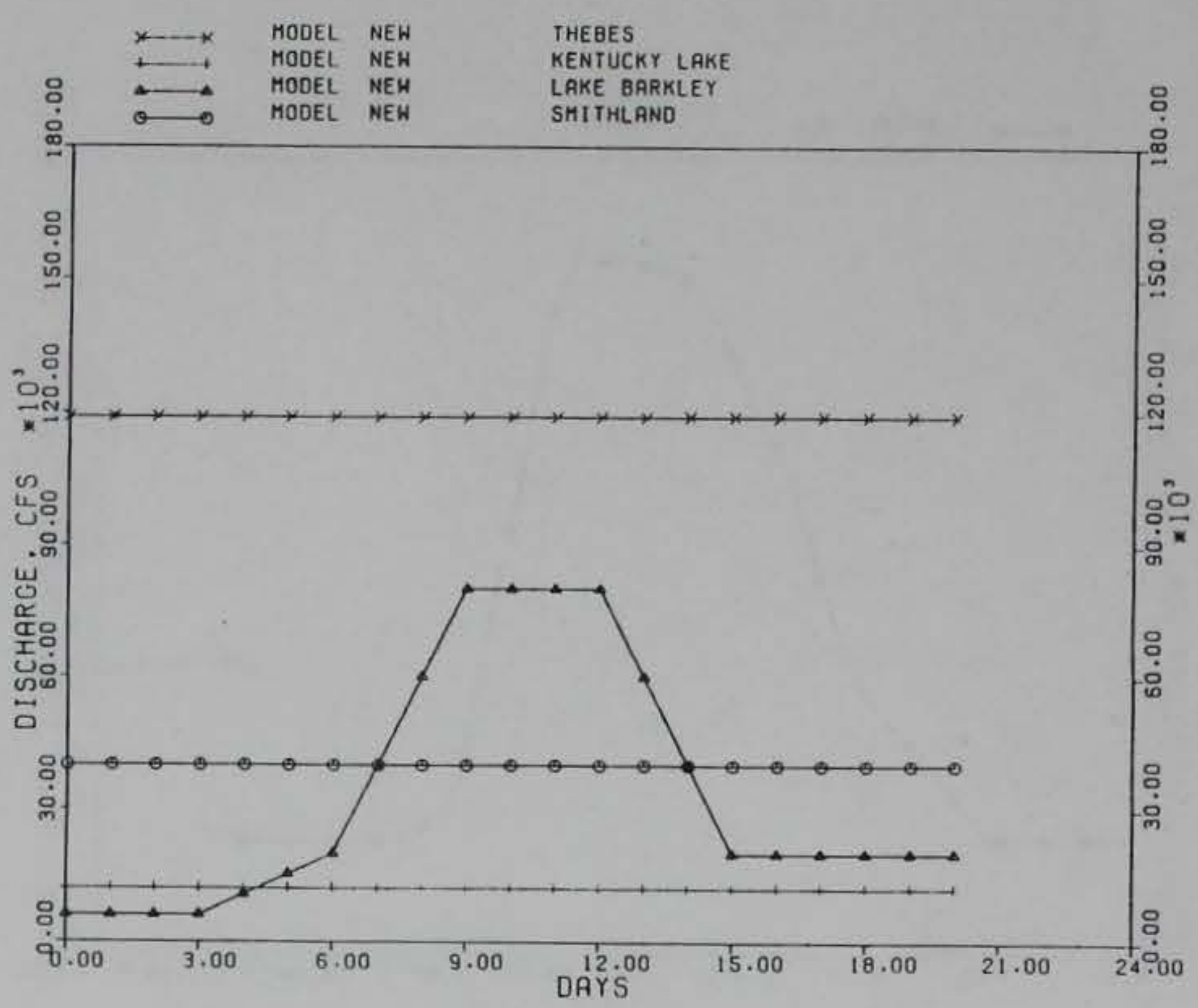

Figure 35. Inflows for first Barkley flow event

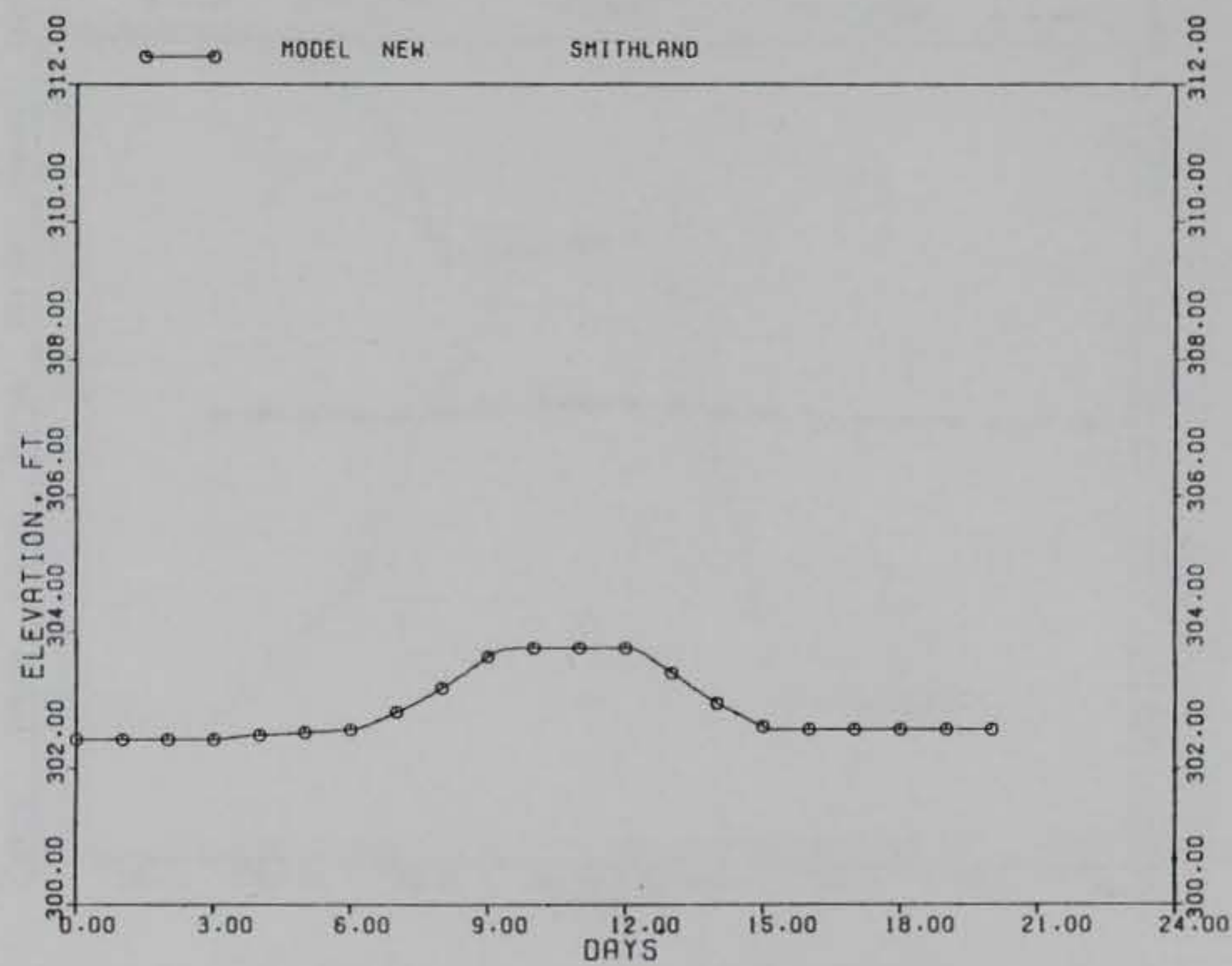

Figure 36. Computed ( $\approx$ NGVD) Smithland tailwater for first Barkley flow event 


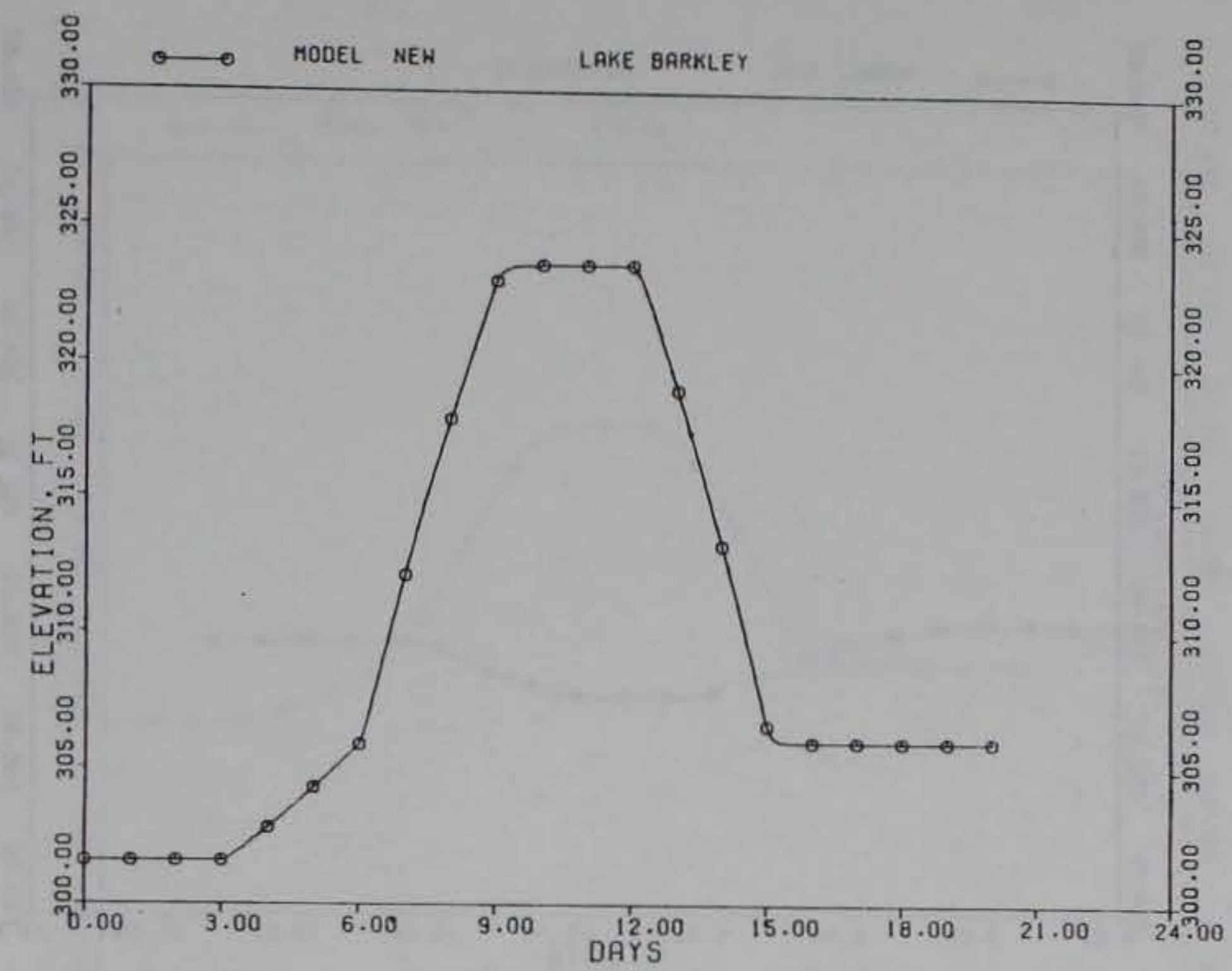

Figure 37. Computed $(\approx$ NGVD) Barkley tailwater for first Barkley flow event

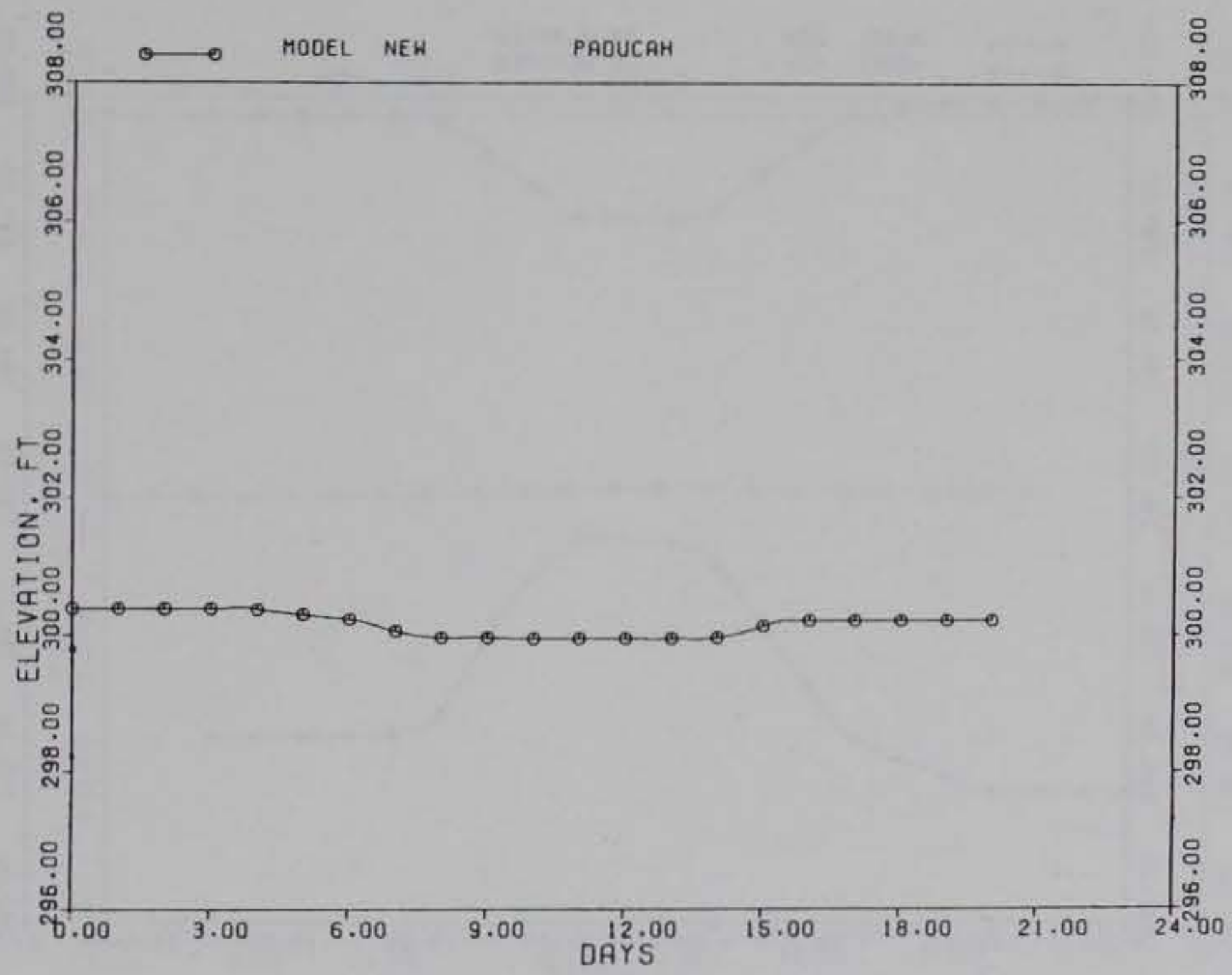

Figure 38. Computed $(\approx$ NGVD) elevations at Paducah, KY, for first Barkley flow event 


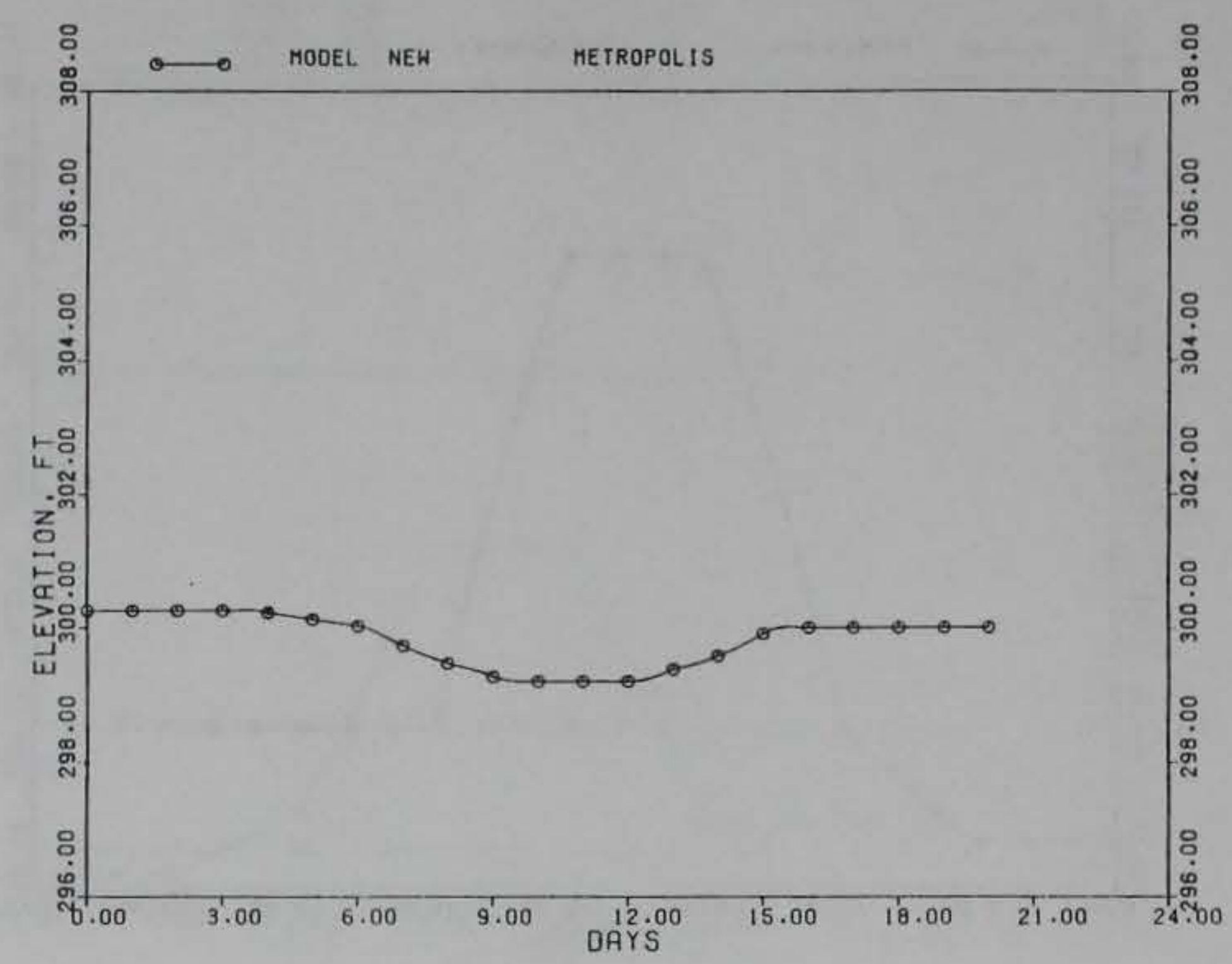

Figure 39. Computed $(\approx$ NGVD) elevations at Metropolis, IL, for first Barkley flow event

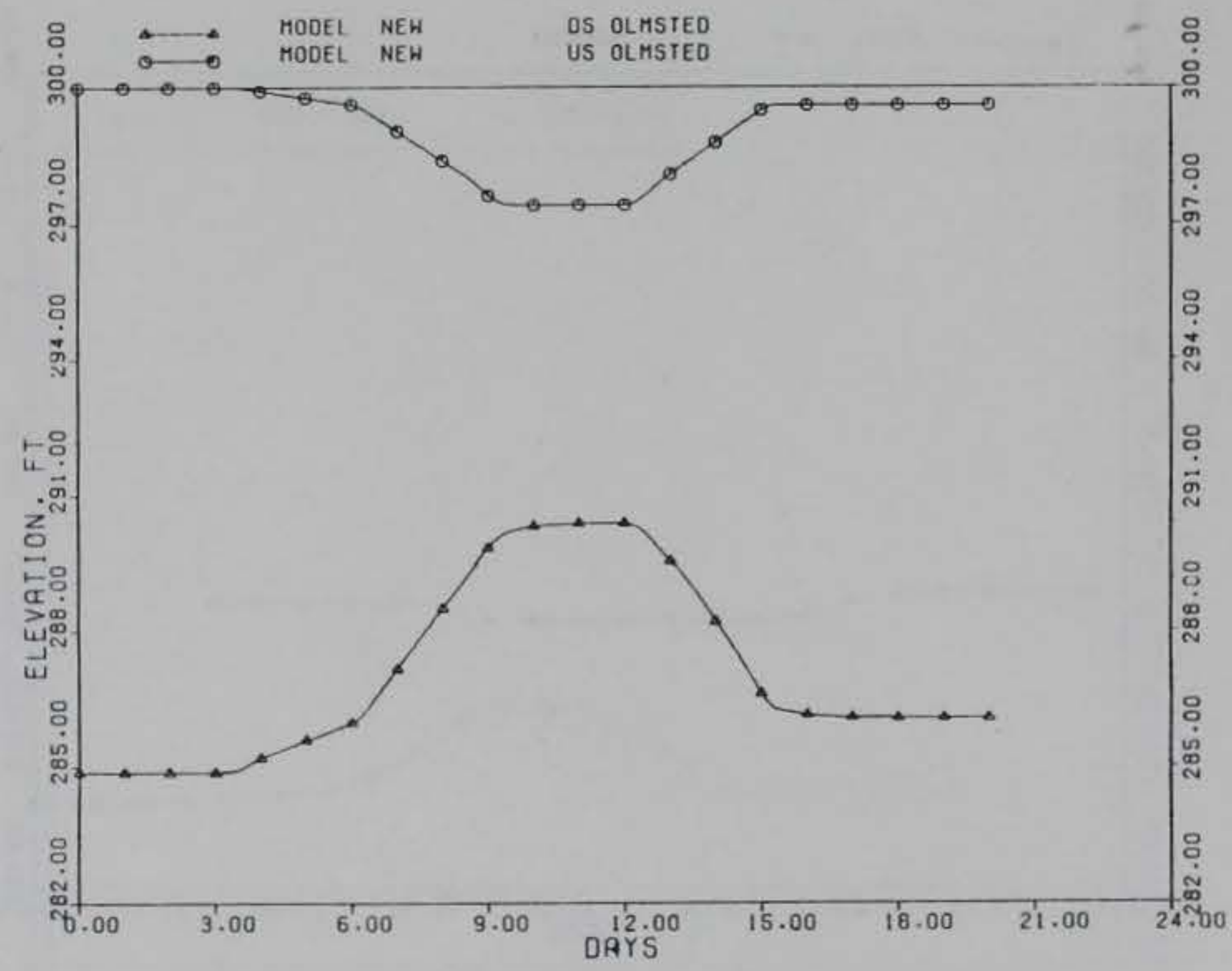

Figure 40. Computed $(\approx$ NGVD) Olmsted headwater and tailwater for first Barkley flow event 


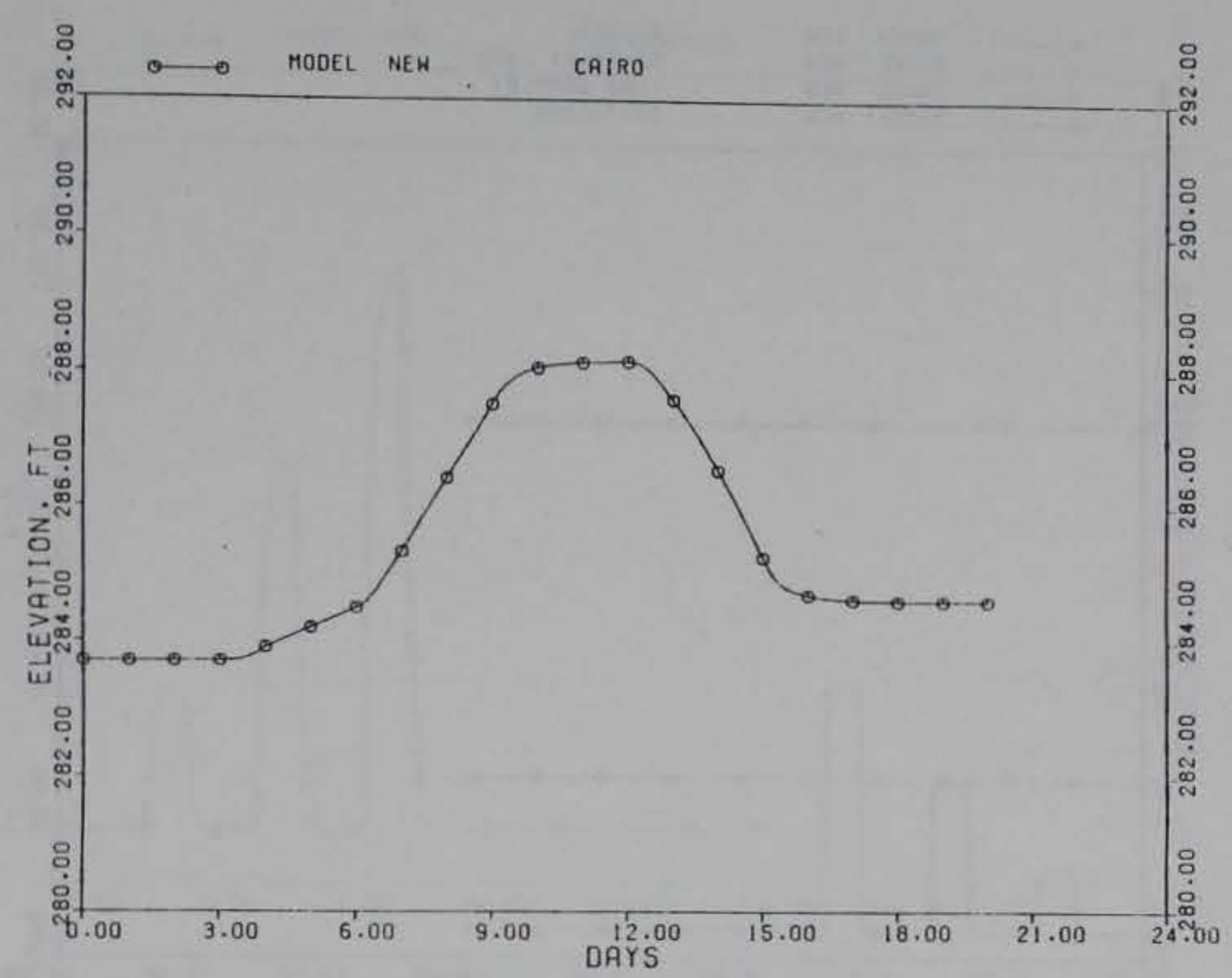

Figure 41. Computed $(\approx$ NGVD) elevations at Cairo, IL, for first Barkley flow event

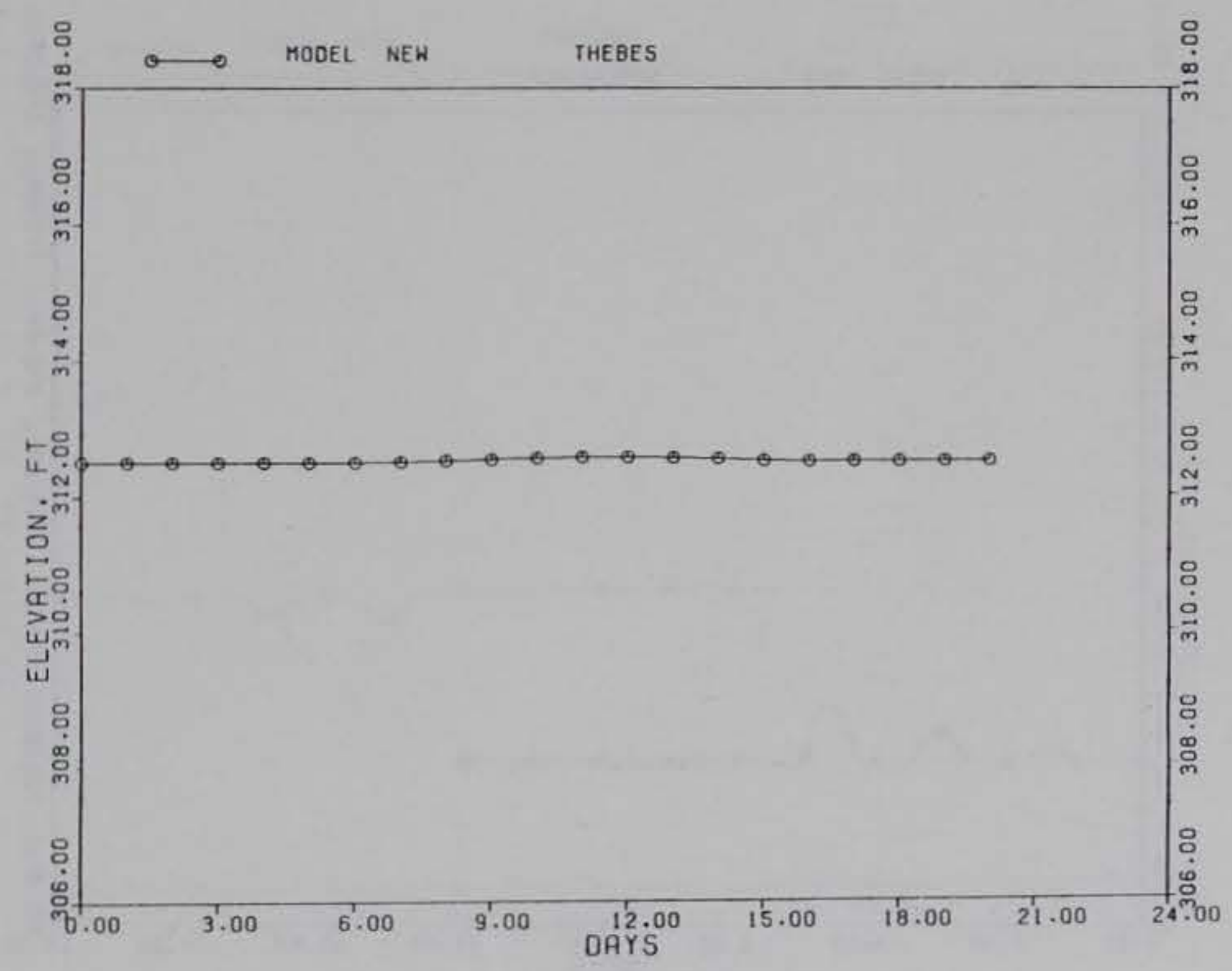

Figure 42. Computed ( $\approx$ NGVD) elevations at Thebes, MO, for first Barkley flow event 


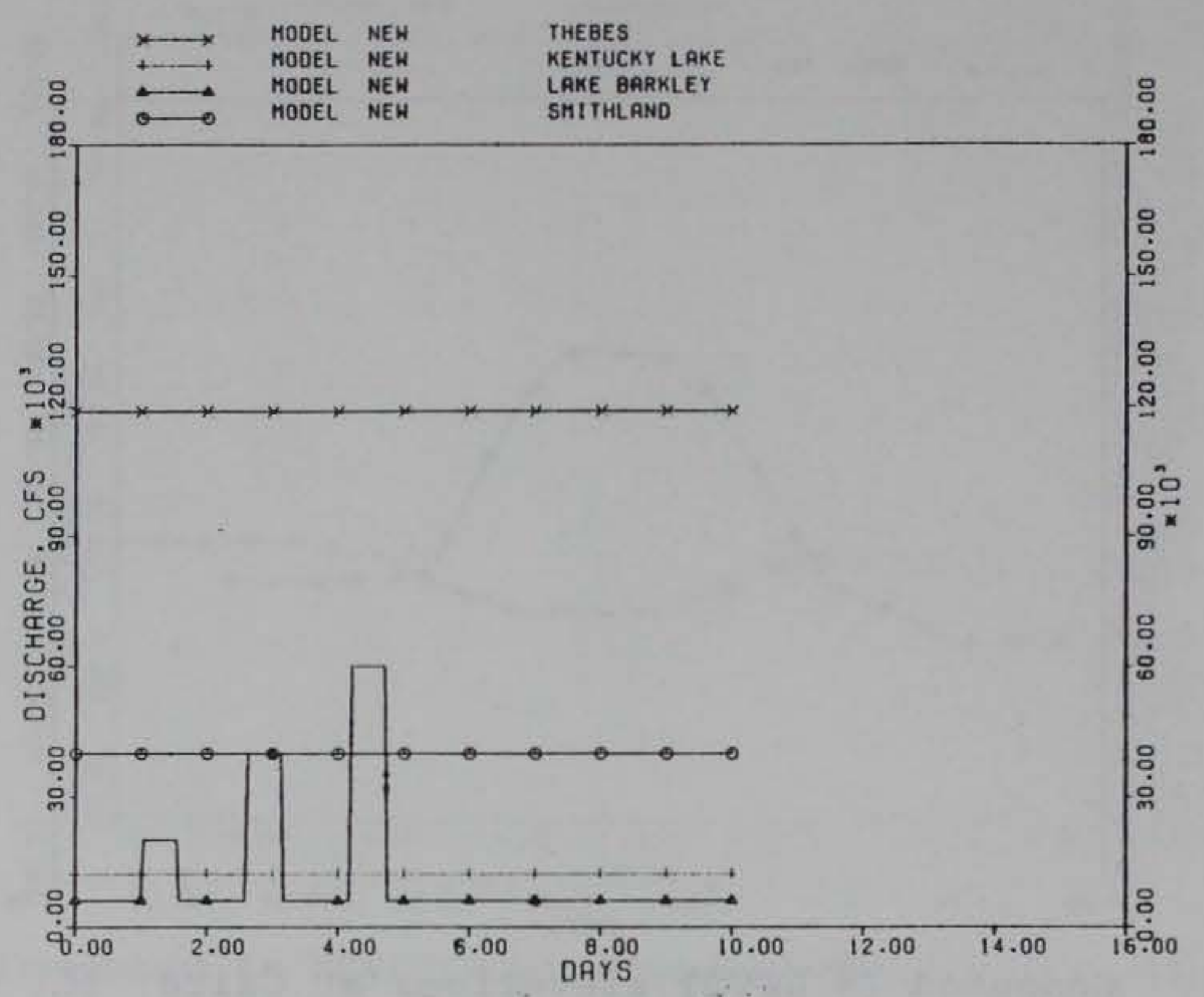

Figure 43. Inflows for second Barkley flow event

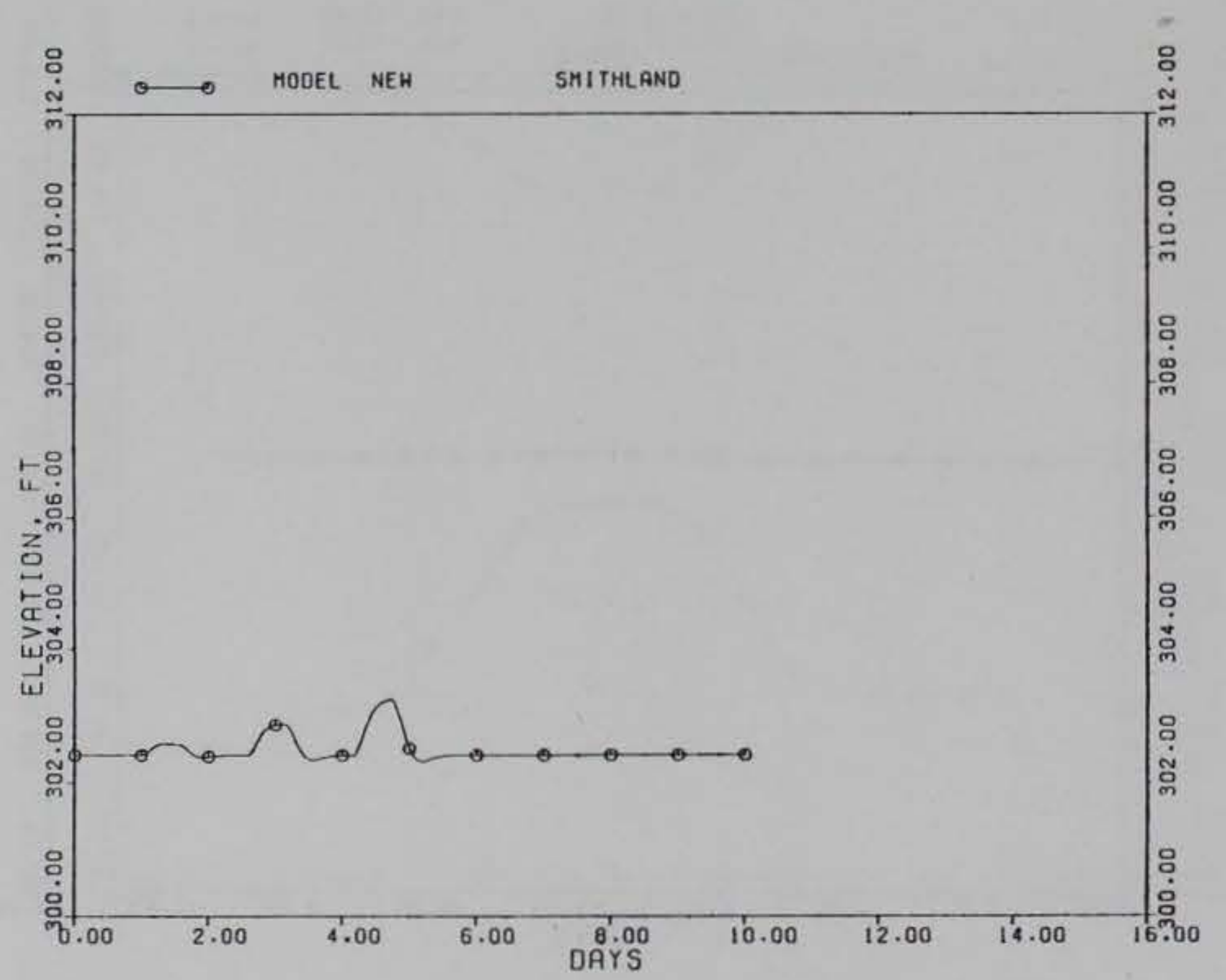

Figure 44. Computed $(\approx$ NGVD) Smithland tailwater for the second Barkley flow event 


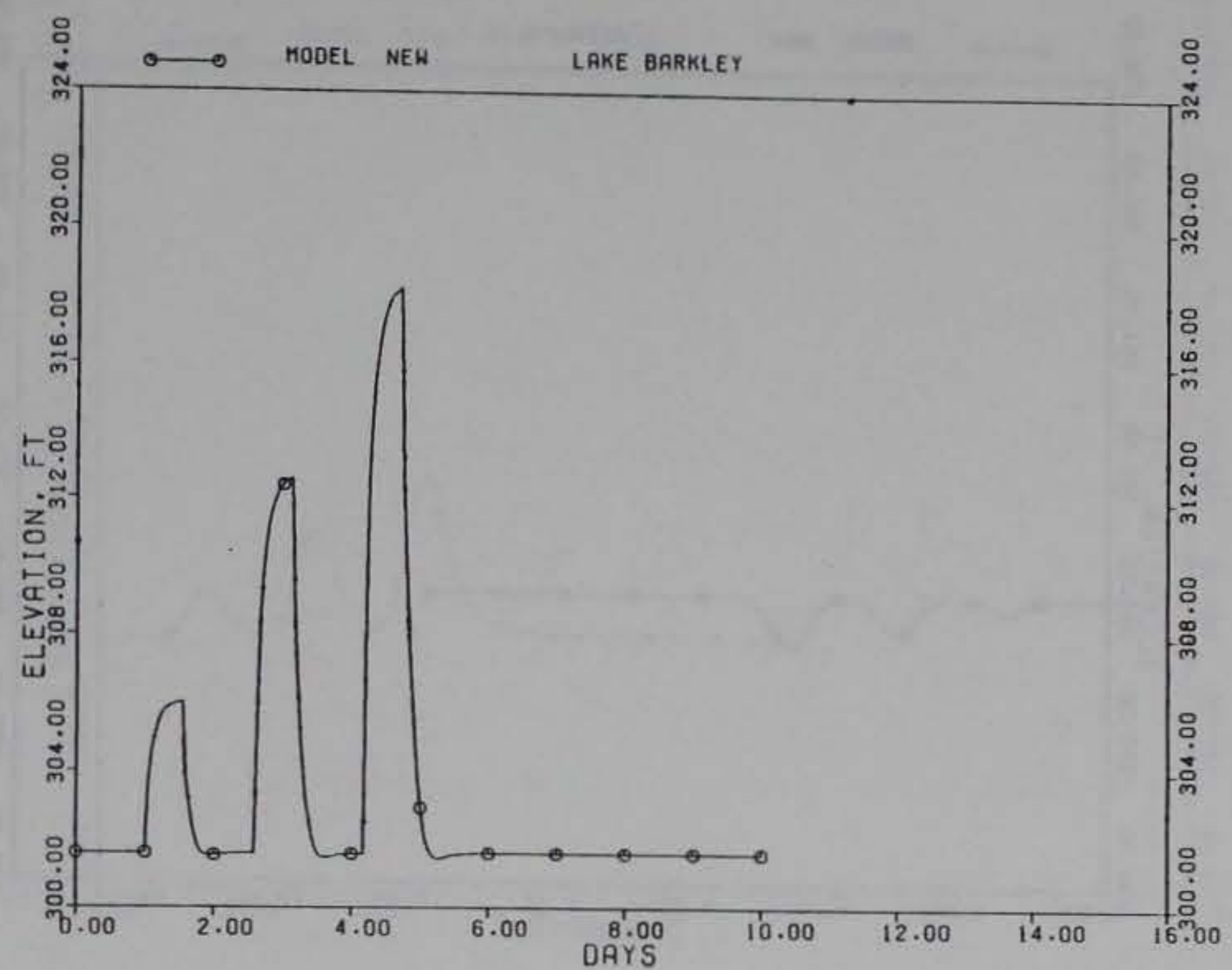

Figure 45. Computed ( $\approx$ NGVD) Barkley tailwater for the second Barkley flow event

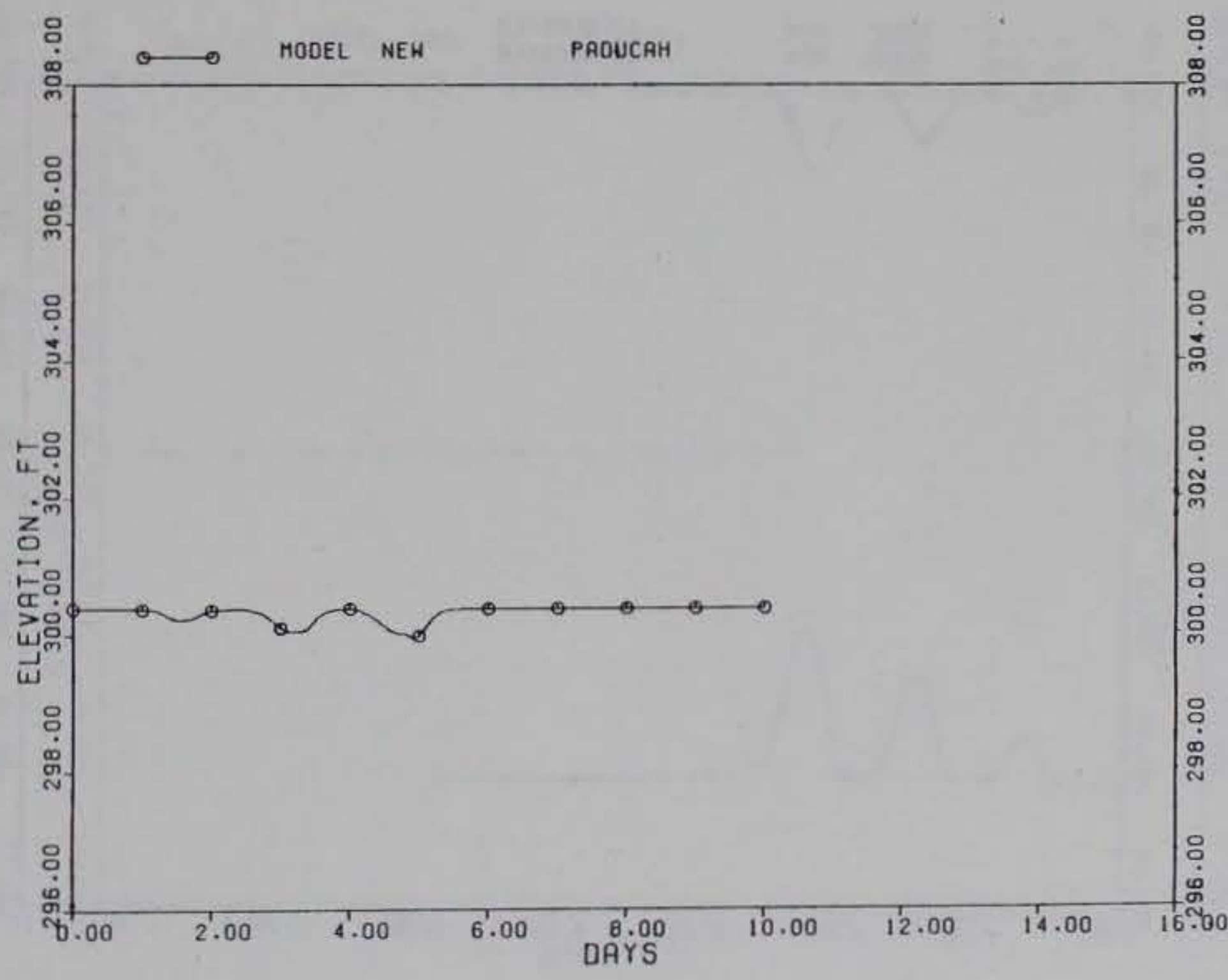

Figure 46. Computed $(\approx N G V D)$ elevations at Paducah, KY, for the second Barkley flow event 


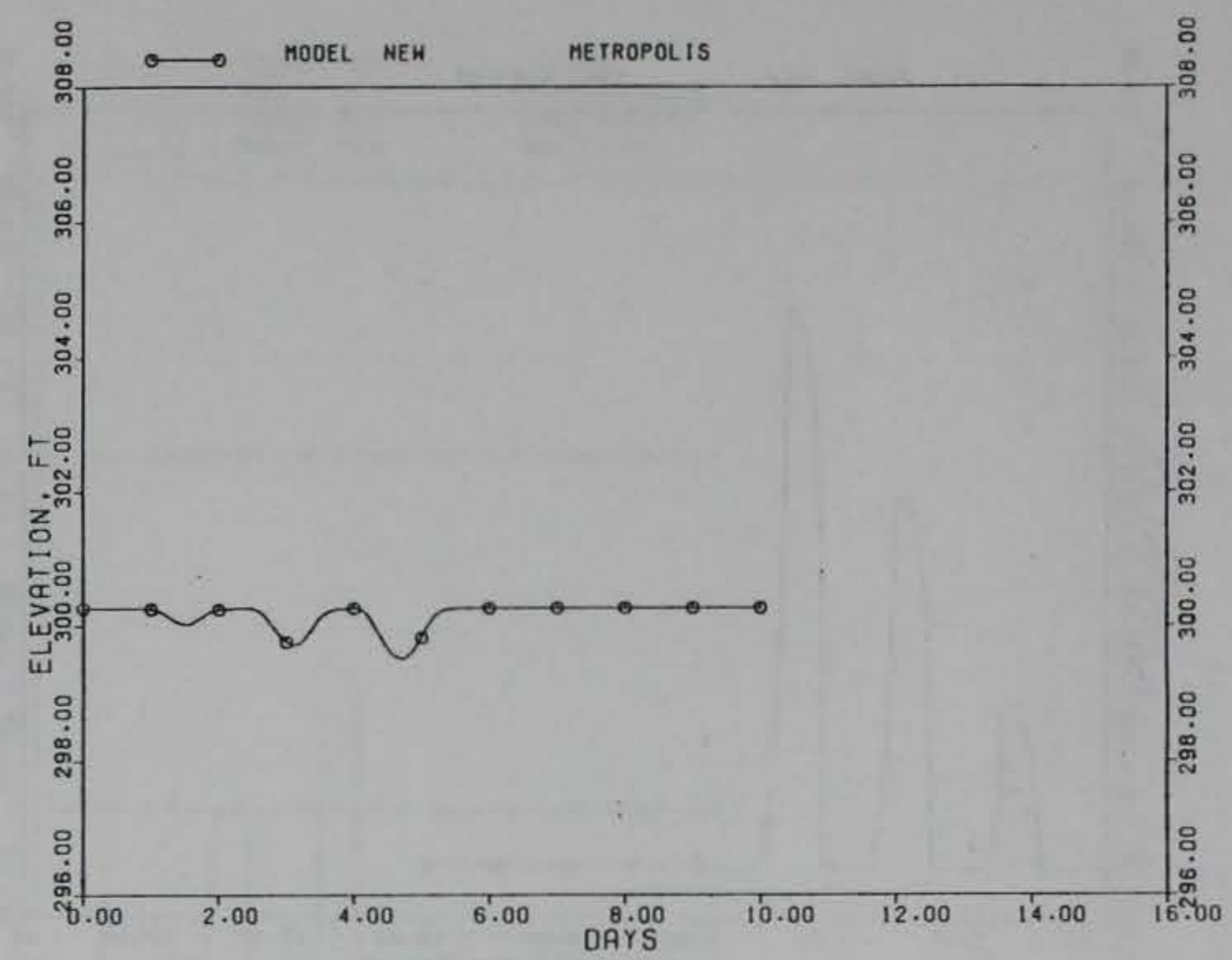

Figure 47. Computed ( $\approx$ NGVD) elevations at Metropolis, IL, for the second Barkley flow event

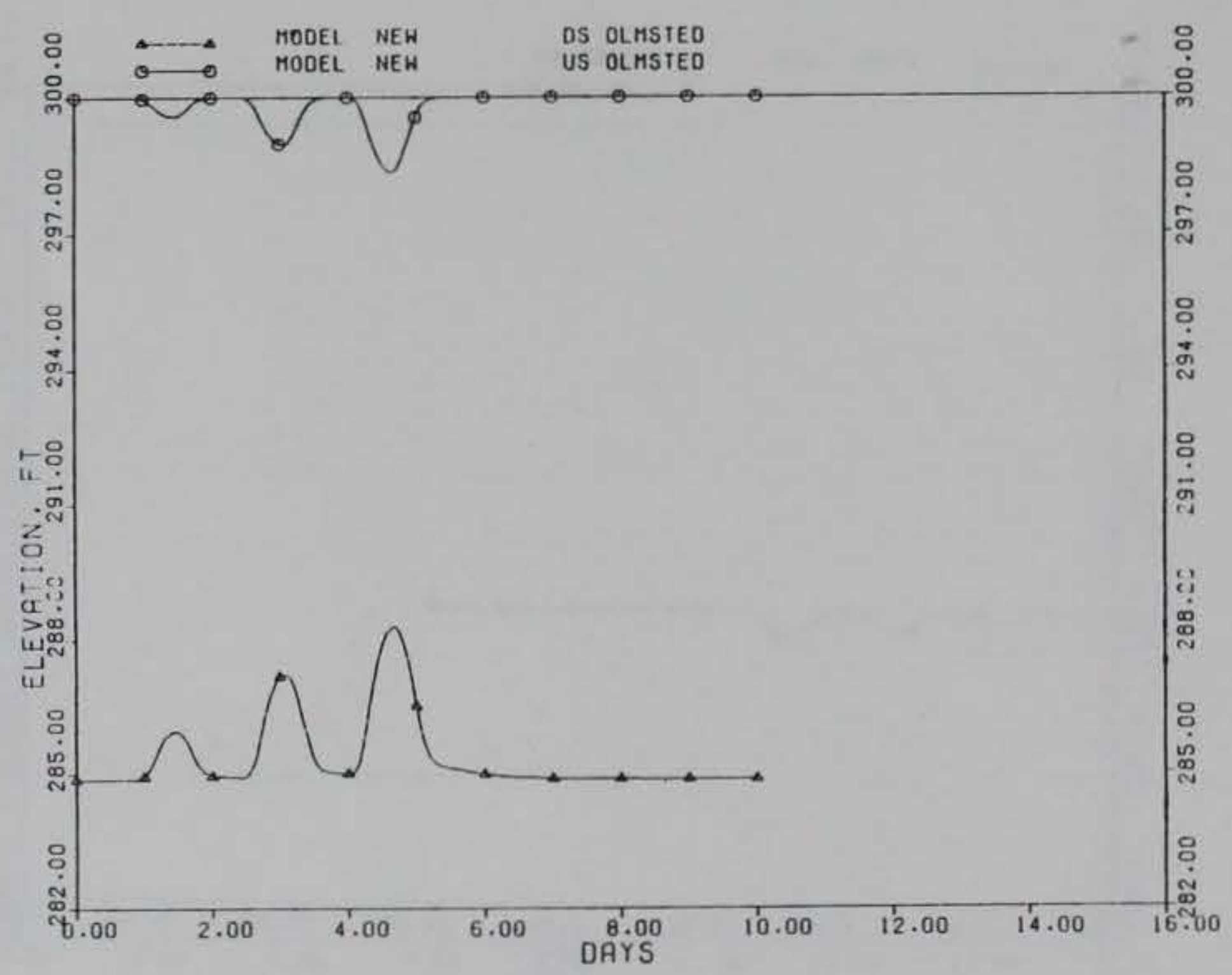

Figure 48. Computed ( $\approx$ NGVD) Olmsted headwater and tailwater for the second Barkley flow event 


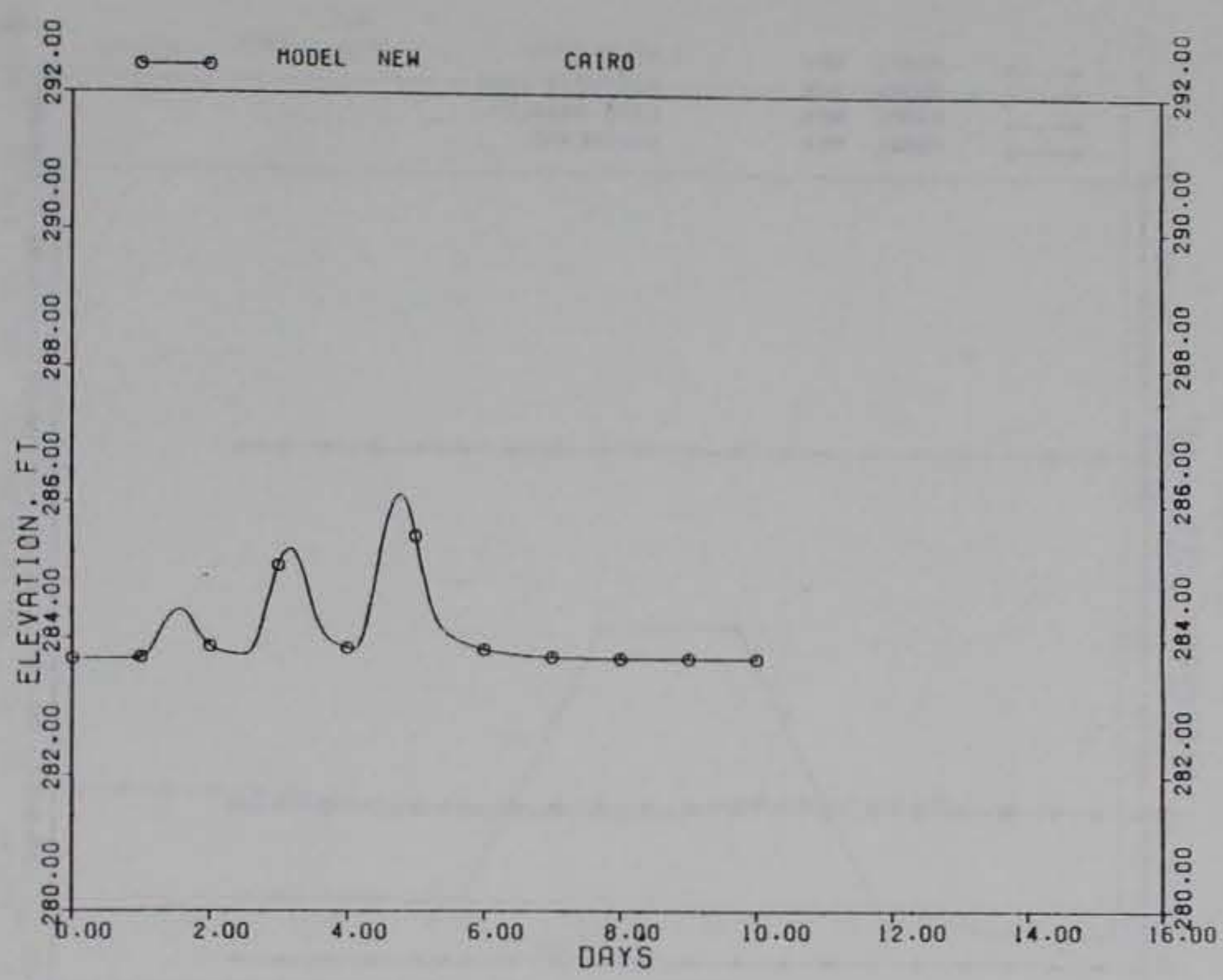

Figure 49. Computed $(\approx$ NGVD) elevations at Cairo, IL, for the second Barkley flow event

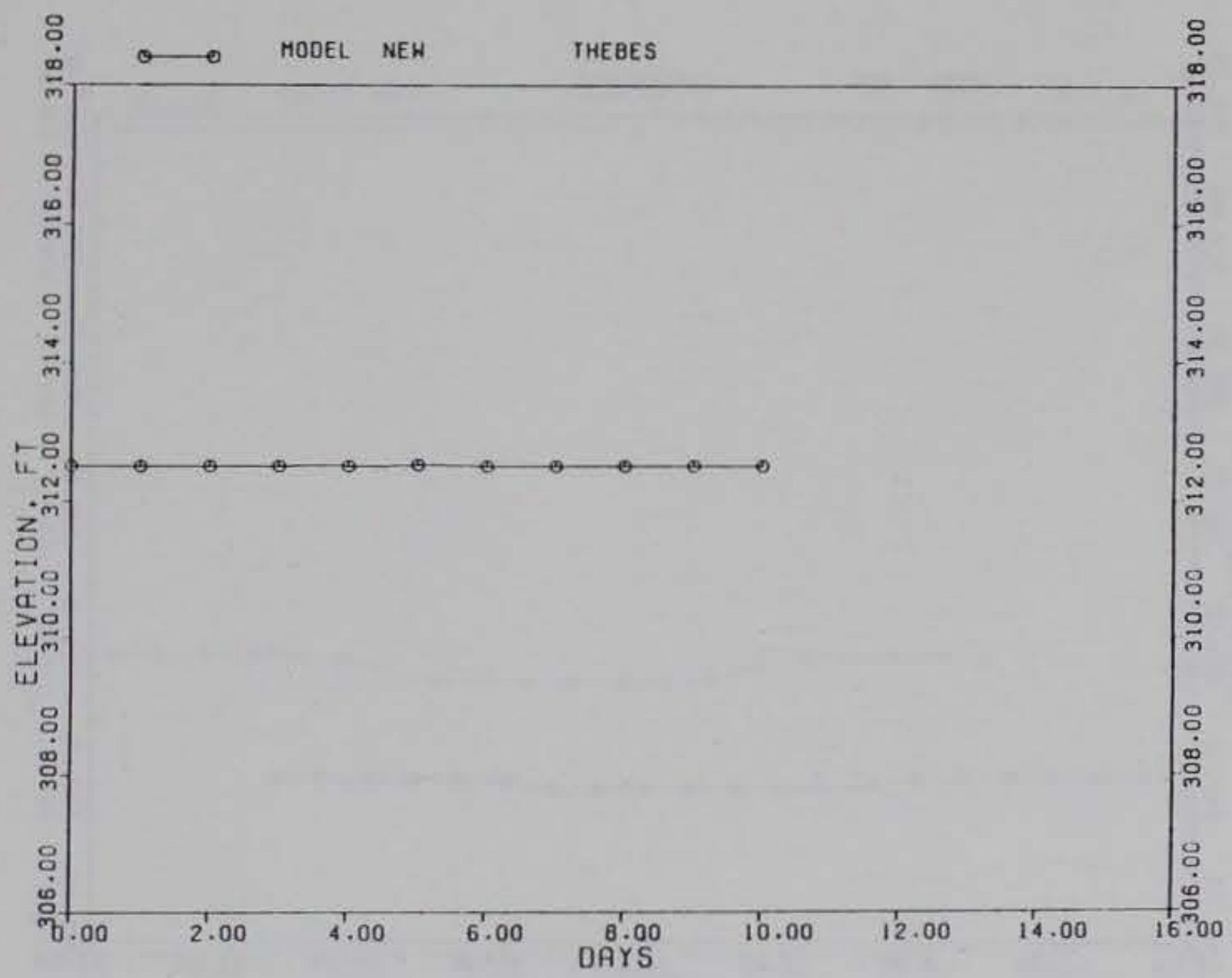

Figure 50. Computed $(\approx$ NGVD) elevations at Thebes, MO, for the second Barkley flow event 


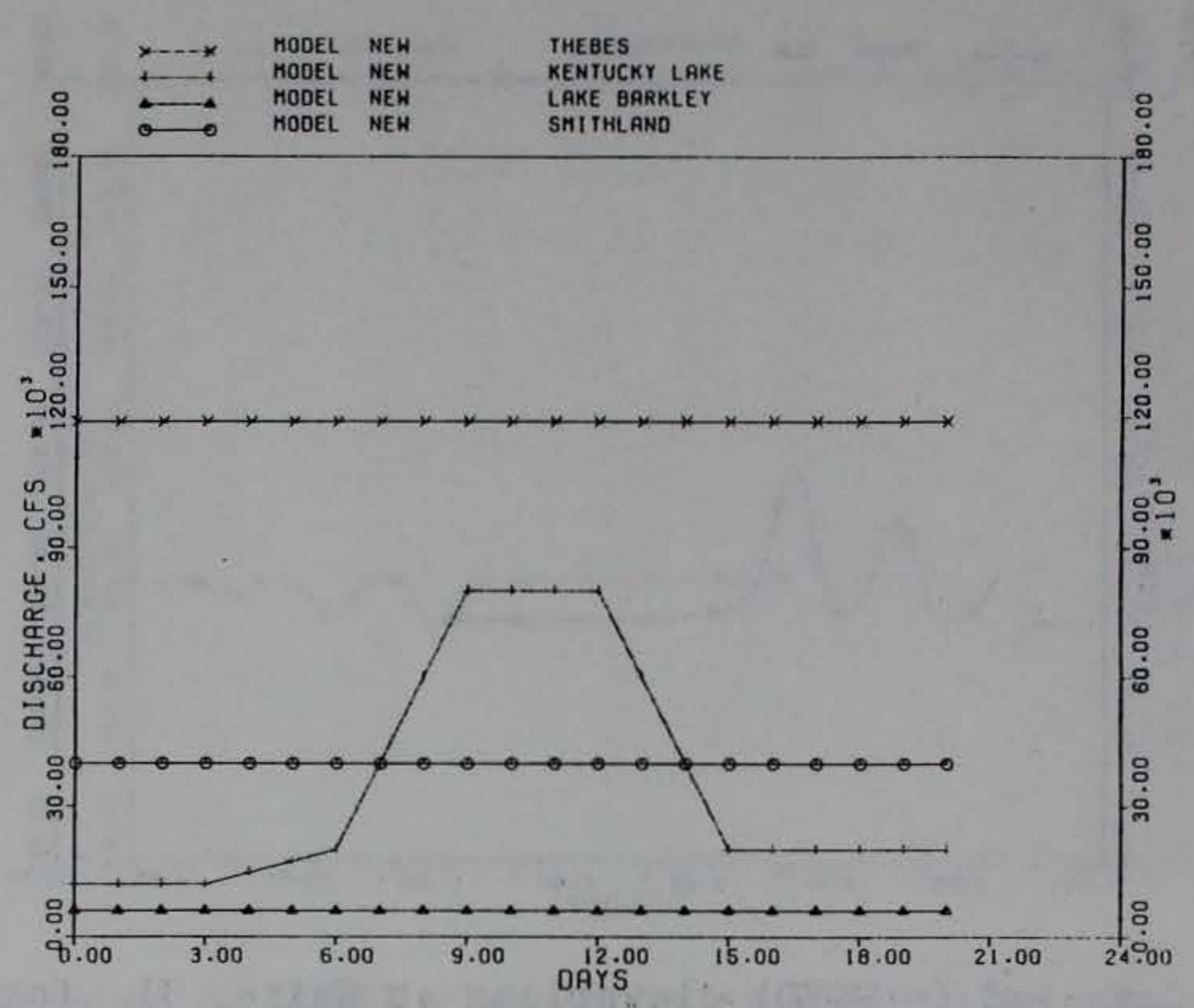

Figure 51. Inflows for first Kentucky flow event

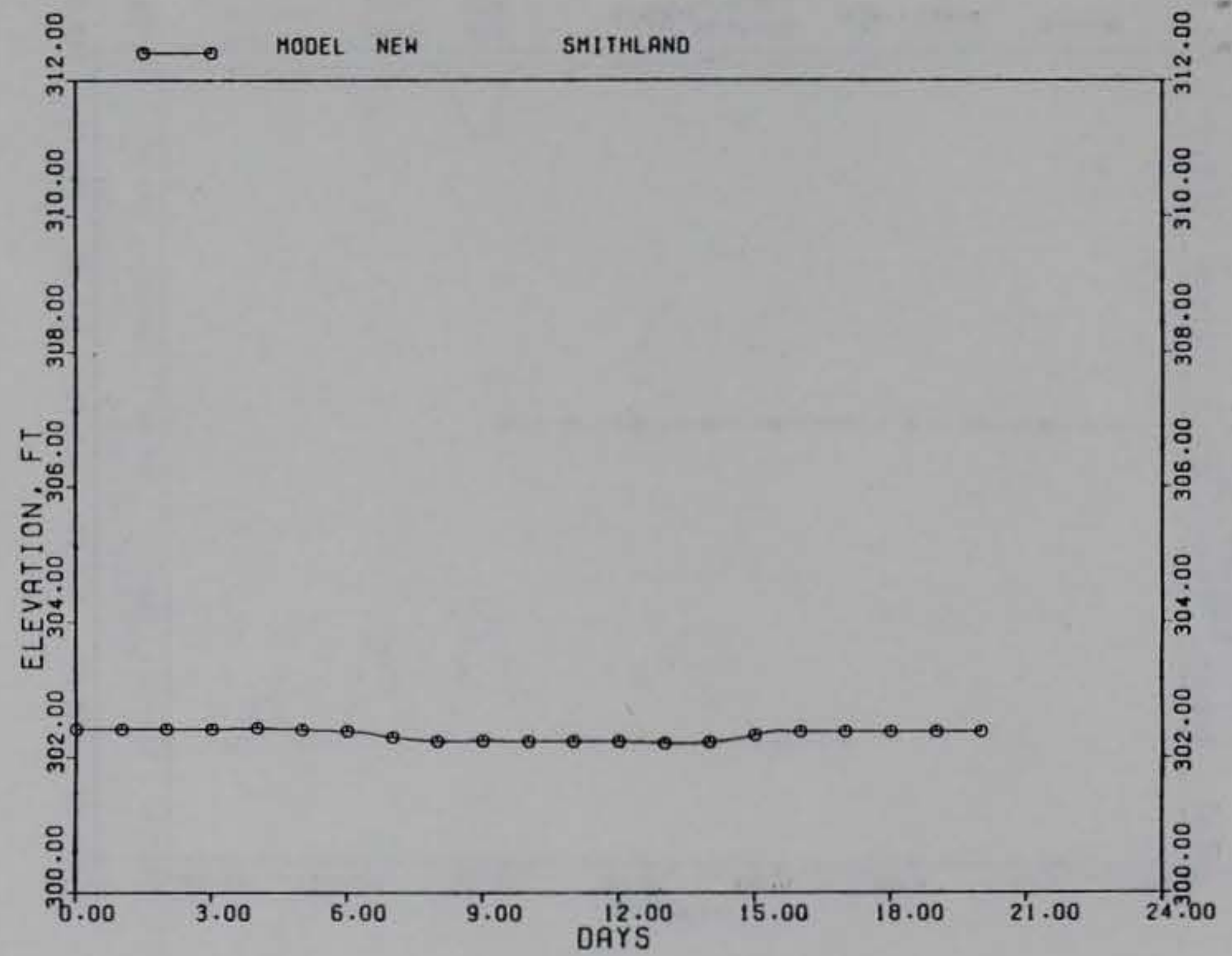

Figure 52. Computed $(\approx$ NGVD) Smithland tailwater for first Kentucky flow event 


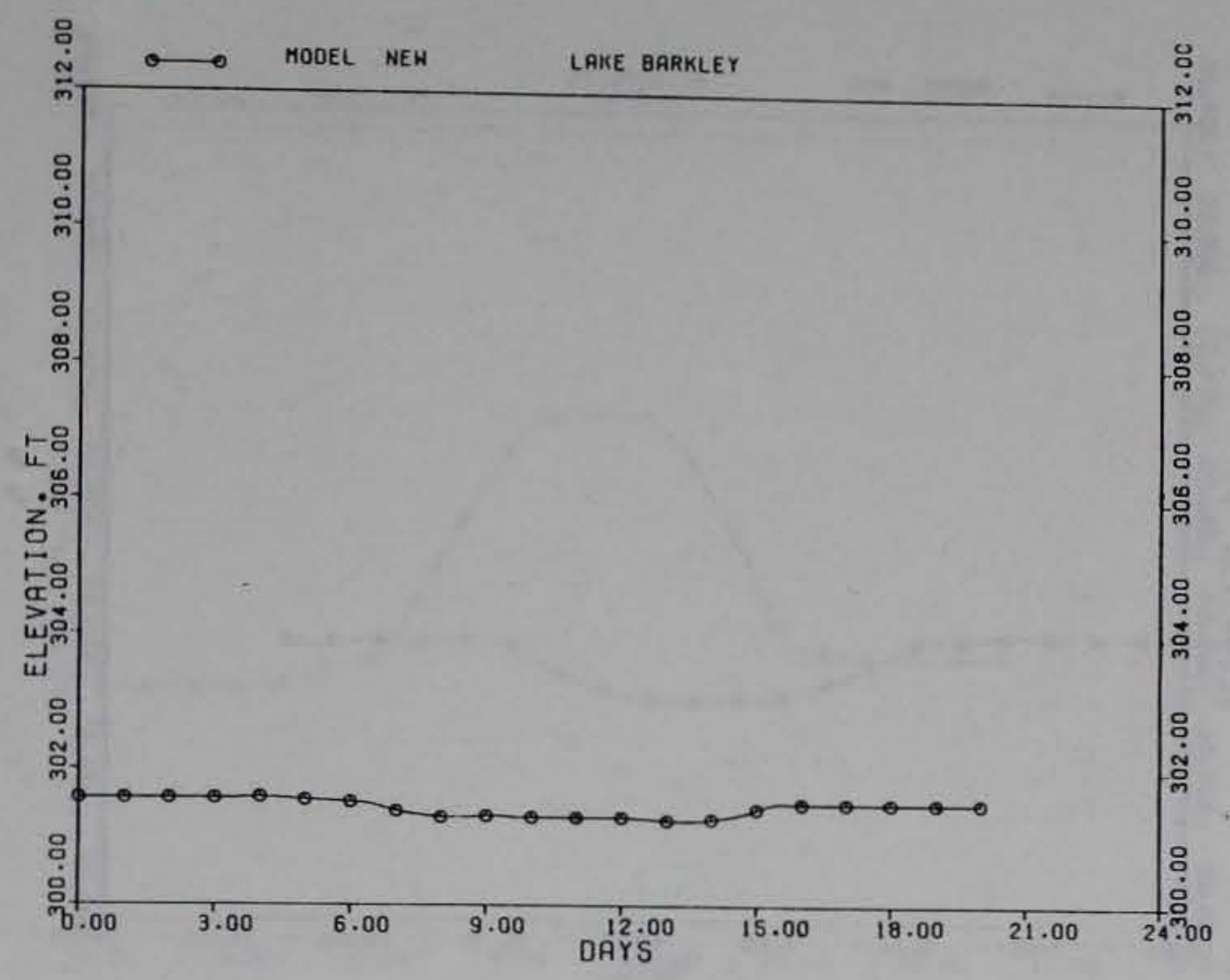

Figure 53. Computed ( $\approx$ NGVD) Barkley tallwater for first Kentucky flow event

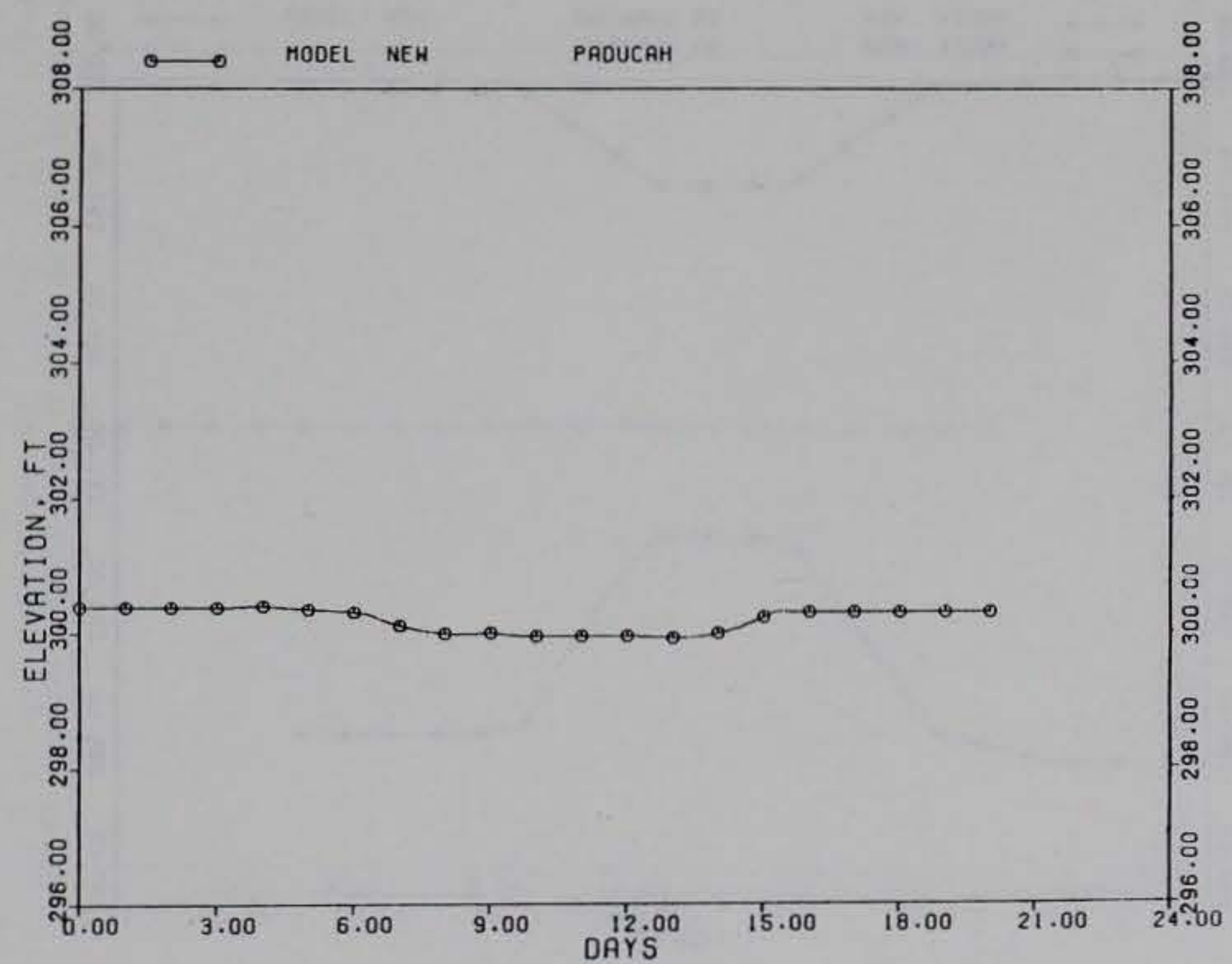

Figure 54. Computed $(\approx$ NGVD) elevations at Paducah, KY, for first Kentucky flow event 


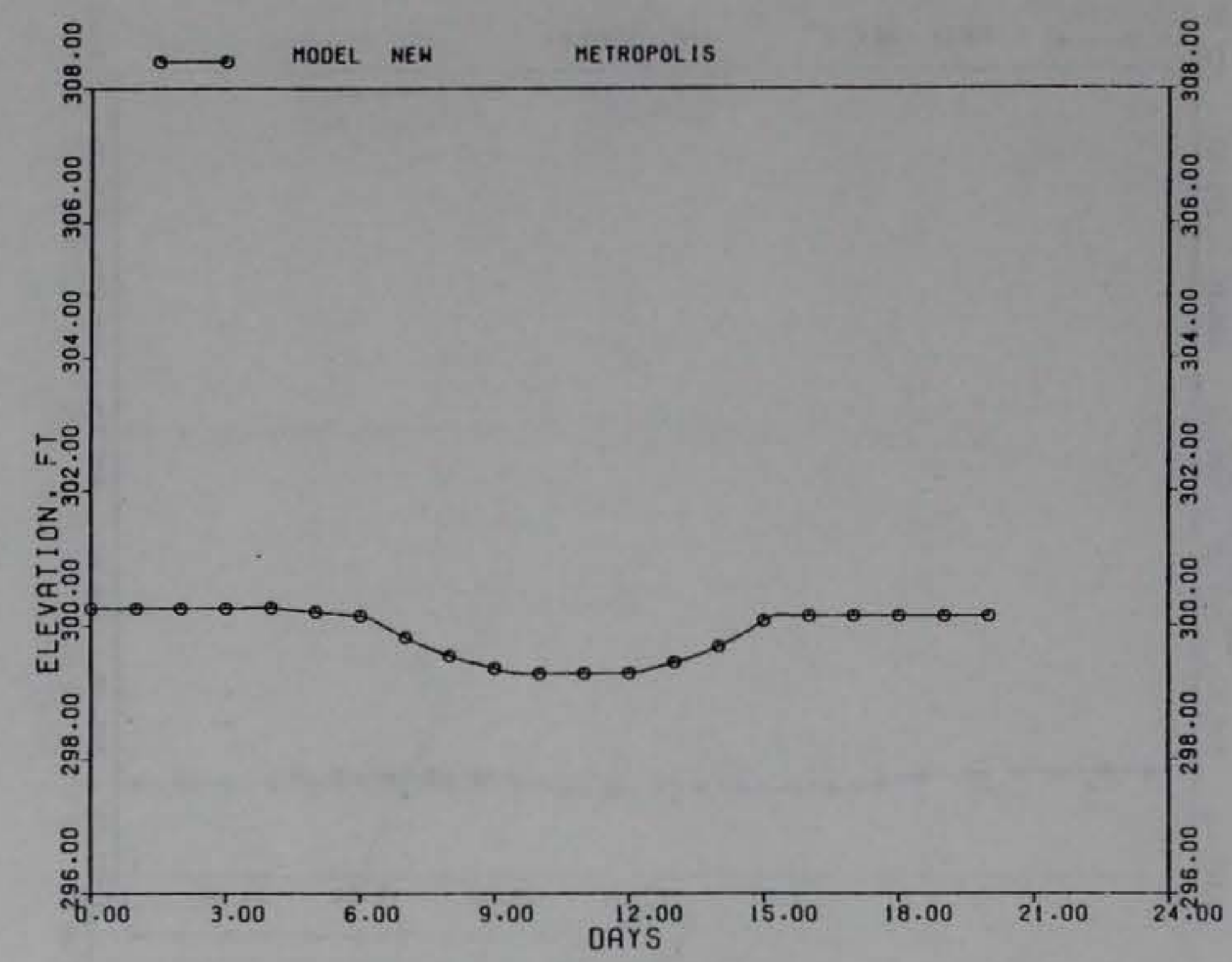

Figure 55. Computed $(\approx$ NGVD) elevations at Metropolis, IL, for first Kentucky flow event

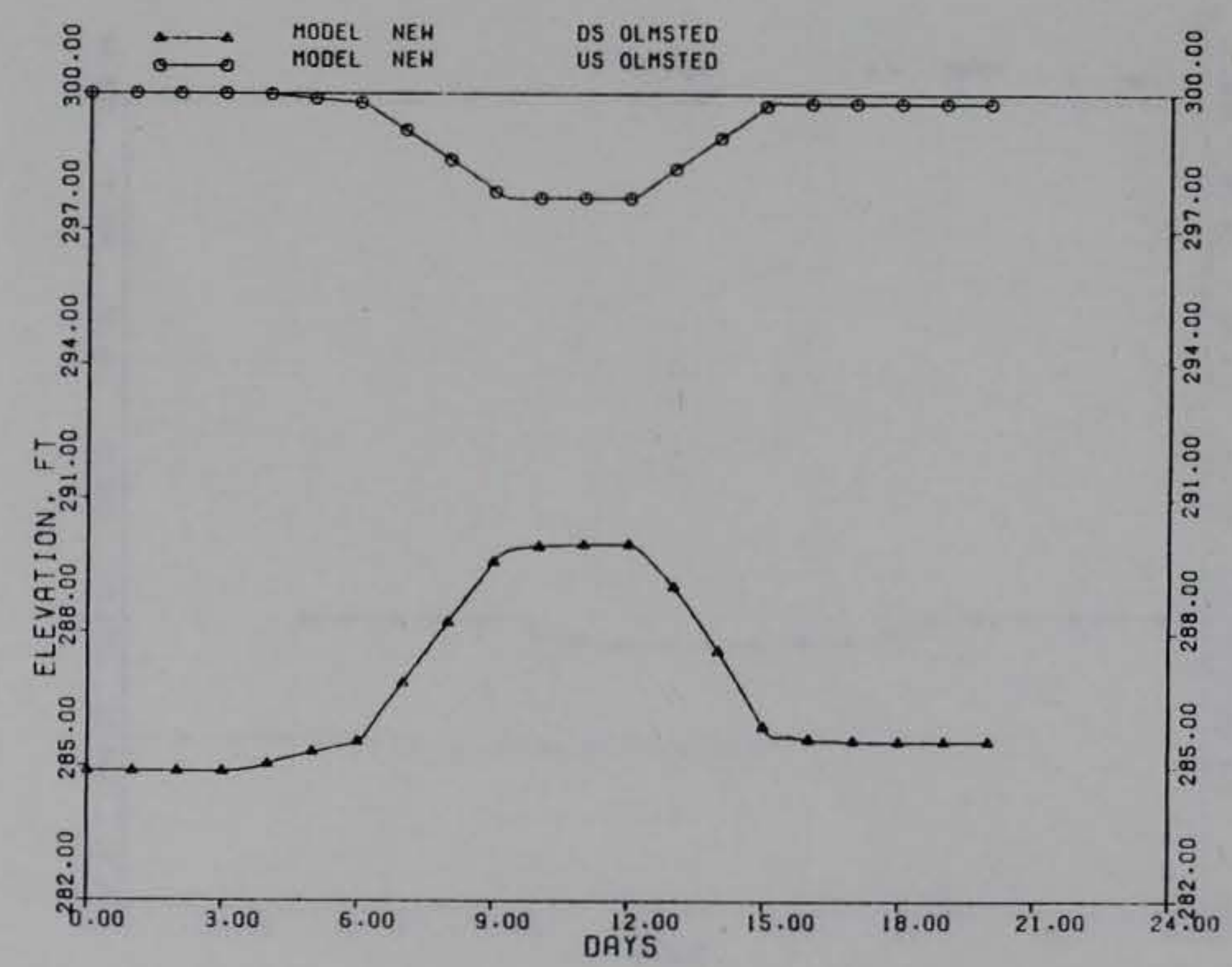

Figure 56. Computed $(\approx$ NGVD) Olmsted headwater and tailwater for first Kentucky flow event 


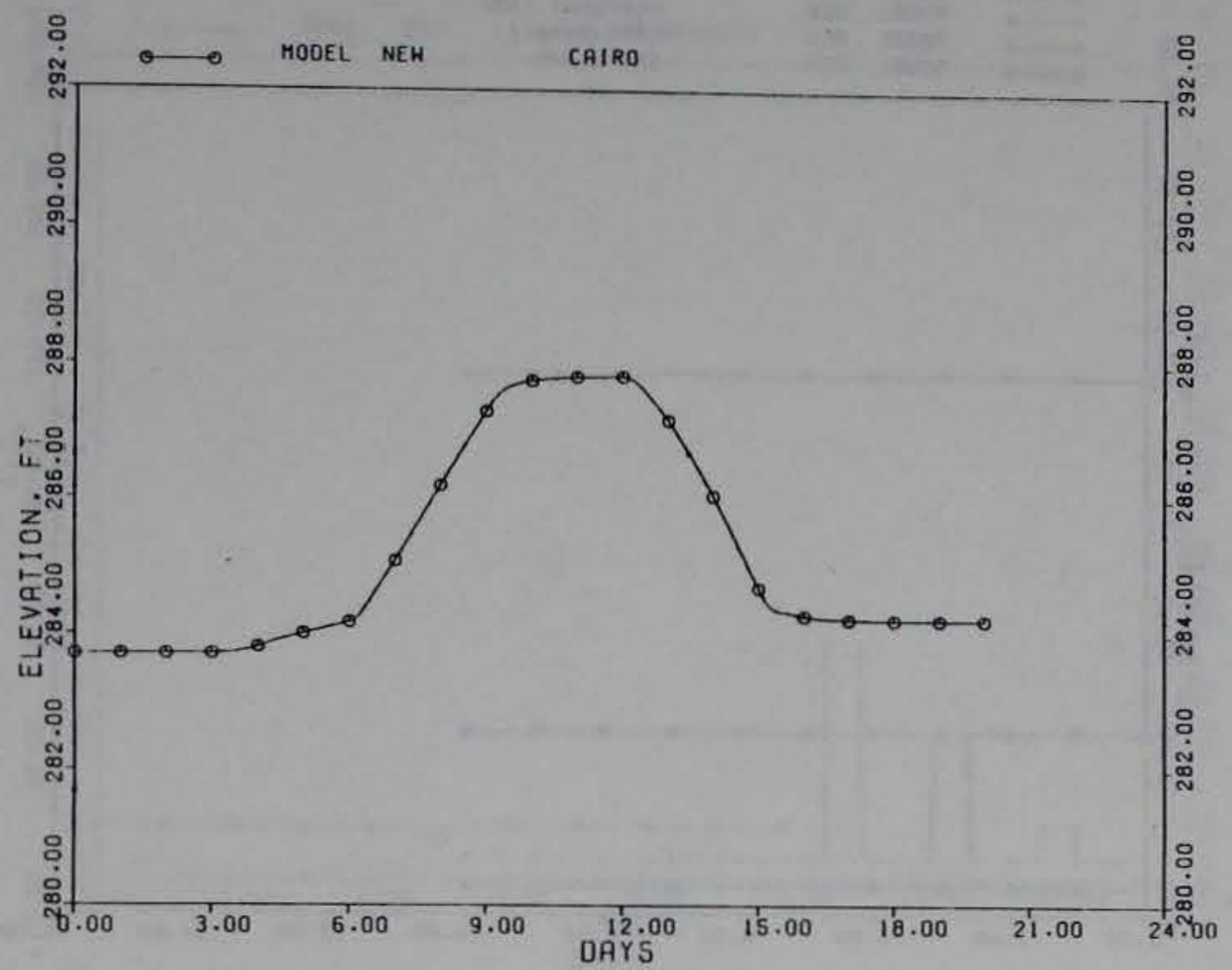

Figure 57. Computed ( $\approx$ NGVD) elevations at Cairo, IL, for first Kentucky flow event

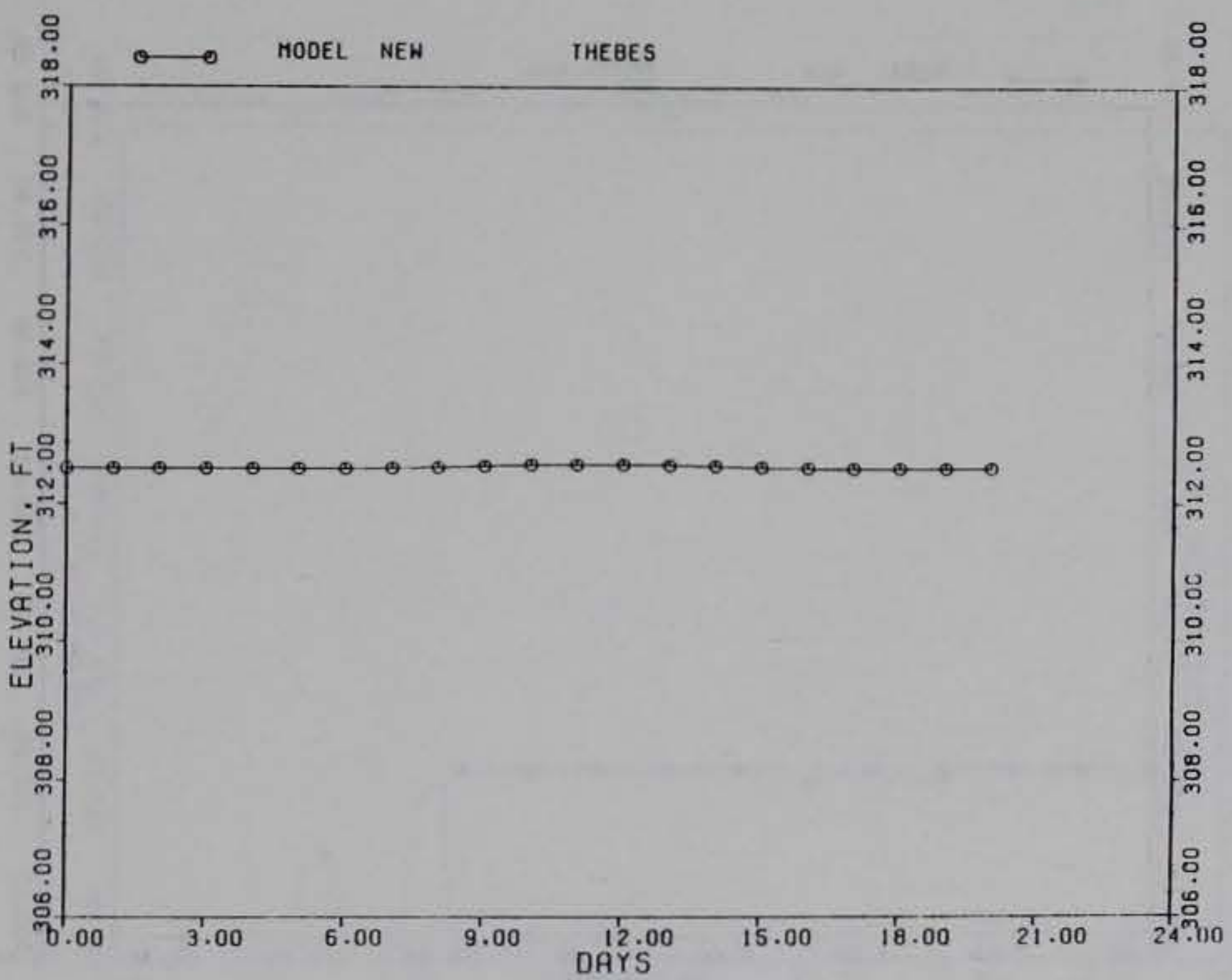

Figure 58. Computed $(\approx$ NGVD) elevations at Thebes, MO, for first Kentucky flow event 


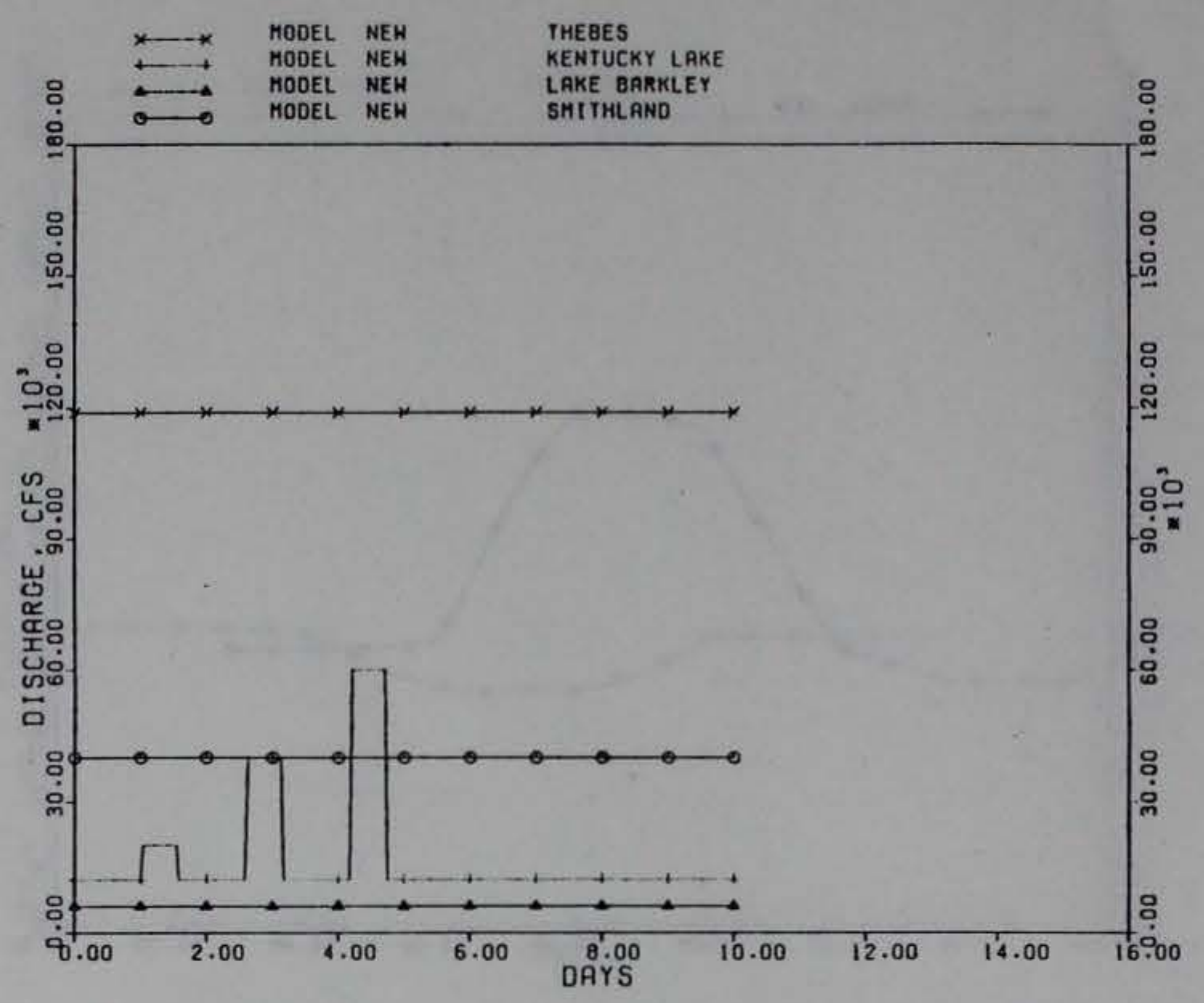

Figure 59. Inflows for the second Kentucky flow event

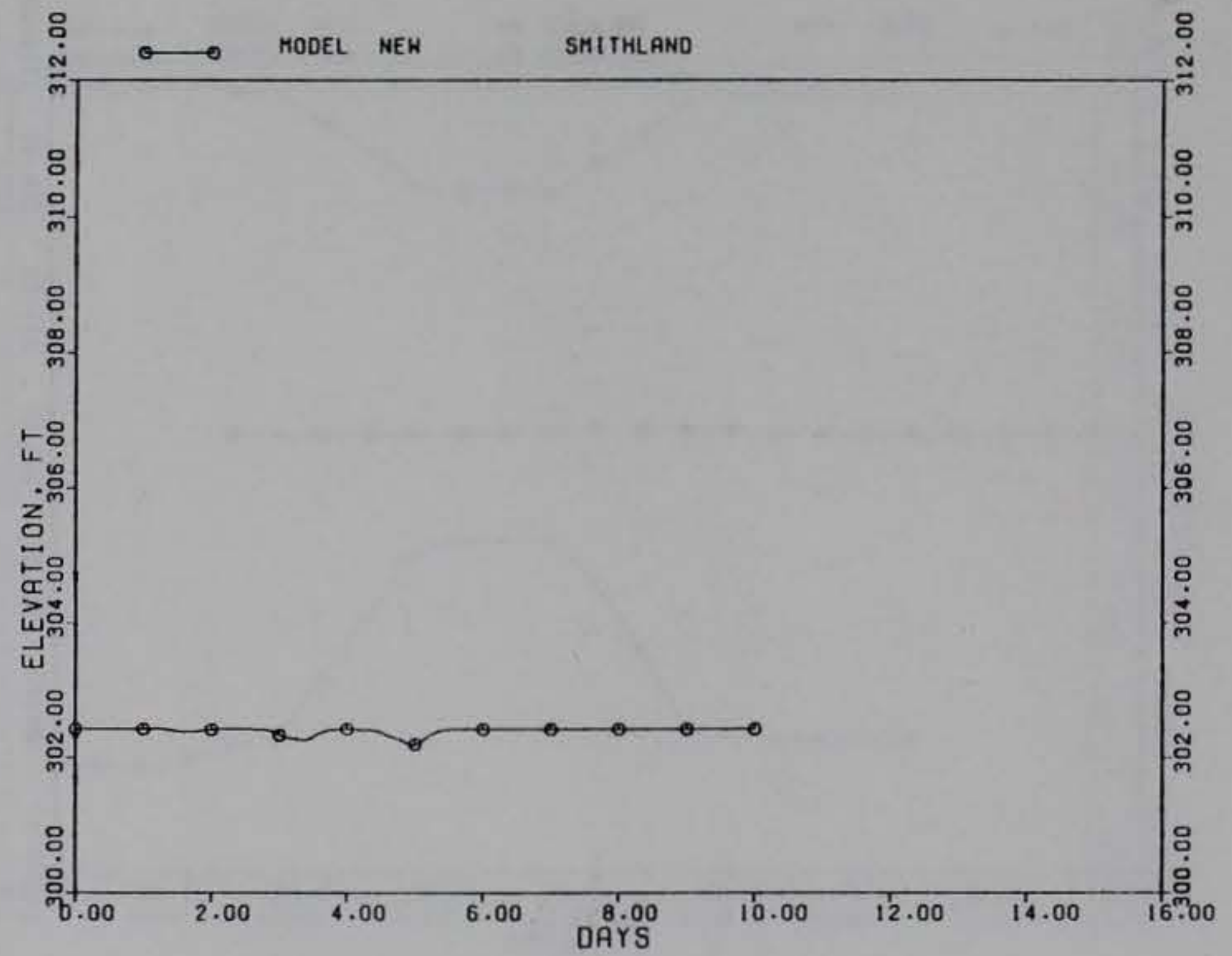

Figure 60. Computed $(\approx$ NGVD) Smithland tailwater for the second Kentucky flow event 


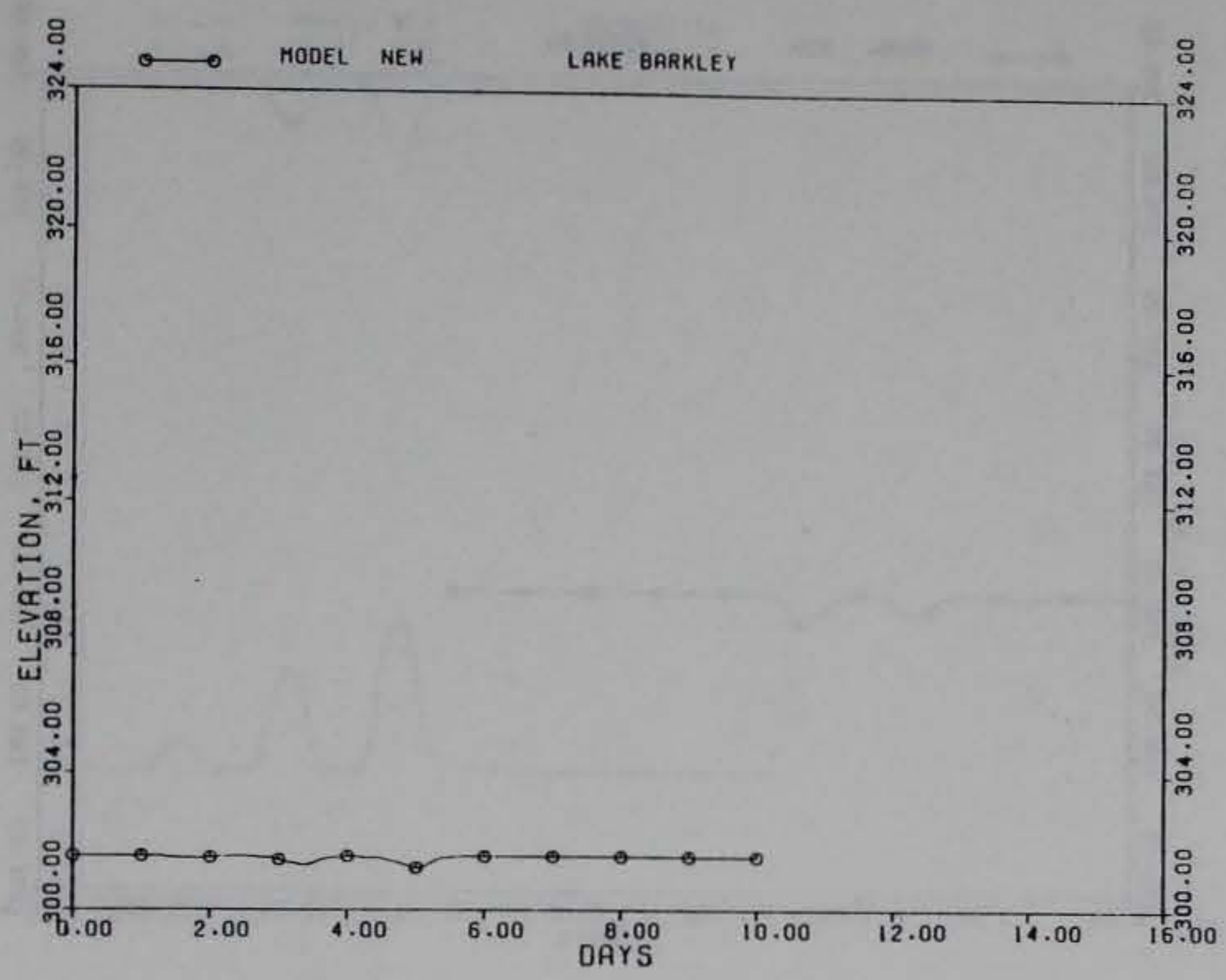

Figure 61. Computed ( $\approx$ NGVD) Barkley tailwater for the second Kentucky flow event

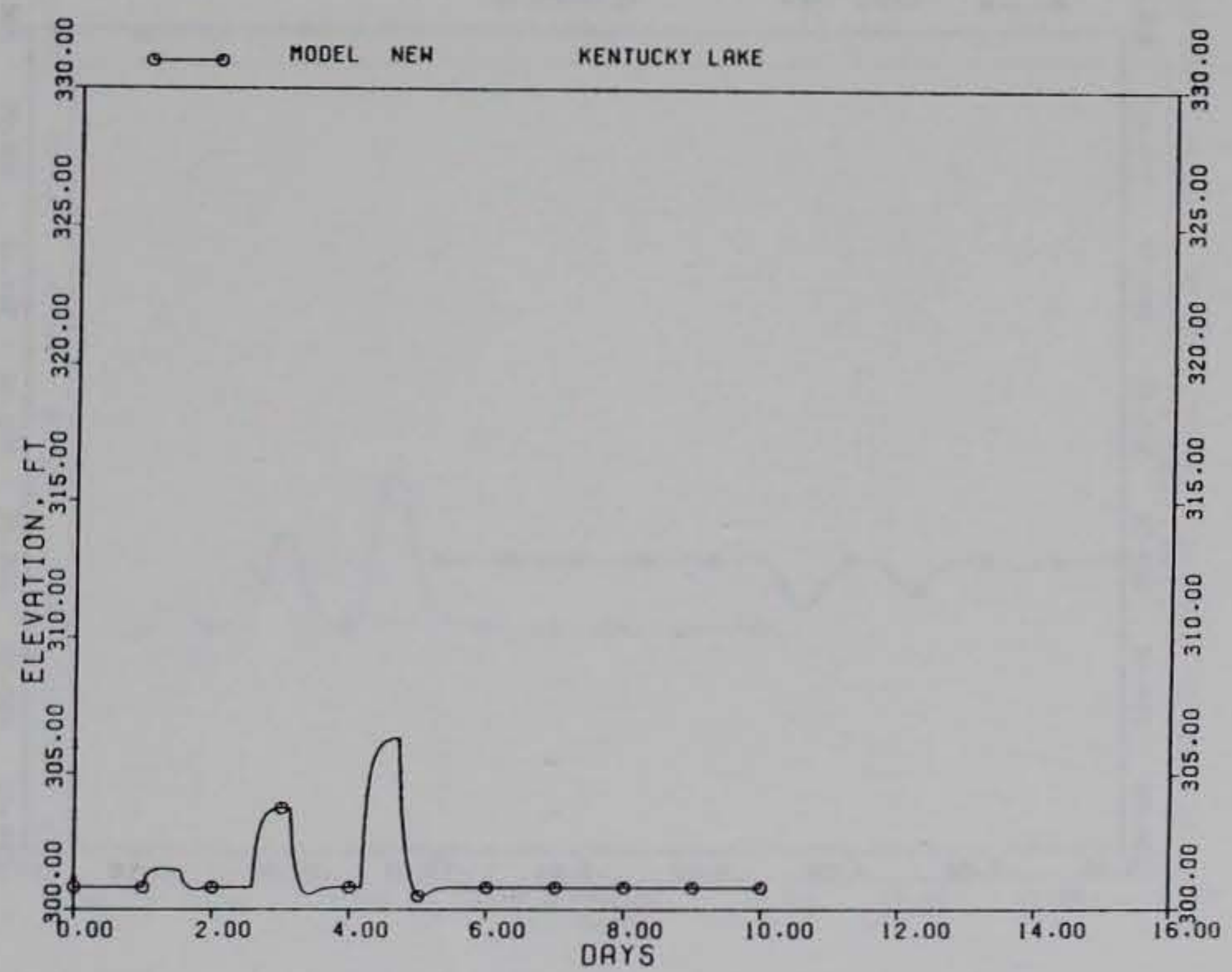

Figure 62. Computed $(\approx$ NGVD) Kentucky tailwater for the second Kentucky flow event 


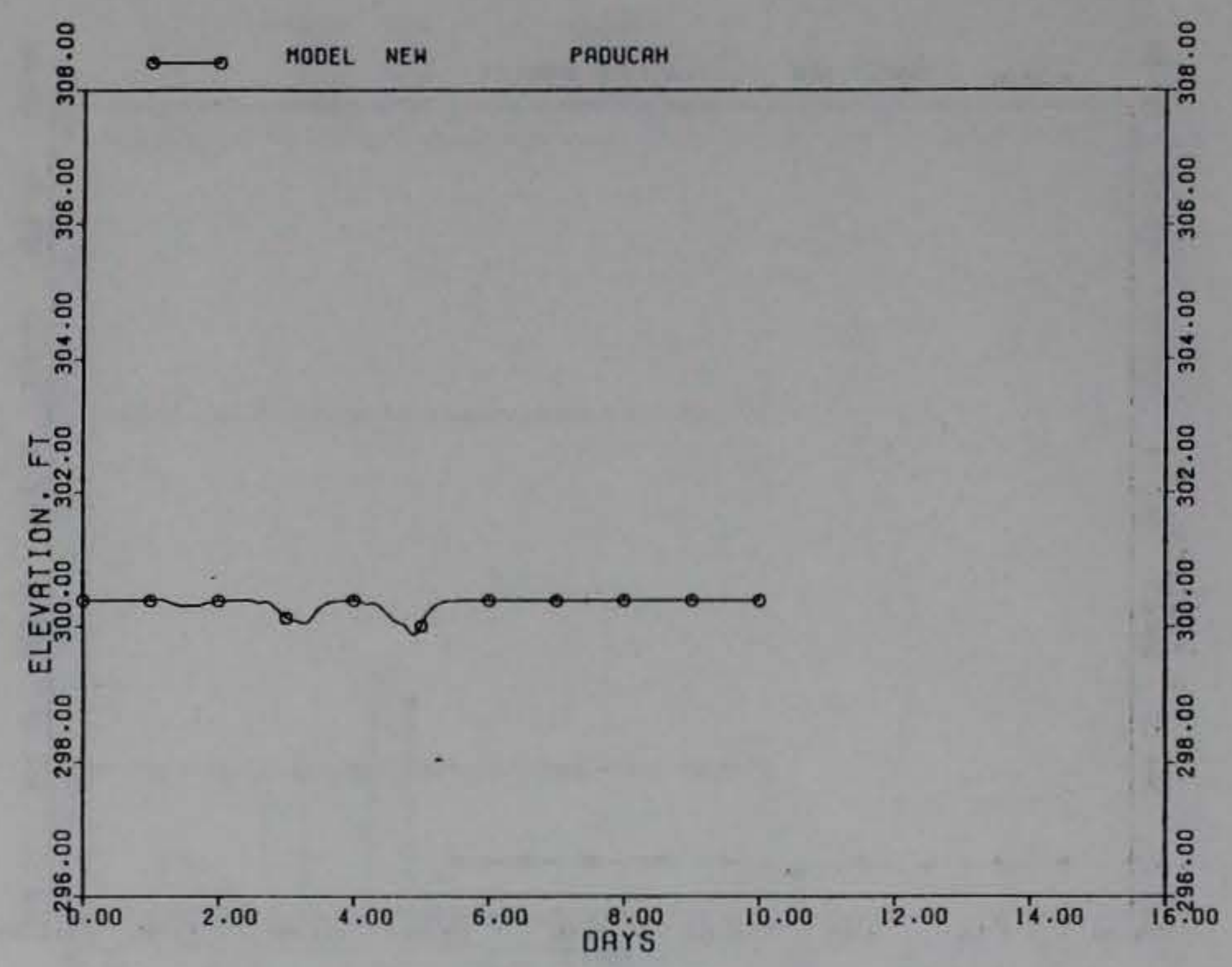

Figure 63. Computed ( $\approx$ NGVD) elevations at Paducah, KY, for the second Kentucky flow event

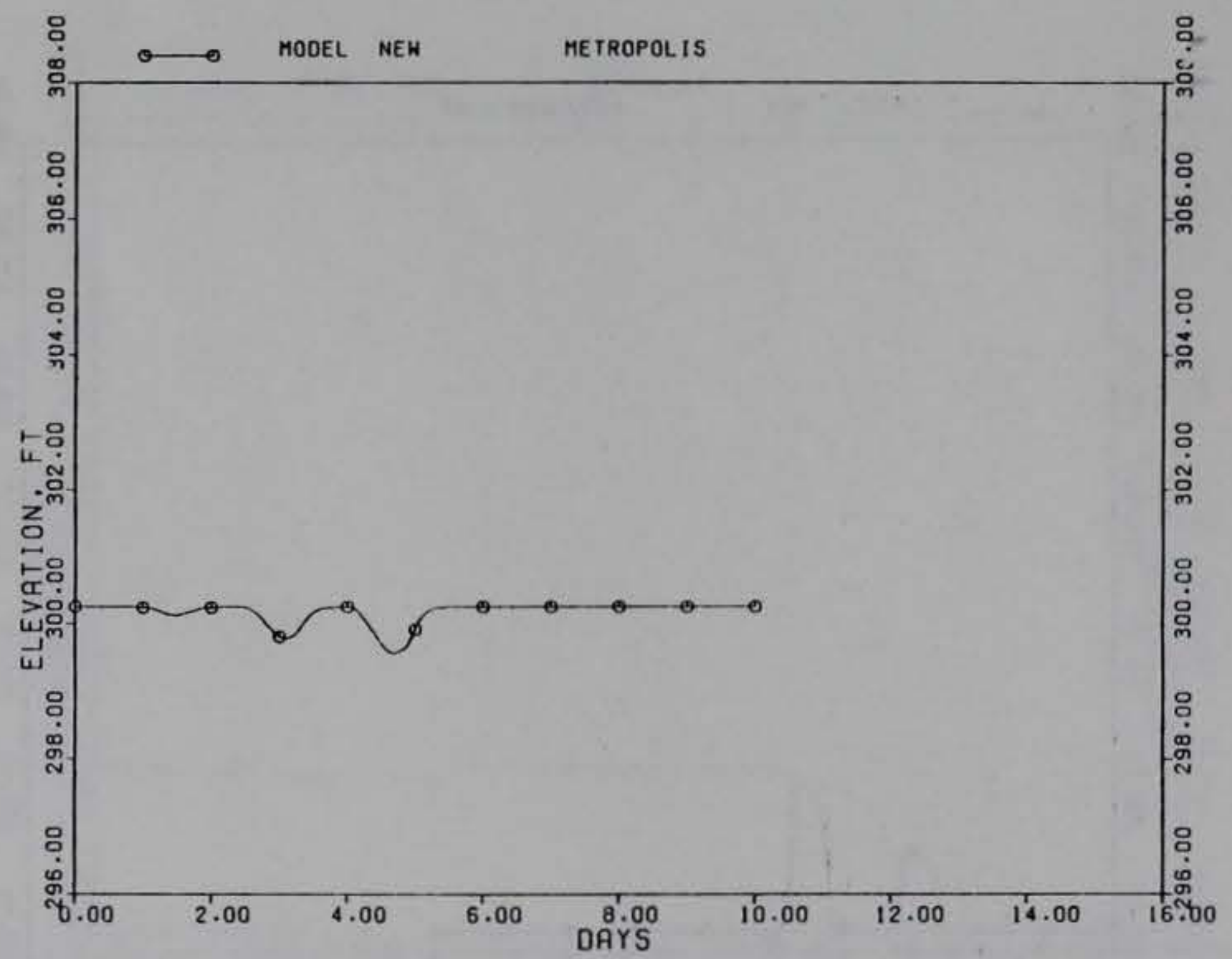

Figure 64. Computed $(\approx$ NGVD) elevations at Metropolis, IL, for the second Kentucky flow event 


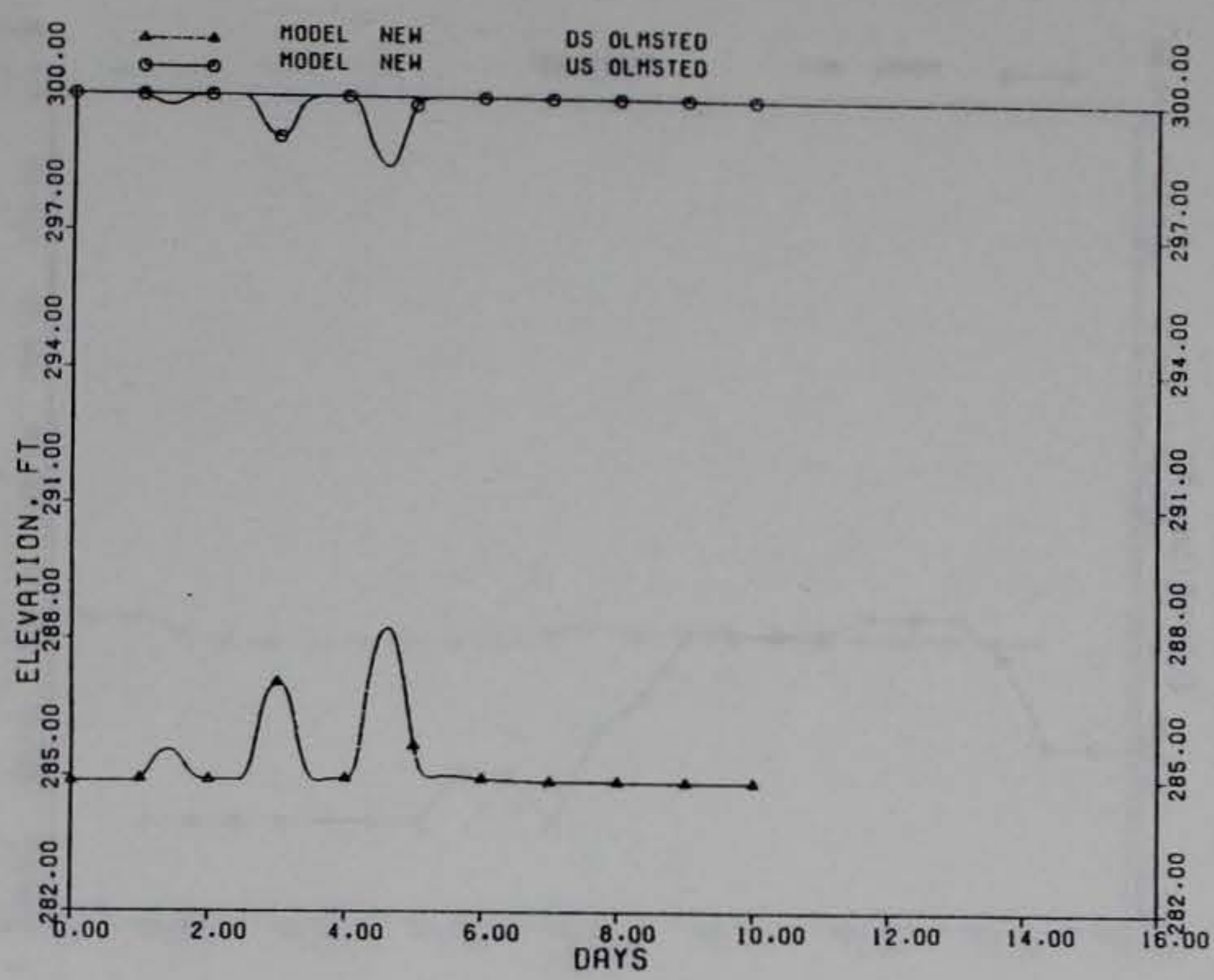

Figure 65. Computed ( $\approx$ NGVD) Olmsted headwater and tailwater for the second Kentucky flow event

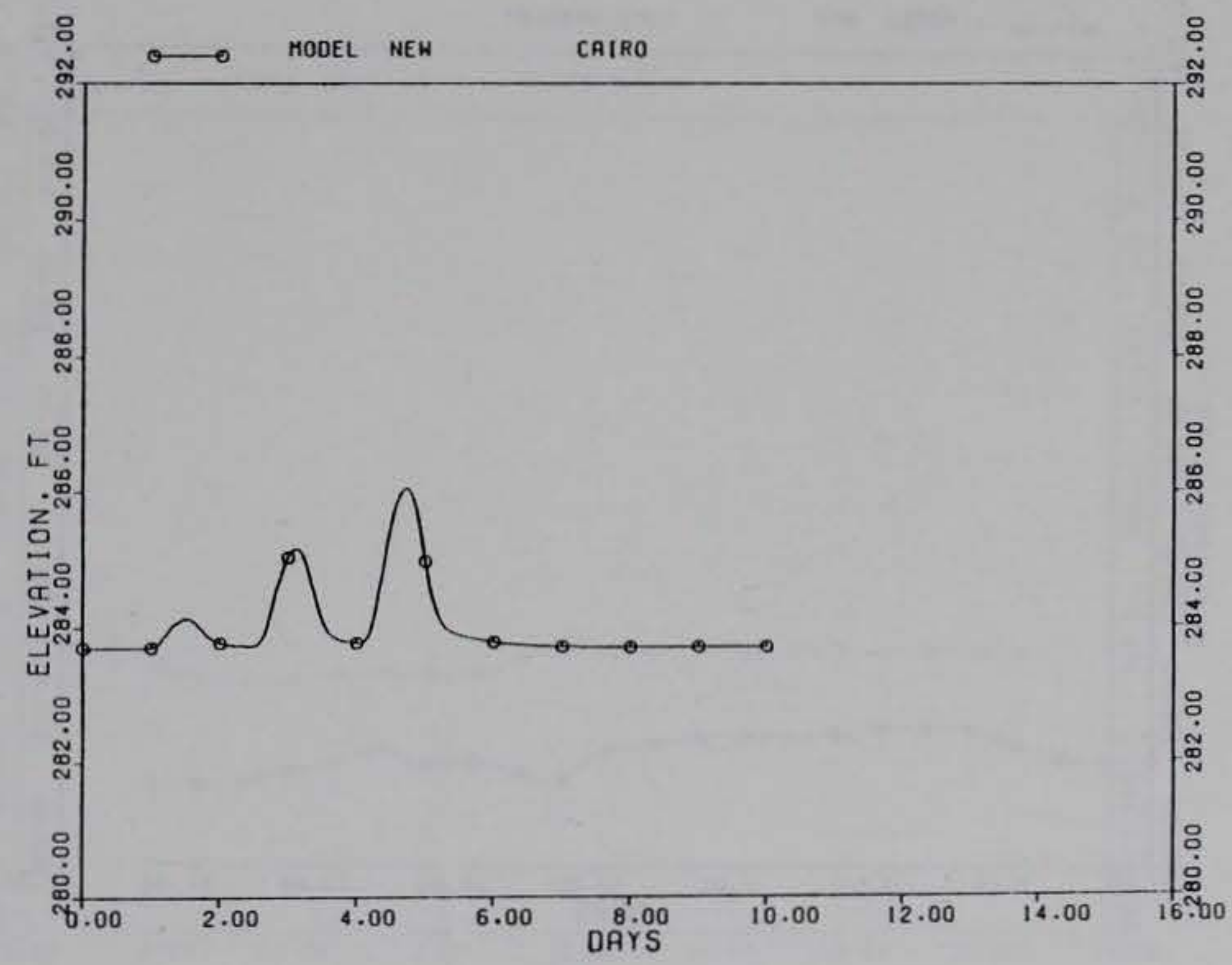

Figure 66. Computed ( $\approx$ NGVD) elevations at Cairo, IL, for the second Kentucky flow event 


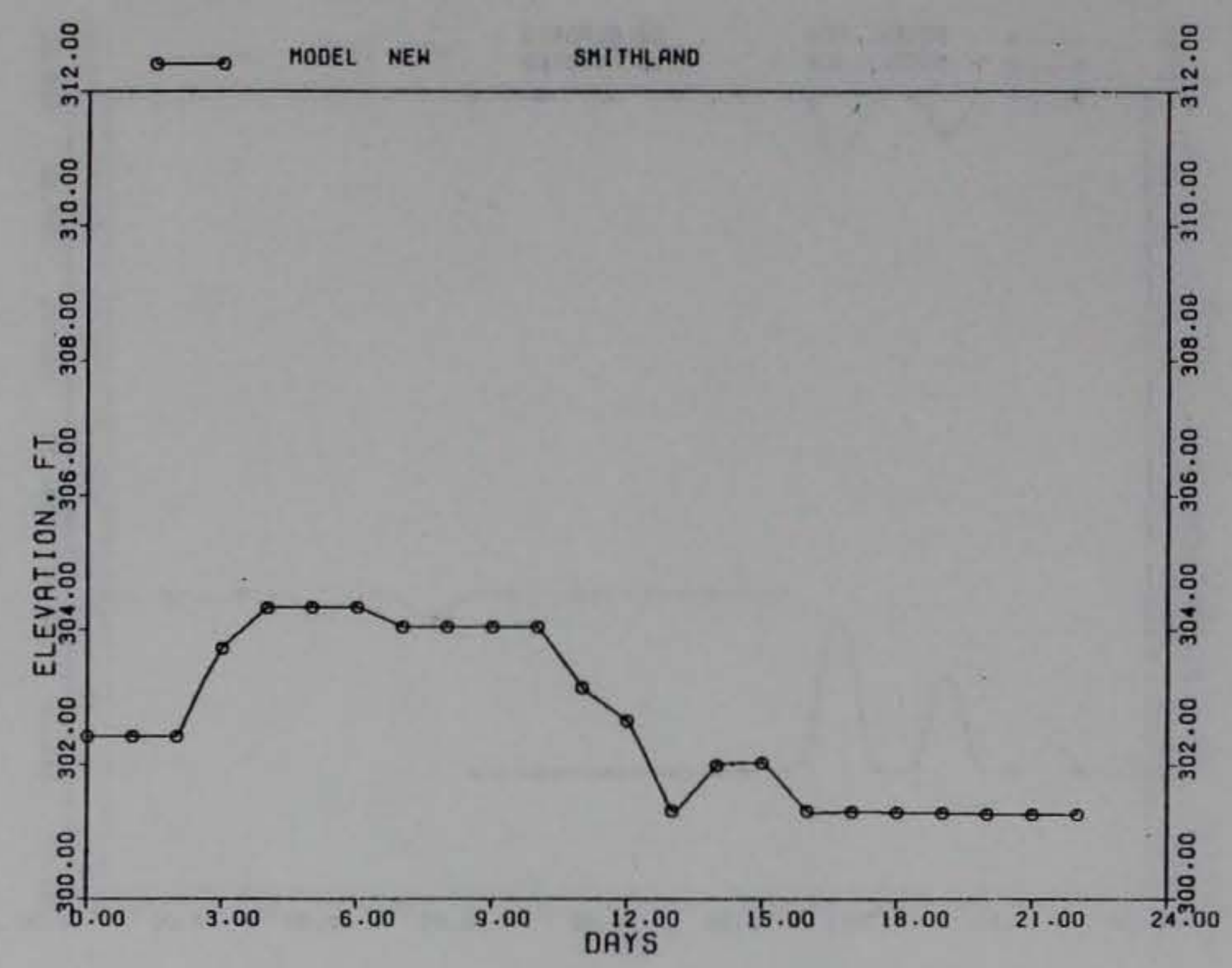

Figure 67. Computed ( $\approx$ NGVD) Smithland tailwater for May-June 1988 with Olmsted in place

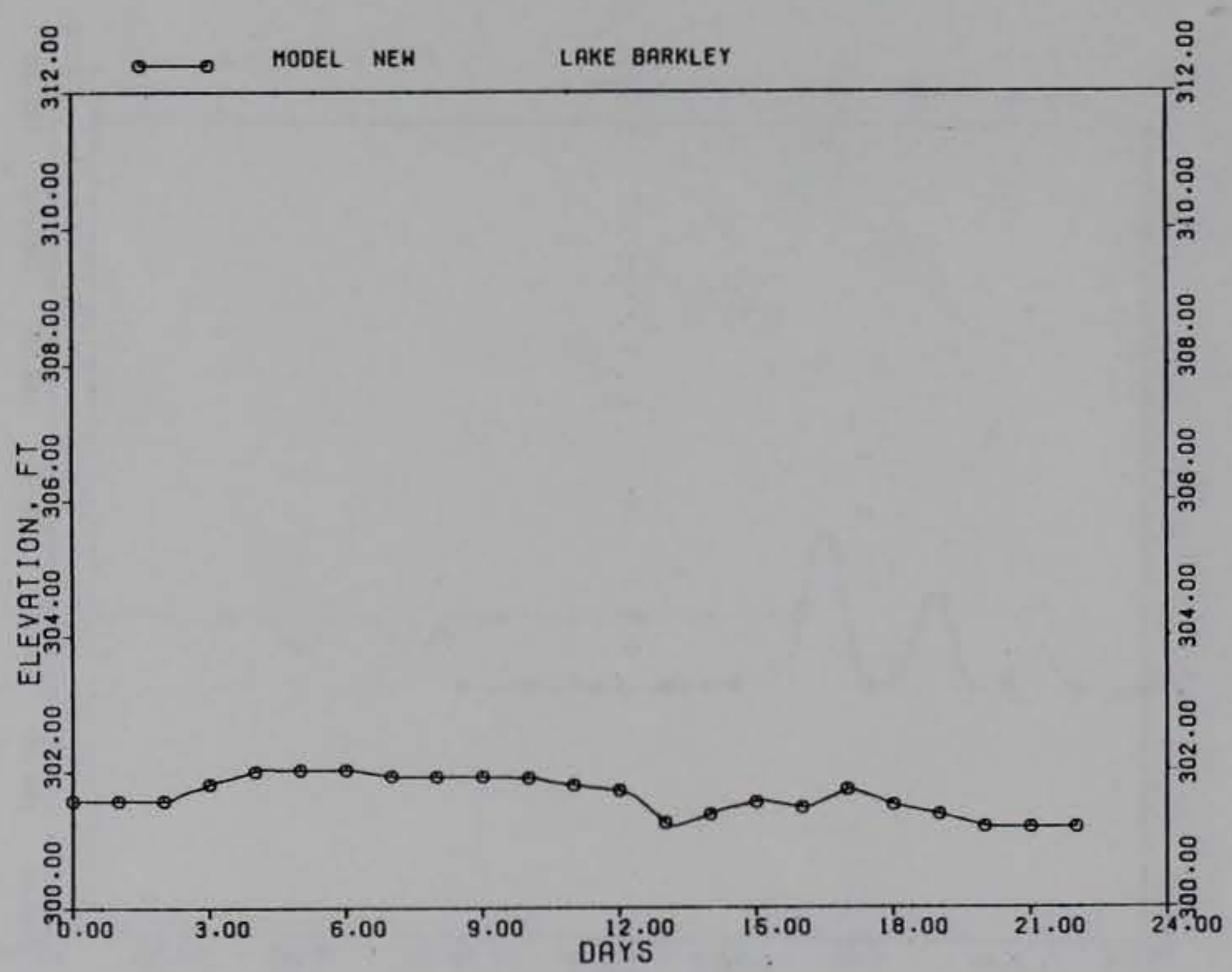

Figure 68. Computed ( $\approx$ NGVD) Barkley tailwater for May-June 1988 with olmsted in place 


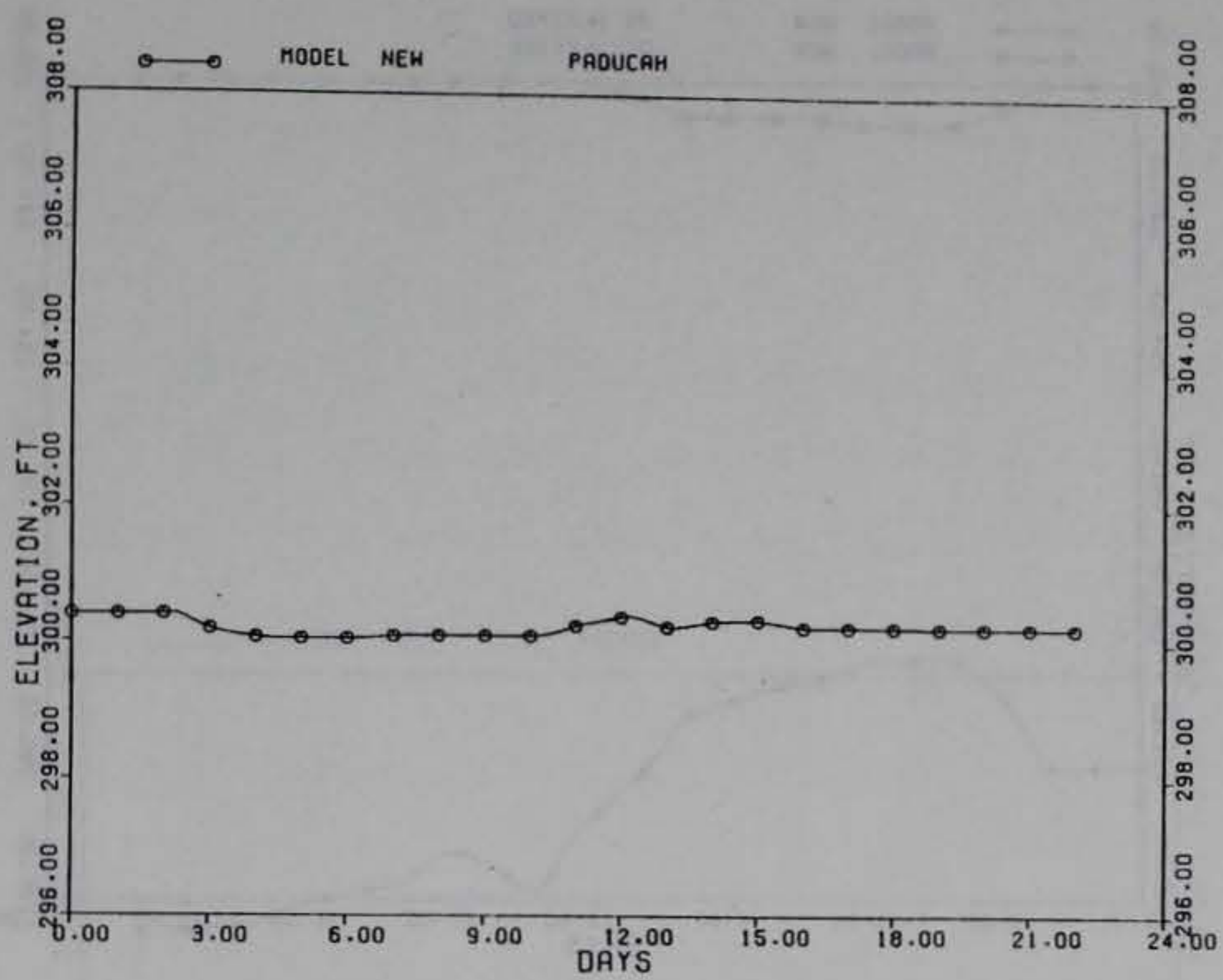

Figure 69. Computed $(\approx$ NGVD) elevations at Paducah, KY, for May-June 1988 with Olmsted in place

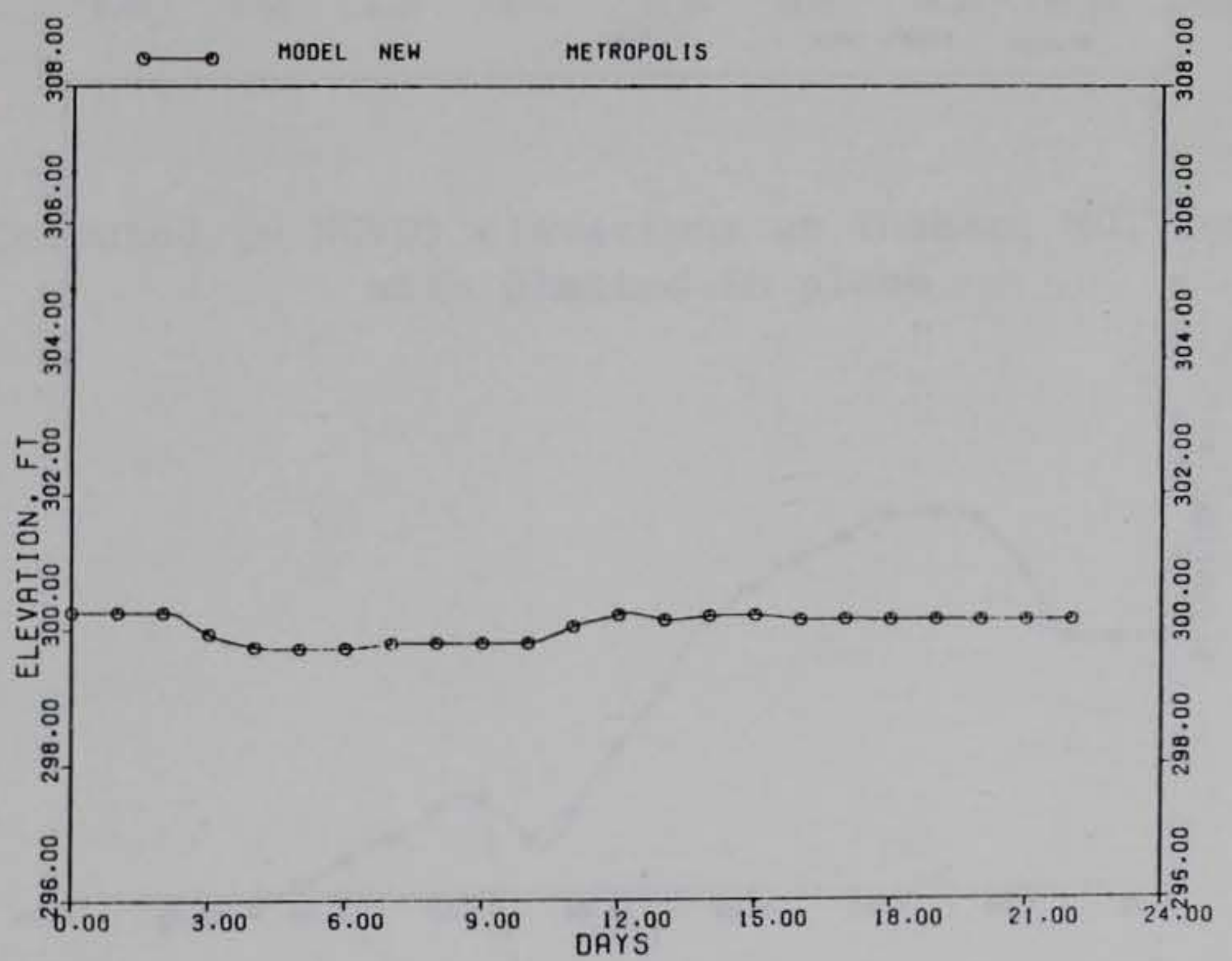

Figure 70. Computed $(\approx$ NGVD) elevations at Metropolis, IL, for May-June 1988 with 0lmsted in place 


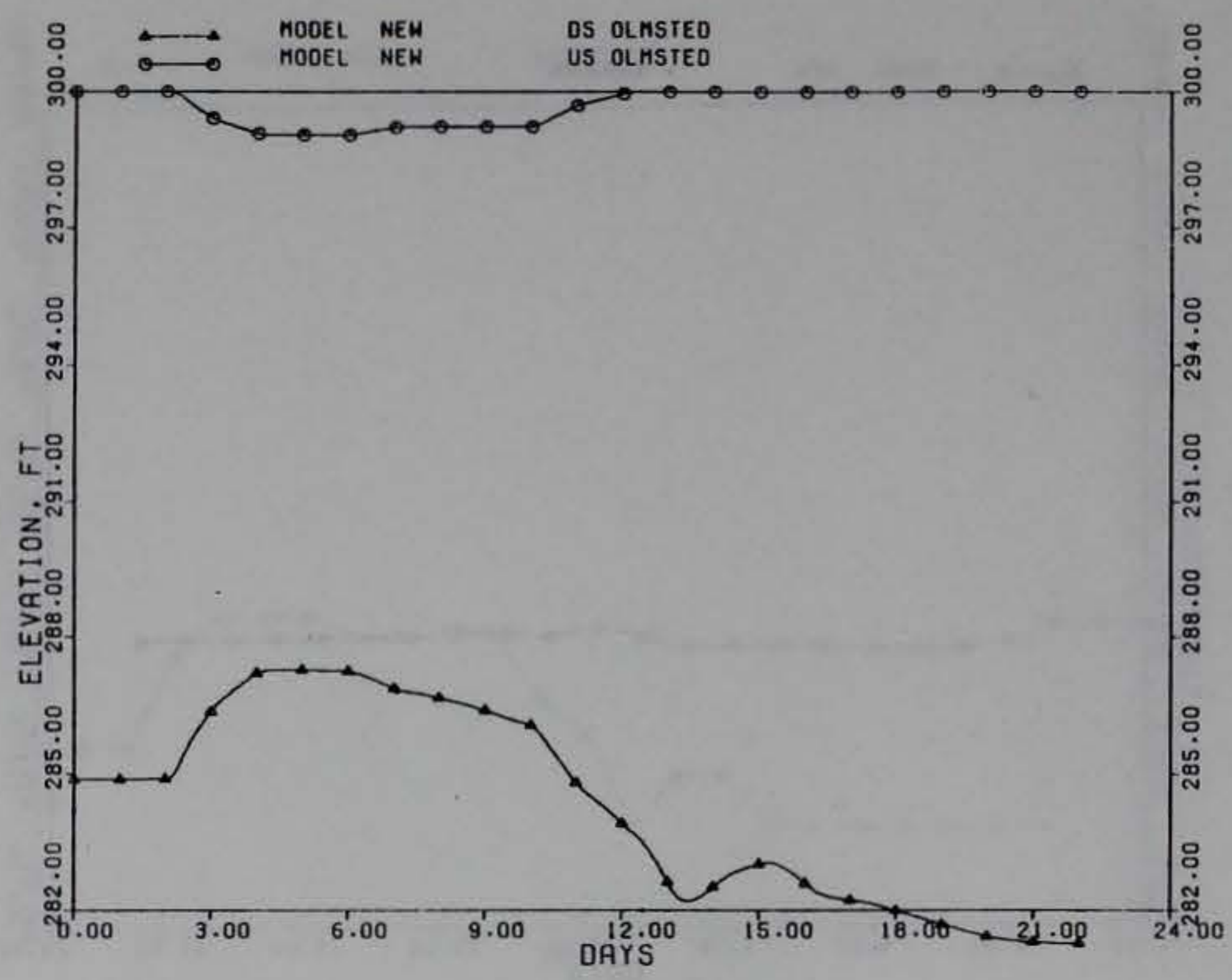

Figure 71. Computed $(\approx$ NGVD) 0lmsted headwater and tailwater for May-June 1988 with Olmsted in place

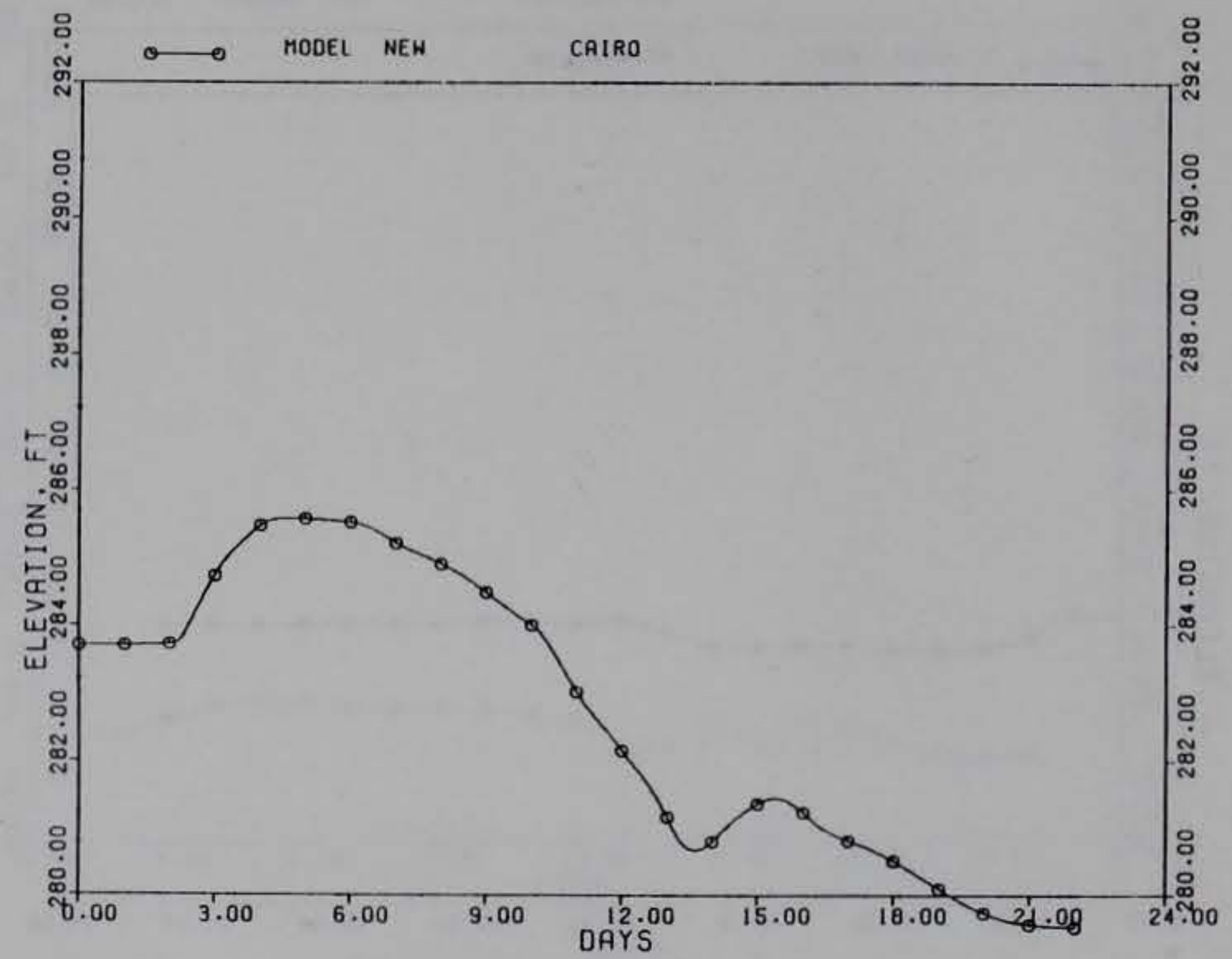

Figure 72. Computed $(\approx$ NGVD) elevations at Cairo, IL, for May-June 1988 with Olmsted in place 


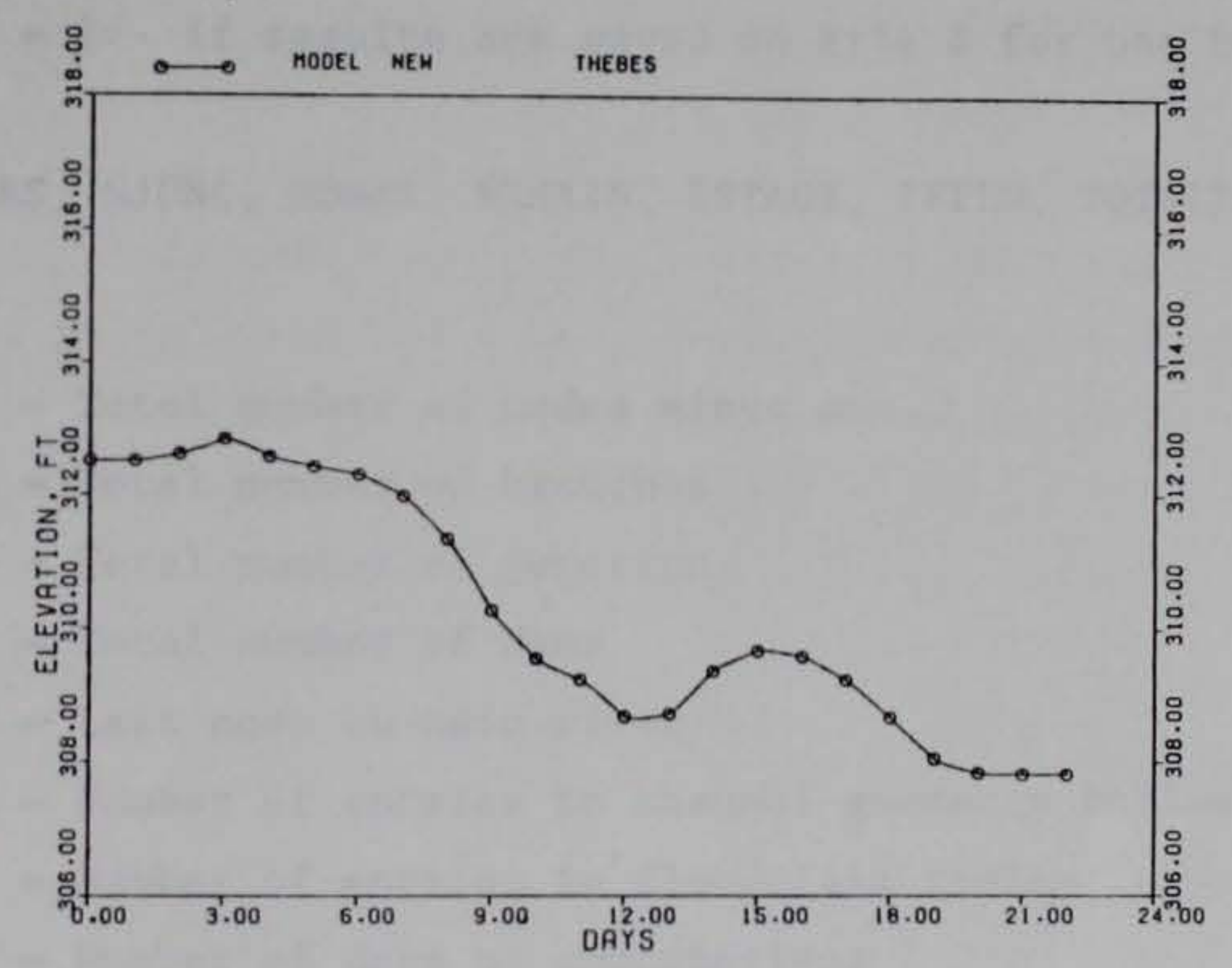

Figure 73. Computed ( $\approx$ NGVD) elevations at Thebes, MO, for May-June 1988 with Olmsted in place 
1. TITLE (I)

2. IGEOM, ILUG, IPUNCH, IBACK, IRERUN, KSMOO, IQUAL

IGEOM $=1$ - If geometry tables are printed

ILUG $=$ File from which geometry tables are read

IPUNCH $=1$ - If results are saved on File 55 for a hot start

IBACK $=1$ - If detailed printout requested

IRERUN $=1$ - If Olmsted Dam is in operation

KSMOO = Number of times computations at 01msted Dam are smoothed

IQUAL $=1$ - If results are saved on File 8 for use by RIVQUAL Model

3. NC, NBRS, NJUNC, NDAMS, NXMAIN, ISTAGE, IFPLN, TOTALT, TSTEP (715,

NC $\quad$ Total number of nodes minus one

NBRS $=$ Total number of branches

NJUNC = Total number of junction

NDAMS $=$ Total number of dams

NXMAIN $=$ Last node on main river

ISTAGE $=$ Number of entries in channel geometry tables

IFPLN = Number of entries in floodplain tables

TOTALT $=$ Number of days of computations

TSTEP = Time-step in seconds

NOTE - IF IQUAL $=0$ OMIT ENTRY 4

4. $(\mathrm{IQW}(\mathrm{I}), \mathrm{I}=1, \mathrm{NC}+1)$

$\mathrm{IQW}(\mathrm{I})=1$ - If output is saved at this node

for use in RIVQUAL Model, 0-otherwise

5. NSTAT, IPRINT, INTVG, INTVD, INTVP, NOXS

(6I5)

NSTAT = Number of nodes at which output is desired

IPRINT $=0$ - Limited output 
- 1 - Detailed output

INTVG - Major print interval

INTVD - Print interval for particular days (see next card)

INTVP - Interval for placing points in plot file

NOXS - Number of stations for plotting

$$
\text { NOTE - IF INTVD - INTVG OMIT ENTRY } 6
$$

6. STDP, ISDDP, ISMDP, ISYDP, ETDP, IEDDP, IEMDP, IEYDP (F10.0, 3I5, $5 \mathrm{X}, \mathrm{F} 10.0,3 \mathrm{I} 5)$

STDP = Starting time on 24-hr clock for small print interval ISDDP = Starting day for small print interval ISMDP = Starting month for small print interval ISYDP = Starting year for small print interval ETDP = Ending time on 24-hr clock for small print interval IEDDP = Ending day for small print interval IEMDP = Ending month for small print interval IEYDP = Ending year for small print interval

$$
\text { NOTE - IF NSTAT - } 0 \text { OMIT ENTRY } 7
$$

7. (NPRINT(I), I=1, NSTAT)

NPRINT $=$ Node numbers at which output is requested

8. IPTL

IPLT $=0$ - No Plots

= 1 - Elevation, discharge and velocity saved for plotting

$$
\text { NOTE - IF NOXS - } 0 \text { OMIT ENTRY } 9
$$

9. $\operatorname{STITLE}(I), \operatorname{NPLOT}(I), \operatorname{GWF}(I)$ (A32, 3X, I5, F10.0) $\operatorname{STITLE}(I)=$ station name 
$\begin{aligned} \operatorname{NPLOT}(I)= & \text { Node number upstream of gage } \\ \text { GWF }(I)= & \text { Fraction of distance between NPLOT(I) and NPLOT(I+1) where } \\ & \text { gage is located }\end{aligned}$

NOTE - REPEAT ENTRY 9 NOXS TIMES

10. ID, $\operatorname{IBRNCH}(I, 1), \operatorname{IBRNCH}(I, 2), \operatorname{IBRS}(I), \operatorname{IBC}(I)$

ID

= Branch number

$\operatorname{IBRNCH}(I, 1)=$ First node on branch

$\operatorname{IBRNCH}(I, 2)=$ Last node on branch

IBRS (I) $\quad=1$ - Branch has upstream outer boundary

$=0$ - Branch is an interior branch

$=-1$ - Branch has downstream outer boundary

IBC(I) = - 1 - Rating curve will be used if this branch contains downstream outer boundary

$=0$ - If this is an interior branch or discharge is input at its boundary

- 1 - Elevations will be input if this branch contains downstream outer boundary

NOTE - ENTRY 10 WILL BE REPEATED FOR EACH BRANCH

NOTE - IF NJUNC $=0$ OMIT ENTRY 11

11. ID ( $\mathrm{IJUN}(\mathrm{I}, \mathrm{K}), \mathrm{K}=1,3), \mathrm{AL}(\mathrm{J}), \mathrm{AL}(\mathrm{J}+1) \quad(4 \mathrm{I} 5,10 \mathrm{X}, 2 \mathrm{~F} 10.0)$

ID $\quad=$ Junction number

$\operatorname{IJUN}(I, 1)=$ Number of upstream branch on main river

$\operatorname{IJUN}(I, 2)=$ Number of tributary branch

$\operatorname{IJUN}(I, 3)=$ Number of downstream branch on main river

$\mathrm{AL}(\mathrm{J}) \quad=$ Velocity head correction factor associated with junction of upstream main river and downstream main river

$\mathrm{AL}(\mathrm{J}+1)=$ Velocity head correction factor associated with junction of tributary and downstream river

NOTE - REPEAT ENTRY 11 FOR EACH JUNCTION 
12. $\operatorname{TDAM}(I), \operatorname{HSETO}(I), \operatorname{NL}(I), \operatorname{NVARY}(I)$

$(\mathrm{A} 8,2 \mathrm{X}, \mathrm{F} 10.0,2 \mathrm{I})$

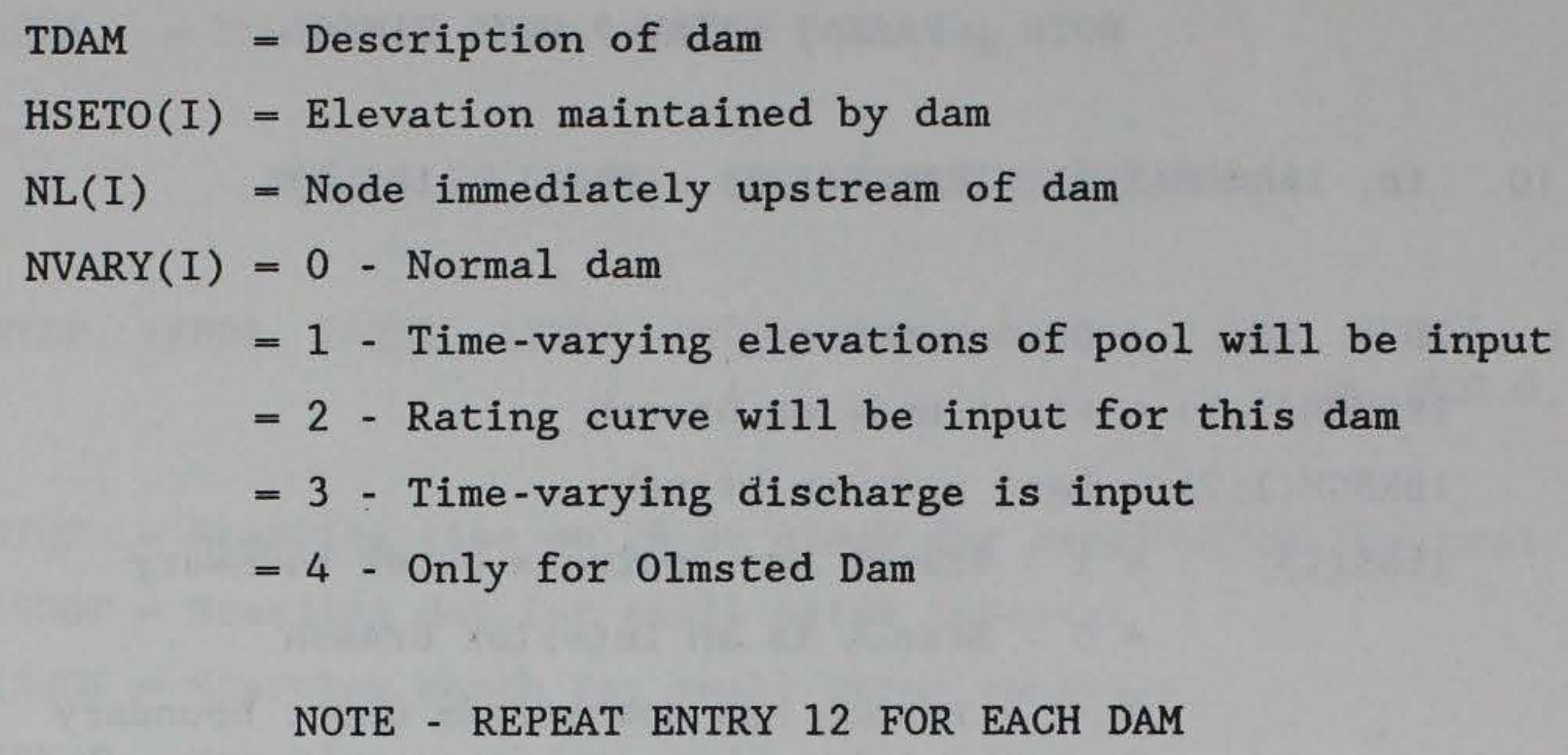

13. IEDYHD

IEDYHD $=$ Number of nodes where eddy head loss coefficients will be read in

$$
\text { NOTE - IF IEDYHD }=0 \text { OMIT ENTRY } 14
$$

14. N, $\operatorname{CKE}(\mathrm{N})$ (I5, 5X, F10.0)

$\mathrm{N} \quad$ Node number
$\mathrm{CKE}(\mathrm{N})=$ Coefficient in eddy loss term

NOTE - REPEAT ENTRY 14 IEDYHD TIMES

15. $\mathrm{NRCH},(\operatorname{IRCH}(I), I=1, \mathrm{NRCH})$

NRCH $=$ Total number of reaches containing lateral inflows $\operatorname{IRCH}(I)=$ Upstream node of the reach containing lateral inflow

16. NLEVEE, (ILEVEE(I), I=1, NLEVEE) 
NLEVEE = Number of reaches with levees

$\operatorname{ILEVEE}(I)=$ Upstream node of the reach with a levee

$$
\text { NOTE }=\text { IF NLEVEE }=0 \text { OMIT ENTRY } 17
$$

17. (ELEVEE $(\mathrm{K}), \mathrm{K}=1$, NLEVEE)

$(8 \mathrm{~F} 10.0)$

$\begin{aligned} \operatorname{ELEVEE}(K)= & \text { Average elevation in feet of the top of the levee along } \\ & \text { this reach }\end{aligned}$

NOTE - IF THE MOST DOWNSTREAM BRANCH DOES NOT CONTAIN A RATING CURVE OMIT ENTRIES 18-19

18. NSEG

NSEG $=$ Number of linear segments in the rating curve

19. $\mathrm{QRC}(\mathrm{N}), \operatorname{HRC}(\mathrm{N})$

$\mathrm{QRC}(\mathrm{N})=$ Discharge at end of segment

$\operatorname{HRC}(\mathrm{N})=$ Elevation at end of segment

NOTE - IF OLMSTED DAM IS NOT IN THE SYSTEM OMIT ENTRIES 20-21

20. IHINGE(I), $\operatorname{HTOL}(I), \operatorname{PCC}(I)$

$\operatorname{IHINGE}(I)=$ Node number of the hinge point

HTOL $(I)=$ Allowable range of elevation at hinge point

$\operatorname{PCC}(\mathrm{I})=$ Fraction of HTOL(I) that can occur in one $\Delta t$

21. IH1, IH2, IH3

IH1 $=$ Node number on Ohio used to compute a check $Q$

IH2 = Node number on Cumberland used to compute a check $Q$

IH3 = Node number on Tennessee used to compute a check $Q$

NOTE - IF NVARY(I) $\neq 2$ OMIT ENTRY 22 
22. $\operatorname{KRC}(I), \operatorname{QLIMIT}(I), \operatorname{QCHECKO}(I), \operatorname{ODRCF}(I)$, $(\mathrm{QDRC}(\mathrm{K}, \mathrm{I}), \operatorname{HDRC}(\mathrm{K}, \mathrm{I}), \mathrm{K}=1, \mathrm{KRC}(\mathrm{I}))$

KRC = Number of entries in rating curve table at the I'th dam

QLIMIT = Discharge below which a fixed water-surface elevation is prescribed

QCHECKO = Initial discharge of I'th dam

QDRCF = Discharge above which the falling portion of the rating curve will be used if the discharge is decreasing

QDRC = Discharge in rating curve table

HDRC = Water-surface elevation corresponding to QDRC

NOTE - REPEAT CARD 22 FOR EACH DAM WITH A RATING CURVE 


\section{APPENDIX B: LIST OF INPUT DATA IN FILE 40}

$$
\text { NOTE - IF NRCH }=0 \text { OMIT ENTRY } 1
$$

1. $\mathrm{J},(\mathrm{QL2}(\mathrm{K}), \mathrm{K}=1, \mathrm{NRCH})$
$\mathrm{J}=$ Number of time-step before new lateral inflows will be input

QL2 $(K)=$ Lateral inflow in $\mathrm{cfs}$

NOTE - ENTRY 2 IS INPUT FOR EACH BRANCH WITH AN UPSTREAM EXTERNAL BOUNDARY

2. $Q(I, 2), \operatorname{IQCK}(I)$

$(\mathrm{F} 10.0, \mathrm{I5})$

$\mathrm{Q}(\mathrm{I}, 2)=$ New boundary discharge in cfs

$\operatorname{IQCK}(I)=$ Number of time-steps before a new discharge will be input

NOTE - ENTRY 3 IS INPUT FOR THE DOWNSTREAM BOUNDARY OF THE LAST BRANCH ON THE MAIN RIVER IF ELEVATIONS ARE PRESCRIBED. OTHERWISE OMIT

3. $\mathrm{H}(\mathrm{I}, 2), \operatorname{IHCK}(I)$ $(\mathrm{F} 10.0, \mathrm{I5})$

$\mathrm{H}(\mathrm{I}, 2)=$ New downstream boundary water surface elevation $\operatorname{IHCK}(I)=$ Number of time-steps before a new elevation will be input

NOTE - IF THERE ARE NO DAMS WITH A FORCED ELEVATION OR DISCHARGE READ IN AS DATA, OMIT ENTRY 4

4. S, J

$(\mathrm{F} 10.0$, I5)

$S=$ Forced elevation upstream of dam if NVARY(I) $=1$ or forced discharge through the dam if $\operatorname{NVARY}(I)=3$

$\mathrm{J}=$ Number of time-steps before a new value is input 
1. MNTH, KDAY, KYEAR, TIME

MNTH = Starting month of simulation

KDAY = Starting day of simulation

KYEAR = Starting year of simulation

TIME = Starting time (24 hour clock) of simulation

2. $(\mathrm{H}(\mathrm{I}, \mathrm{JSP}), \mathrm{I}=1, \mathrm{NX})$

$\mathrm{H}(\mathrm{I}, \mathrm{JSP})=$ Initial elevation at each node

3. $(\mathrm{Q}(\mathrm{I}, \mathrm{JSP}), \mathrm{I}=1, \mathrm{NX})$

$\mathrm{Q}(\mathrm{I}, \mathrm{JSP})=$ Initial discharge at each node

$$
\text { NOTE - IF NRCH }=0 \text { OMIT ENTRY } 4
$$

4. (QL2L $(K), \mathrm{K}=1$, $\mathrm{NRCH})$

QL2L $(K)=$ Initial lateral flow

NOTE - IF THERE ARE NO DAMS CONTROLLED BY A RATING CURVE OMIT ENTRY 5

5. QCHECKI (I)

QCHECKI $(I)=$ Initial discharge passing through the dam

NOTE - REPEAT ENTRY 5 FOR EACH DAM CONTROLLED BY A RATING CURVE 
1. $\operatorname{RANGE}(I), X L(I), Z F(I), Z(I), \operatorname{BETA}(I)$

RANGE $(I)=$ Description of $I^{\prime}$ th node

$\mathrm{XL}(\mathrm{I}) \quad=$ River mileage of $\mathrm{I}^{\prime}$ th node. Tributary mileage is zero at the junction

$\mathrm{ZF}(\mathrm{I}) \quad=$ Top bank elevation for $I^{\prime}$ th node

$\mathrm{Z}(\mathrm{I}) \quad=$ Bed elevation of $\mathrm{I}^{\prime}$ th node

$\operatorname{BETA}(\mathrm{I})=$ Momentum correction factor

2. $\mathrm{HI}(I, J), A I(I, J), T I(I, J), \operatorname{RNI}(I, J)$

$(4 \mathrm{~F} 10.0)$

$\mathrm{HI}(\mathrm{I}, \mathrm{J})$ = Elevation of channel geometry

$\operatorname{AL}(\mathrm{I}, \mathrm{J})=$ Flow area

$\operatorname{TI}(I, J)=$ Top width

$\operatorname{RNI}(I, J)=$ Manning's " $n$ "

NOTE - ENTRY 2 IS REPEATED ISTAGE TIMES

3. $\operatorname{HF}(I, J), \operatorname{AFI}(I, J), \operatorname{RNIFP}(I, J)$

$(3 \mathrm{~F} 10.0)$

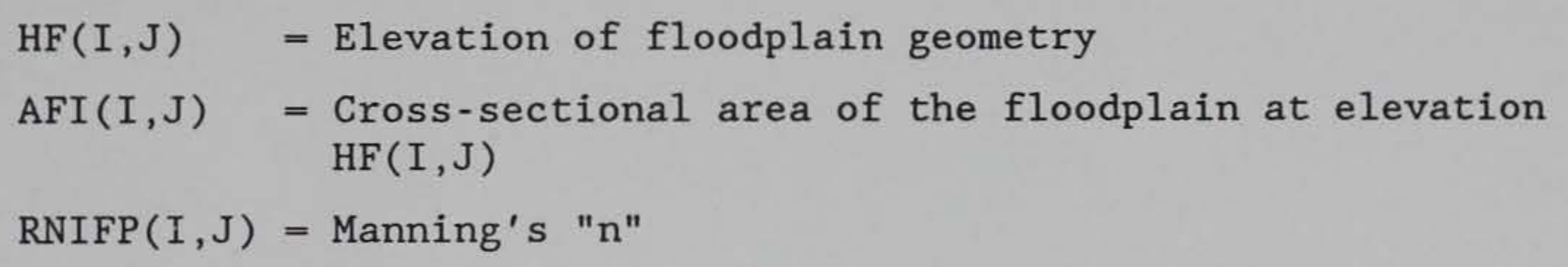

NOTE - ENTRY 3 IS REPEATED IFPLN TIMES

NOTE - ENTRIES 1-3 ARE REPEATED FOR EACH NODE IN THE SYSTEM 